NUREG-0040

Vol. 19, No. 2

\title{
Licensee Contractor \\ and Vendor Inspection \\ Status Report
}

Quarterly Report

April - June 1995

U.S. Nuclear Regulatory Commission

Office of Nuclear Reactor Regulation 


\section{AVAILABILITY NOTICE \\ Availability of Reference Materials Cited in NRC Publications}

Most documents cited in NRC publications will be available from one of the following sources:

1. The NRC Public Document Room, 2120 L Street, NW., Lower Level, Washington, DC 20555-0001

2. The Superintendent of Documents, U.S. Government Printing Office, P. O. Box 37082 , Washington, DC 20402-9328

3. The National Technical Information Service, Springfield, VA 22161-0002

Although the listing that follows represents the majority of documents cited in NRC publications, it is not intended to be exhaustive.

Referenced documents available for inspection and copying for a fee from the NRC Public Document Room include NRC correspondence and internal NRC memoranda; NRC bulletins, circulars, information notices, inspection and investigation notices; licensee event reports; vendor reports and correspondence; Commission papers; and applicant and licensee documents and correspondence.

The following documents in the NUREG series are available for purchase from the Government Printing Office: formal NRC staff and contractor reports, NRC-sponsored conference proceedings, international agreement reports, grantee reports, and NRC booklets and brochures. Also available are regulatory guides, NRC regulations in the Code of Federal Regulations, and Nuclear Regulatory Commission Issuances.

Documents available from the National Technical Information Service include NUREG-series reports and technical reports prepared by other Federal agencies and reports prepared by the Atomic Energy Commission, forerunner agency to the Nuclear Regulatory Commission.

Documents available from public and special technical libraries include all open literature items, such as books, journal articles, and transactions. Federal Register notices, Federal and State legislation, and congressional reports can usually be obtained from these libraries.

Documents such as theses, dissertations, foreign reports and translations, and non-NRC conference proceedings are available for purchase from the organization sponsoring the publication cited.

Single copies of NRC draft reports are available free, to the extent of supply, upon written request to the Office of Administration, Distribution and Mail Services Section, U.S. Nuclear Regulatory Commission, Washington, DC 20555-0001.

Copies of industry codes and standards used in a substantive manner in the NRC regulatory process are maintained at the NRC Library. Two White Flint North, 11545 Rockville Pike, Rockville, MD 20852-2738, for use by the public. Codes and standards are usually copyrighted and may be purchased from the originating organization or, if they are American National Standards, from the American National Standards Institute, 1430 Broadway, New York, NY 10018-3308.

A year's subscription of this report consists of four quarterly issues. 


\section{DISCLAIMER}

Portions of this document may be illegible in electronic image products. Images are produced from the best available original document. 
NUREG-0040

Vol. 19, No. 2

\section{Licensee Contractor and Vendor Inspection Status Report}

Quarterly Report

April - June 1995

Manuscript Completed: August 1995

Date Published: August 1995

Division of Inspection and Support Programs

Office of Nuclear Reactor Regulation

U.S. Nuclear Regulatory Commission

Washington, DC 20555-0001
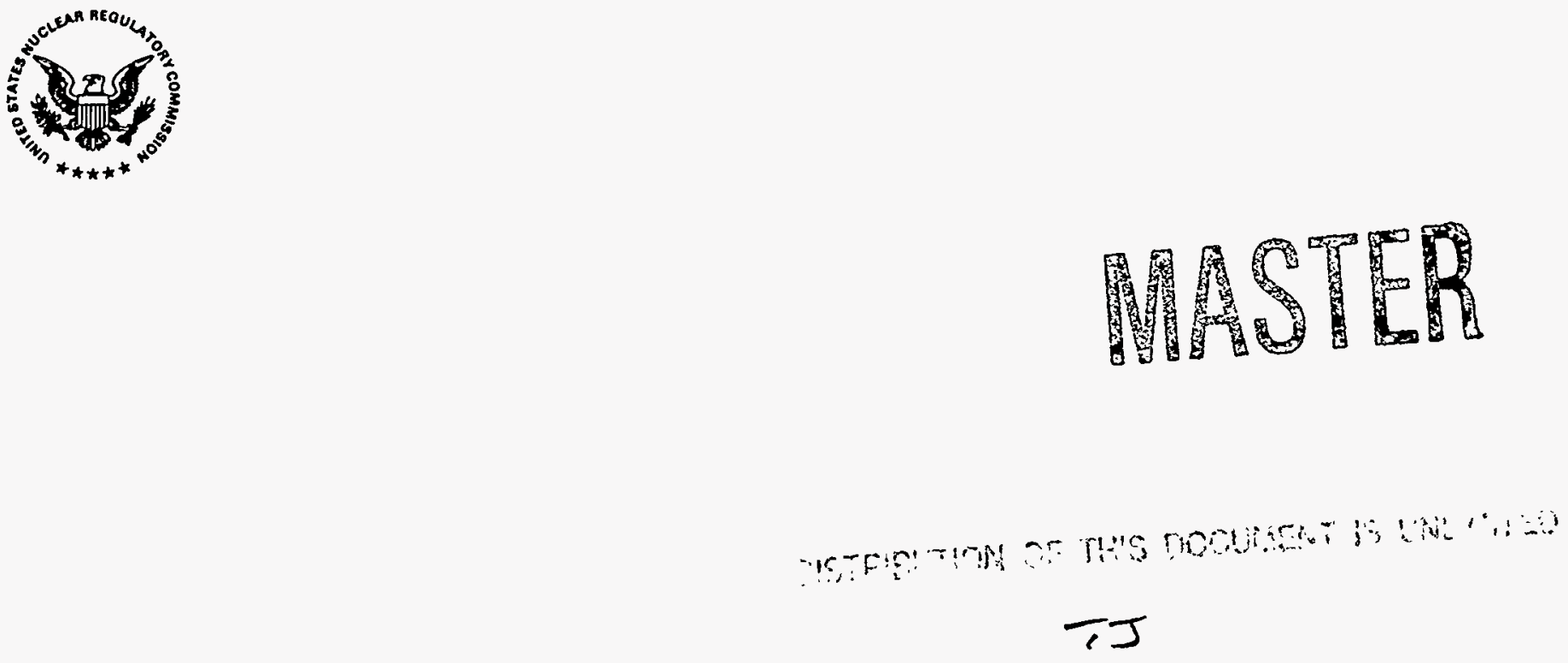



\section{ABSTRACT}

This periodical covers the results of inspections performed by the NRC's Special Inspection Branch, Vendor Inspection Section, that have been distributed to the inspected organizations during the period from April 1995 through June 1995.

\section{DISCLAIMER}

This report was prepared as an account of work sponsored by an agency of the United States Government. Neither the United States Government nor any agency thereof, nor any of their employees, makes any warranty, express or implied, or assumes any legal liability or responsibility for the accuracy, completeness, or usefulness of any information, apparatus, product, or process disclosed, or represents that its use would not infringe privately owned rights. Reference herein to any specific commercial product, process, or service by trade name, trademark, manufacturer, or otherwise does not necessarily constitute or imply its endorsement, recommendation, or favoring by the United States Government or any agency thereof. The views and opinions of authors expressed herein do not necessarily state or reflect those of the United States Government or any agency thereof. 


\section{CONTENTS}

PAGE

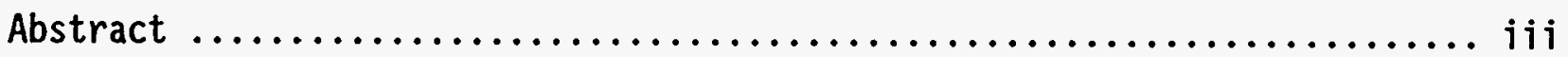

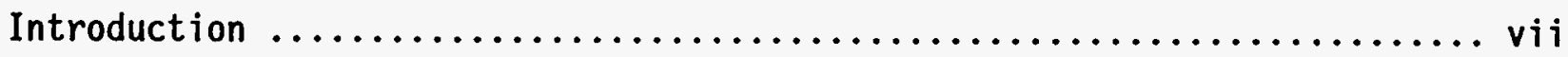

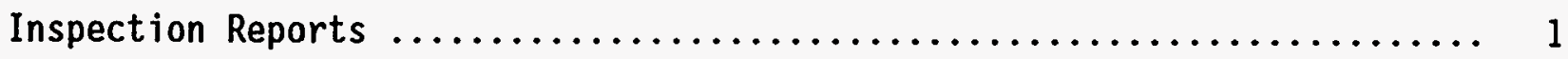

Automatic Switch Company $\quad(99900369 / 95-01) \ldots \ldots \ldots \ldots .2$

Florham Park, New Jersey

$(99900538 / 95-01) \ldots \ldots \ldots \ldots \ldots, 15$

ABB Combustion Engineering

Nuclear Operations

Windsor, Connecticut

Dow Corning U.S.A.

Midl and, Michigan

Dresser Industries, Inc.

Alexandria, Louisiana

Energy \& Process Corporation

Tucker, Georgia

Rosemount Nuclear Instruments

Eden Prarie, Minnesota

(99901284/95-01) ........... 31

Unistrut Corporation

Wayne, Michigan

(99900054/95-01) ........... 41

Whittaker Electronic Systems

Simi Valley, California

$(99900866 / 95-01) \ldots \ldots \ldots \ldots .49$

$(99900271 / 95-01) \ldots \ldots \ldots \ldots \ldots 69$

$(99900362 / 90-01) \ldots \ldots \ldots \ldots \ldots 81$

(99901164/95-01) ............ 115

Select Generic Correspondence on the Adequacy of Vendor ............. 125

Audits and the Quality of Vendor Products

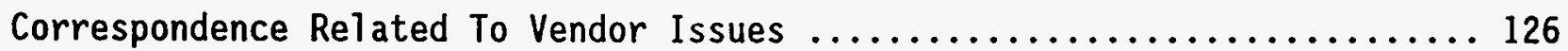





\section{INTRODUCTION}

A fundamental premise of the U.S. Nuclear Regulatory Commission (NRC) licensing and inspection program is that licensees are responsible for the proper construction and safe and efficient operation of their nuclear power plants. The Federal government and nuclear industry have established a system for the inspection of commercial nuclear facilities to provide for multiple levels of inspection and verification. Each licensee, contractor, and vendor participates in a quality verification process in compliance with requirements prescribed by the NRC's rules and regulations (Title 10 of the Code of Federal Regulations). The NRC does inspections to oversee the commercial nuclear industry to determine whether its requirements are being met by licensees and their contractors, while the major inspection effort is performed by the industry within the framework of quality verification programs.

The licensee is responsible for developing and maintaining a detailed quality assurance (QA) plan with implementing procedures pursuant to 10 CFR Part 50. Through a system of $\mathrm{planned}$ and periodic audits and inspections, the licensee is responsible for ensuring that suppliers, contractors and vendors also have suitable and appropriate quality programs that meet NRC requirements, guides, codes, and standards.

The Vendor Inspection Section (VIS) of the Special Inspection Branch reviews and inspects nuclear steam system suppliers (NSSSs), architect engineering (AE) firms, suppliers of products and services, independent testing laboratories performing equipment qualification tests, and holders of NRC construction permits and operating licenses in vendor-related areas. These inspections are done to ensure that the root causes of reported vendor-related problems are determined and appropriate corrective actions are developed. The inspections also review vendors to verify conformance with applicable NRC and industry quality requirements, to verify oversight of their vendors, and coordination between licensees and vendors.

The VIS does inspections to verify the quality and suitability of vendor products, licensee-vendor interface, environmental qualification of equipment, and review of equipment problems found during operation and their corrective action. When nonconformances with NRC requirements and regulations are found, the inspected organization is required to take appropriate corrective action and to institute preventive measures to preclude recurrence. When generic implications are found, NRC ensures that affected licensees are informed through vendor reporting or by NRC generic correspondence such as information notices and bulletins. 
This quarterly report contains copies of all vendor inspection reports issued during the calendar quarter for which it is published. Each vendor inspection report lists the nuclear facilities inspected. This information will also alert affected regional offices to any significant problem areas that may require special attention. Appendices 1 ist selected bulletins, generic letters, and information notices, and include copies of other pertinent correspondence involving vendor issues. 
INSPECTION REPORTS 


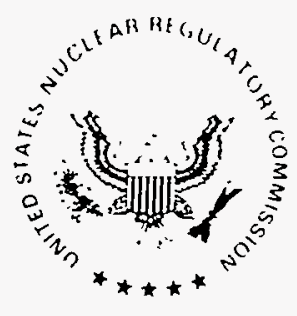

\author{
UNITED STATES \\ NUCLEAR REGULATORY COMMISSION \\ WASHINGTON, D.C. 20555-0001 \\ May 15, 1995
}

Mr. Randy P. Smith, President

Automatic Switch Company

50-56 Hanover Road

Florham Park, NJ 07932

SUBJECT: NRC INSPECTION NO. 99900369/95-01

Dear Mr. Smith:

This letter transmits the report of the U.S. Nuclear Regulatory Commission (NRC) inspection of Automatic Switch Company (ASCO), Florham Park, New Jersey, conducted on March 13 and 14, 1995. The NRC inspection team, led by Joseph Petrosino and comprised of other inspectors named in the report, conducted a limited inspection to evaluate the establishment and implementation of selected portions of your quality assurance program, including the period when ASCO was actively manufacturing NP8323 solenoid-operated valves (SOVs) that were supplied for use in nuclear power plant reactor main steam isolation valves (MSIVS) for boiling-water reactors. This letter also discusses activities that were performed after the completion of this inspection and that were discussed among NRC, ASCO and NRC 1 icensees. Any new information developed after this inspection regarding the conclusions and statements made in the enclosed report may be submitted to the NRC. The inspection was conducted to provide a basis for NRC staff confidence that ASCO's NP8323 SOVs supplied to the nuclear industry would perform their safety-related function.

The NRC team (a) examined technical documentation, procedures and representative records, (b) held discussions, (c) listened to presentations and (d) observed an ASCO technician assemble one NP8323 SOV without using any lubricant and witnessed its related testing. On the basis of this inspection, the NRC team identified one nonconformance relative to Appendix $B$ to Part 50 of Title 10 of the Code of Federal Requlations (Appendix B of 10 CFR Part 50). The team identified that ASCO failed to ensure that its September 29, 1989, engineering department decision to cease using silicone based fluids and greases in its NP8323 SOVs was translated into an ASCO manufacturing department procedure or instruction. As a result, ASCO continued to fabricate NP8323 SOVs using silicone fluids and greases. The enclosed inspection report contains a detailed discussion of the areas examined and the NRC team observations.

Please provide us within 30 days of the date of this letter a written statement in accordance with the instructions specified in the enclosed Notice of Nonconformance. We will consider extending the response time if you can show good cause for us to do so. 
The response requested by this letter is not subject to the clearance procedures of the Office of Management and Budget as required by the Paper Reduction Act of 1980, Pubic Law No. 96-511. In accordance with 10 CFR 2.790 of the Commission's regulations, a copy of this letter and the enclosed inspection report will be placed in the NRC's public document room. If you have any questions regarding this matter, please contact Mr. Joseph Petrosino at (301) 415-2979.

$$
\text { Sincerely, }
$$

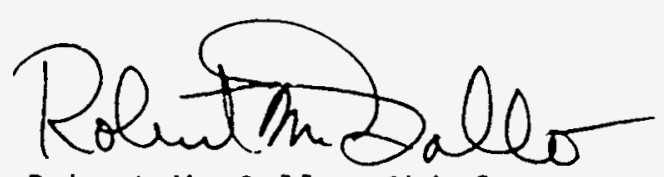

Robert M. Gallo, Chief

Special Inspection Branch

Division of Technical Support

Office of Nuclear Reactor Regulation

Docket No. 99900369

Enclosures: 1. Notice of Nonconformance

2. Inspection Report 99900369/95-01

cc w/encls.: Mr. F. R. B. Matthews, Vice President

Product Development and Technology

Valve Department

Automatic Switch Company

50-56 Hanover Road

Florham Park, NJ 07932

Mr. David B. Tompsen, Quality Assurance Director

Automatic Switch Company

50-56 Hanover Road

Florham Park, NJ 07932

Mr. William C. Kirchhoff, NED Superintendent

LaSalle Site Support Engineering

LaSalle County Nuclear Station

RR\#1 Post office Box 220

2601 North 21st Road

Marseilles, IL 61341 
NOTICE OF NONCONFORMANCE

Automatic Switch Company

Docket No.: 99900369

Florham Park, New Jersey

Report No.: 95-01

Based on the results of a U.S. Nuclear Regulatory Commission (NRC) inspection conducted at the Automatic Switch Company (ASCO) facility on March 13 and 14, 1995, it appeared that certain of your activities were not conducted in accordance with NRC requirements.

Criterion III, "Design Control," of Appendix B to 10 CFR Part 50 requires, in part, that measures shall be established to assure that the design basis for those components to which this appendix applies are correctly translated into specifications, drawings, procedures, and instructions.

Criterion V, "Instructions, Procedures, and Drawings," of Appendix B to 10 CFR Part 50 requires, in part, that activities affecting quality be prescribed by appropriate instructions, procedures, or drawings and be accomplished according to those instructions, procedures, or drawings.

Contrary to these requirements, as of March 14, 1995, ASCO failed to ensure that its September 29, 1989, engineering department decision to cease using silicone-based fluids and greases in its NP8323 solenoidoperated valves was translated into a procedure or instruction for ASCO's manufacturing department personnel implementation. Subsequent to that decision, solenoid-operated valves supplied for nuclear use were manufactured using silicone-based greases. (95-01-01)

Please provide a written statement or explanation to the U.S. Nuclear Regulatory Commission, ATTN: Document Control Desk, Washington, D.C. 205550001 , with a copy to the Chief, Special Inspection Branch, Division of Technical Support, Office of Nuclear Reactor Regulation, within 30 days of the date of the letter transmitting this Notice of Nonconformance. This reply should be clearly marked as a "Reply to a Notice of Nonconformance" and should include (1) a description of steps that have been or will be taken to correct this item, (2) a description of steps that have been or will be taken to prevent recurrence, and (3) the dates your corrective actions and preventative measures were or will be completed. 
U.S. NUCLEAR REGULATORY COMMISSION

OFFICE OF NUCLEAR REACTOR REGULATION

DIVISION OF TECHNICAL SUPPORT
REPORT NO.:

ORGANIZATION:

ORGANIZATIONAL

CONTACT :

NUCLEAR INDUSTRY

ACTIVITY:

INSPECTION DATES:

LEAD INSPECTOR:

REVIEHED BY:

APPROVED BY:
$99900369 / 95-01$

Automatic Switch Company

50-56 Hanover Road

Florham Park, New Jersey 07932

Mr. David B. Tompsen, QA Director

(201) 966-2731

Manufacturer of solenoid-operated valves and pressure and temperature switches.

March 13 and 14, 1995

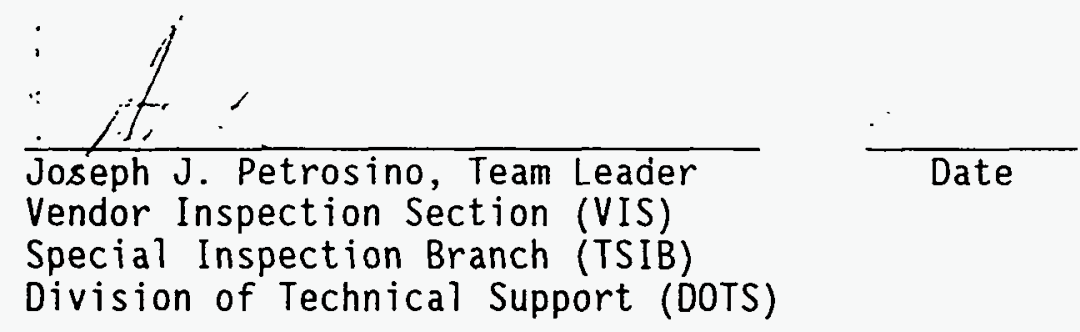

Kamalakar R. Naidu, VIS:TSIB

Edward R. Schweibinz, Region III
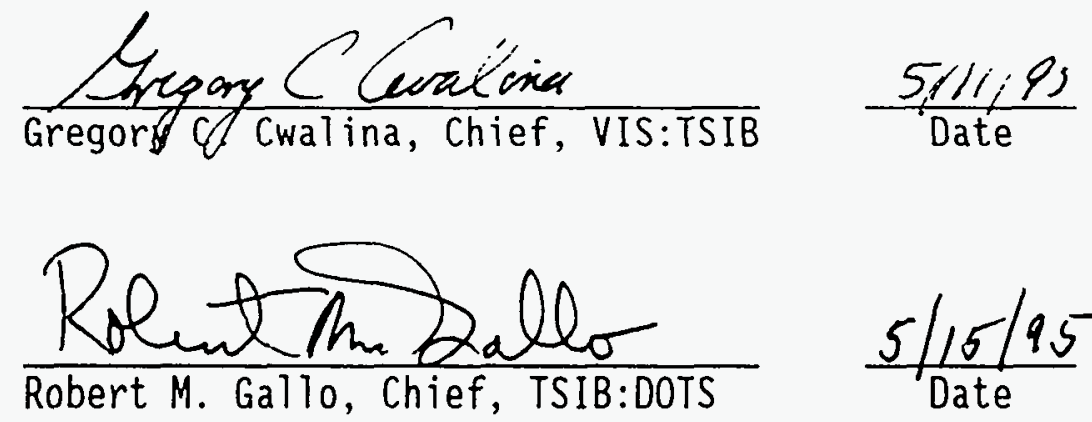

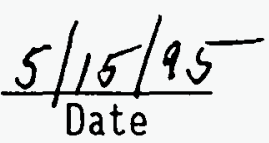


During this inspection, the NRC inspection team evaluated the Automatic Switch Company (ASCO) quality programs and their implementation for the fabrication of solenoid-operated valves (SOVs). The inspection was conducted to provide a basis for confidence that NP8323 SOVs supplied to the U.S. nuclear industry would perform their safety function.

The inspection basis consisted of the following:

- Appendix B, "Quality Assurance Criteria for Nuclear Power Plants and Fuel Reprocessing Plants," to Part 50 of Title 10 of the Code of Federal Regulations (Appendix B of 10 CFR 50)

- Part 21, "Reporting of Defects and Noncompliance," of 10 CFR

One nonconformance was identified and is discussed in Section 3.7 herein.

\section{STATUS OF PREVIOUS INSPECTION FINDINGS}

During this inspection effort, the NRC inspection team did not review any findings identified during previous NRC staff inspections.

\section{INSPECTION FINDINGS AND OTHER COMMENTS}

\subsection{Background}

The Ralph A. Hiller Company (RAH), Pittsburgh, Pennsylvania, designed and manufactured speciality valve actuators for various nuclear industry applications. For nuclear power plant applications, RAH's fluid power actuators were generally categorized as being either pneumatic or hydraulic, with a number of design variations. MSIV applications typically use a pneumatic-hydraulic combination actuator. RAH pneumatic-hydraulic combination actuators are used to operate MSIVs at Commonwealth Edison Company's (ComEd's) LaSalle County Station (LaSalle). A typical RAH actuator consists of two subassemblies. The pneumatic control assembly (PCA) and the pneumatic hydraulic assembly (PHA). The PCA subassembly was designed to use ASCO Model NP8323 SOVs for the pilot valve to control the opening and closing of the MSIVs. The ASCO NP8323 SOV is a dual coil, three-way solenoid valve used by many licensees in their main steam isolation valve (MSIV) applications. In 1989, ASCO issued an ASCO field notification to all applicable customers advising that its NP8323 SOV series valves would be discontinued and suggested that all NP8323 SOVs be removed from MSIV piloting applications. ASCO also recommended to licensees that they use two ASCO NP8320 SOVs instead of one NP8323 SOV in its MSIV applications.

On February 18, 1995, while LaSalle, Unit 2, was entering into a refueling outage, an operator in the control room was unable to close an MSIV when he turned the selector switch to the "close" position. When he moved the selector switch to the "test" position, the MSIV slow-closed. When he moved the switch to the "close" position, the MSIV reopened. On February 19, 1995, a second outboard MSIV in Unit 2 would not close when the operator in the control room moved the control switch to the "close" position. This MSIV 
would also not close when the operator moved the switch to the "test" position. ComEd stated that ASCO NP8323 SOVs were installed on the MSIVs which exhibited the problems.

\subsection{Entrance and Exit Meetings}

During the entrance meeting in Florham Park, New Jersey, on March 13, 1995, the NRC team met with members of ASCO management and staff, discussed the scope of the inspection, and established contact persons for the NRC team within ASCO management and staff. During the exit meeting on March 14, 1995, the NRC team summarized the inspection findings for ASCO management and staff. Inspection participants and personnel contacted during the performance of the inspection-related activities are listed in Section 4 of this report.

\subsection{Principle of Operation of the MSIV Actuator}

The RAH actuators that operated the MSIVs at LaSalle are used at other nuclear power plants. Typically, the licensee staff operators use pushbutton stations on the main control panel to operate the actuators to fast-close, slow-close, or open the MSIVs from the control room. The reactor protection system logic can automatically initiate a signal to the actuator to close the MSIV when the logic senses adverse operating conditions. The RAH actuators typically are energized with a 120 volt alternating current (ac) electrical power source and 90 psig air pressure. ASCO's NP8323 series, dual coil, three-way SOVs are installed in the PCA and function as pilot valves to direct air in the appropriate direction to the PHA to either close or open the MSIV. When energized, which is the normal operating state, the SOV directs air into the PHA, creating a force against the springs to keep the MSIV open; when the SOV is de-energized, it directs the air away from the PHA, which allows the spring pressure to close the MSIV. Sticking internals inside the SOV and foreign particles lodged in the SOV can prevent change of state, so that the direction of the air to the PHA is not reversed and the MSIV remains open.

Over the last several years, the NRC staff has issued numerous generic communications discussing several solenoid valve concerns, such as foreign material found lodged inside SOVs and degraded operation of various SOV internals that experienced degraded operation due to a variety of problems, including sticky residues on certain internals. Examples of generic communications include:

- $\quad$ NUREG-1275, Volume 6, "Operating Experience Feedback Report-Solenoid Operated Valve Problems," February 1991.

- Generic Letter 91-15, "Operating Experience Feedback Report, SolenoidOperated Valve Problems at U.S. Reactors," September 1991.

- IN 89-66, "Qualification Life of Solenoid Valves," September 1989.

- IN 87-28, "Air System Problems at U.S. Light Water Reactors," June 1987.

- Supplement 1 to IN 87-28, December 1987;

- IN 86-57, "Operating Problems With Solenoid Operated Valves at Nuclear Power Plants," July 1986; 
- IN 85-17, "Possible Sticking of ASCO Solenoid Valves," March 1985

- Supplement 1 to IN 85-17, October 1985.

\subsection{Actions and Conclusions Following the MSIV SOV Failures}

\subsubsection{Commonwealth Edison}

Following the failures of the MSIVs to close on February 18, $1995^{1}$, as discussed in Section 3.1 above, LaSalle personnel continuously energized solenoids A and B of the ASCO NP8323 dual solenoid SOV for 1 hour and measured the current in both the coils and also monitored the pressure of the air supply. When the operators de-energized solenoids $A$ and B simultaneously, they observed that the SOV did not change its internal valve air flow position, indicating that the SOV had failed. Consequently, the LaSalle personnel removed the following SOVs for analysis: the two ASCO NP8323 SOVs which had failed, the remaining two outboard SOVs which did not fail, one inboard SOV, and one ASCO single-action test solenoid which was mounted outboard. The SOVs were disassembled utilizing ASCO's Installation and Maintenance Instruction (I\&M) sheets. Upon disassembling the SOVs, the LaSalle personnel did not find any anomalies on the side of the SOV where solenoid A was located. However, on the solenoid B side of several of the SOVs, LaSalle personnel found some residue on the disc holder (milk stool), backup washer, and stem. LaSalle personnel also observed a brownish gelatinous film around the mating surfaces of the core and plug nut of one of the failed SOVs, which appeared to be holding the two parts together.

After the LaSalle personnel's initial analysis of the SOVs, LaSalle sent the SOV components to ComEd's System Materials Analysis Department (SMAD) for further tests. All of SMAD's observations and conclusions were documented in SMAD Report No. M-00954-95, "MSIV Solenoid Failures, LaSalle Station, (A95-140)," issued March 1, 1995. As the report indicated, the SOV components came to SMAD disassembled, and SMAD was informed by the LaSalle staff that two of the SOVs failed to change position during operation and that the other four solenoids were removed from service and disassembled for comparison. The two failed SOVs were identified as being on the Unit 2 outboard MSIVS, 2B21-F028A and 2B21-F028D. The LaSalle personnel also submitted reference samples to SMAD of Dow Corning's 550 silicone fluid and a sample of Nyogel 775A silicone grease.

SMAD photographed all of the ASCO NP8323 SOV core and plug nut sets prior to starting any analyses of the components. The report indicated that the failed sets showed residue on both core and plug nut sets, another outboard set showed a residue, and the fourth outboard set and an inboard set showed no residue. However, the inboard and outboard sets which had no residue showed evidence of core face wear. The report stated that portions of the residues taken from the core and plug nut sets on the failed SOVs were examined by microscopic infrared spectroscopy and found to contain methyl phenyl polysiloxane and that the organic portion of these residue deposits was removed and the residue examined by a scanning electron microscope equipped with an $X$-ray analyzer. This analysis with the $X$-ray analyzer showed that the

1 As discussed in Section 5.2.4.4 of NUREG-1275, Vol. 6, a similar core and plug nut adhesion problem occurred at LaSalle in 1987. 
residue contained major amounts of iron; minor amounts of silicon, chromium and copper; and a trace of zinc. SMAD also analyzed the NP8323 cores and plugs with an alloy analyzer and found that the NP8323 components were $80.1 \%$ iron, $16.9 \%$ chromium, $1 \%$ manganese, and $0.3 \%$ molybdenum.

The SMAD report also speculated that due to vibrations in the plant, the mating surfaces of the core and plug nut rubbed together (fretted) and created microscopic wear particles. The report indicated that the wear particles could then accumulate in a binding material such as Nyogel 775A silicone grease. SMAD's report stated that the elemental analysis of the core and plug nut deposits indicated a large amount of wear particles and that the two failed core and plug nut sets had a total depositing of approximately 1 milligram. SMAD also speculated that as more and more particles accumulated in the grease, the viscosity of the grease increased making it tacky and the formation of this tacky substance between the core and plug nut may have caused them to stick when the solenoid was de-energized.

The SMAD report stated that the reference lubricants were analyzed by infrared spectroscopy and that both reference samples contained methyl phenyl polysiloxanes. The report stated that the two spectra were very similar but with subtle differences, and that peak-by-peak comparison sheets were attached. The report stated that most of the deposits were methyl phenyl polysiloxane and similar to Nyogel 775A except for the core and plug nut set from an outboard NP8323 SOV, which more closely resembled poly(dimethylsiloxane). SMAD's report stated that Nyogel 775A and Dow 550 contain a combination of methyl and phenyl functionality ${ }^{2}$, whereas the poly(dimethylsiloxane) contained only the methyl functionality. The SMAD report indicated that its results indicated that another silicone-based lubricant may have been present.

\subsubsection{Automatic Switch Company}

ASCO did not receive either of the failed NP8323 SOVs from the LaSalle station, nor did it receive any of the SOV components that were analyzed. However, LaSalle did provide ASCO with a copy of SMAD's report, which contained data sheets from its infrared spectra analysis and associated photographs, and also provided ASCO with four unused NP8323 SOVs which had been stored in the ComEd warehouse since 1989. ASCO disassembled the four NP8323 SOVs and observed a small quantity of Nyogel 775A in the vicinity of where the ASCO assembler applied a dab of Nyogel to hold the back-up washer onto the milk-stool disc on each SOV. ComEd personnel from LaSalle witnessed some of ASCO's disassembly and inspection activities.

The ASCO report indicated that no other traces of Nyogel $775 \mathrm{~A}$ were identified on the valve internals. However, the team noted that the ComEd staff who witnessed the disassembly of the SOVs observed a residue on one of the plug nuts. The Comed trip report stated that "a small amount of white colored residue was observed on the surface that interfaces with the core assembly. When picked at with a dental pick, the residue smeared." When ASCO received a copy of the SMAD report, ASCO staff obtained the services of an independent

${ }^{2}$ Functionality refers to the atom or group of atoms that define the structure of a particular family of organic compounds and determines their properties. 
laboratory to review the SMAD report infrared spectra analys is information and to make an independent determination of the SMAD test data. ASCO documented its review and analysis in ASCO "Engineering Report 309, Investigation of Reported Failure to Shift at Commonwealth's LaSalle Unit [2] Nuclear Facility, ASCO SOV NP8323A20V," issued March 27, 1995. In the background section of the report ASCO stated that the failed outboard MSIV SOVs were operated in an ambient temperature environment of approximately $115^{\circ} \mathrm{F}$ and the ambient temperature in this area could increase to as much as $170^{\circ} \mathrm{F}$ for several hours. The SOVs each saw 90-100 psi and each piloted a "Norgren" valve. The background section of the report indicated that a correlation existed between the SOV failures and the different air supply sources that are used for the inboard and outboard MSIVs. That is, the outboard MSIVs, two of which failed, used station instrument air supply, whereas the inboard MSIVs, which did not have any failures, used a nitrogen system. ASCO also stated that ComEd used a "graphoil" paste on the SOV/MSIV interface.

The ASCO report discusses some of the ComEd results, takes exception to some aspects, and discusses the details of others. For example, ASCO noted that SMAD's photographs of the B side core and plug nut mating surfaces showed a brownish residue, whereas the A side components were clean. ASCO indicated that a brownish residue was also apparent on one leg of a disc holder assembly (DHA) and on the back of a DHA back-up washer. ASCO states that it is clear from the residues that contaminants were present in the SOVs. Section 3.0 , "Independent Lab Analysis of Residues," of ASCO's report stated:

the brown residues believed to have caused the two sov shifting failures consist of silicone grease or silicone oil contaminated with an ester-alcohol combination... Although there is a strong indication of the presence of a silicone grease or silicone oil, it is questionable whether it is Nyogel 775A. There are several subtle but significant differences between the reference Nyogel $775 \mathrm{~A}$ spectra and the unknown residue of interest. These findings are consistent with contaminants that have been found to cause slow shifting or failure to shift in ASCO scram solenoid pilot valves. In those cases it was concluded that the silicone grease or silicone oil became contaminated with volatiles from uncured thread sealants or with ester oils possibly used as air compressor lubricants.

Section 6.0, "Conclusions," of ASCO's report generally indicated that the Dow Corning 550 fluid or Nyogel 775A grease alone are not causing the sticking. ASCO believes that the major source of the contaminants is from the instrument air system piping or the Norgren valve backflow air. ASCO states that since only the B side of the SOVs have been contaminated, it is possible that the cylinder connection, the Norgren valve at LaSalle, has introduced the contamination. When the ASCO SOV is de-energized, there is a backflow of air from the Norgren valve through the B side of ASCO's SOV for exhaust. ASCO states that any contamination that may be in the Norgren valve or connecting piping can therefore deposit in the B side of the NP8323 SOV.

As a preface to the conclusions in the report, the ASCO personnel recalled to NRC staff that in December 1987 LaSalle had experienced a similar problem with an ASCO NP8323 SOV used on an outboard MSIV. ASCO compared the 1987 reports and photographs with the recent report and photographs and stated that its review of the two events "show both to be remarkably similar." ASCO stated that in the 1987 event, Comed concluded that Dow Corning 550 fluid caused the 
problem, whereas ASCO concluded that the failure was caused by a brownish residue found on the B side of the NP8323 SOV and that this residue contained contaminants from external sources. ASCO stated that, al though this circumstance was not mentioned in its 1987 report, an independent laboratory and a technical expert identified the brownish residue as a silicone grease or oil contaminated with an ester-alcohol combination.

\subsubsection{Current \& Future Activities by ComED and ASCO}

Following the NRC inspection at ASCO, ComEd and ASCO continued to review the circumstances surrounding the MSIV SOV failures at LaSalle and conducted discussions regarding similar ASCO SOV component analyses concerning "brown residue" that was identified at other licensee facilities. The activities that ComEd and ASCO are performing is an attempt to isolate all of the probable causes of the degraded operation of ASCO's NP8323 SOV in certain conditions. ComED and ASCO have kept the NRC staff apprised of the ongoing actions, for example.

On April 7, 1995, LaSalle staff informed NRC that the last three Unit 2 inboard MSIV SOVs had been examined. Some of The ComEd activities were witnessed by Region III NRC staff. The licensee staff stated that it had observed a brownish gelatinous residue on the interfacing junction of the core and plug nut of one of the three inboard SOVs. This brownish residue appeared to be the same as that found previously on the core and plug nut interface on the outboard SOVs. All three SOV stems also exhibited a small amount of a opaque residue. An opaque, white and colored gelatinous substance was also observed on the core and stem of one of the SOVs. Subsequently, the LaSalle staff transported the three SOVs to SMAD for analysis. The NRC staff informed ASCO personnel about the latest finding by ComEd staff.

During the first three weeks of May 1995, discussions were conducted between LaSalle, SMAD, ASCO, and ASCO's independent laboratories. The discussions involved the individual analysis results of SMAD and ASCO, and the results of previous analyses of other ASCO SOV components which exhibited questionable performance at other licensee facilities and in other licensee applications. The NRC staff perceives that additional information relevant to the brown residue issue will continue to be identified by the research activities of the ComEd and ASCO personnel. Consequently, additional information may be available to the industry after ComEd and ASCO complete their additional reviews of this matter.

\subsection{ASCO Installation and Maintenance Instructions}

While discussing the circumstances of the failures and potential root causes, the inspection team queried ASCO about the adequacy of a 90-day cycling frequency. ASCO indicated that more frequent SOV cycling is better than less frequent cycling. When the inspection team asked ASCO to bound their statement, ASCO stated that its I\&Ms previously recommended that a 30 -day maximum cycling be performed to insure proper opening and closing. However, due to customer pressures that a 30-day cycling was too conservative and set too strict a requirement, ASCO changed the recommendation to allow each customer to set its own standards for cycling. The team reviewed several of ASCO's current and past I\&Ms for its NP8320, NP8323 and NP8321 series SOVs, and found that prior to 1981, each I\&M stated: "while in service, operate valve at least once a month to insure proper opening and closing." The team 
noted that the current I\&Ms for nuclear NP series SOVs stated: "while in service, operate valve periodically to insure proper opening and closing." Discussions with regional NRC staff indicated that some licensee MSIV applications do not have a cycling policy for its MSIV SOVs. The ASCO staff indicated that an 18-month period without cycling would not be recommended by ASCO.

\subsection{Review of ComEd Purchase Order}

After ASCO notified ComEd and its other customers in 1989 that it would discontinue the manufacture of NP8323 dual SOVs, several customers, including several nuclear plant facilities, ordered large quantities of NP8323 SOVs. For example, ComEd decided to procure 50 NP8323 SOVs so that it could continue to use the ASCO's NP8323 SOV in its MSIV application for a few more refueling cycles until it decided upon its replacement course of action. As a result, ComEd issued purchase order (P0) 330255, dated October 6, 1989, to ASCO for the supply of 50 NP8323A solenoid-operated valves with Viton seals and discs, normally closed, coil insulation class $\mathrm{H}$, in explosion proof enclosure suitable for instrument air and environmentally qualified to Revision 1 of ASCO Test Report No. AQR-67368. The PO required ASCO to implement its quality assurance program during the manufacture of the SOVs and to provide a certificate of conformance for the SOVs being supplied. The PO specified all relevant quality requirements including 10 CFR Part 21.

The SOVs shipped to LaSalle in 1990 by ASCO were stored for use in future refueling outages and the two subject failures were the only problems identified with this batch. According to a LaSalle engineer, eight NP8323 SOVs were typically replaced during each refueling outage and were also required to be cycled on a 90 -day $( \pm 10 \%)$ cycle frequency. However, it was noted that the two NP8323 SOVs, which had failed, had their cycling extended to 118 days from the normal cycle period.

\subsection{Discontinuation of Silicone Fluids and Greases in NP8323 SOVs}

ASCO informed the inspection team that based on previously experienced problems with lubricants in NP8323 type SOVs, it had documented in engineering report No. 264, "Discontinuance of Fluid Lubricants from NP8323 Valves," dated September 29, 1989, which was part of ASCO's qualification basis, that it had planned to discontinue the use of silicone-based fluid lubricants in the assembly of NP8323 SOVs. ASCO suspected that Dow Corning compound 550 may have contributed to previous SOV failures, including a 1987 NP8323 failure at LaSalle. The report stated that although ASCO cannot find evidence to implicate lubricants in the failure of the valve to shift to the de-energized state, ASCO is removing all silicone-based fluids and greases from within the NP8323 valve bodies, and that ASCO had used the fluids solely for lubrication of static seals during assembly and for SOVs operating with alternating current to reduce objectionable hum during run-in period. ASCO addressed the latter by 100 percent functional and noise testing, which assured chatter-free operation in the field. The report also recommended a light application of clean water, instead of the silicone fluids and greases, to the 0 -rings at the interfaces of the metallic components. ASCO's engineering department determined that, because the changes did not affect the operation of the SOV, the environmental qualification of the valve was not compromised. 
ASCO engineering expected all NP8323 SOVs manufactured after September 29, 1989, to be free of silicone-based fluids and greases; however, the inspection team determined that ASCO did not ensure that its decisions to discontinue the use of silicone products in NP8323 SOVs were translated into ASCO assembly or fabrication procedures or instructions to ensure that the NP8323 SOVs were assembled in accordance with the engineering department decision. As a result of ASCO's failure to establish new procedures or to modify existing procedures, ASCO NP8323 solenoid-operated valves supplied for nuclear use after September 29, 1989, were supplied and manufactured using silicone-based greases. This matter was reviewed and determined to be contrary to Criterion III and Criterion V of 10 CFR Part 50, Appendix B. Nonconformance 99900369/95-01-01 was identified in this area.

\subsection{ASCO's Actions Pertaining to Transmitted Information Regarding NP8323}

In a letter dated August 23, 1989, ASCO informed ComEd's LaSalle station that it planned to discontinue offering NP8323 series valves as nuclear qualified valves and attached a copy of its field notification. In a letter dated October 2, 1989, concerning NRC's Information Notice 89-66 and recent problems with NP8323 valves at Grand Gulf Nuclear Station Unit 1, ASCO informed the NRC that it was forwarding the following documents to its nuclear customers: a letter explaining the reason for the mailing, ASCO's "Field Notification Concerning the Qualified Life of ASCO Catalog NP-1 Valves," and a "Revised Field Notification of Discontinuation of the NP8323 Valve Line." These notifications provided additional information on the failures that occurred with NP8323 series valves and helped clarify ASCO's position and intention regarding discontinuation of its NP8323 valve line.

On March 16, 1995, ASCO issued a service bulletin to all customers that had procured NP8323 SOVs in the 1989-1990 time period. The bullet in reiterated that ASCO recommended that its NP8323 SOVs be removed from 1 icensees MSIV applications. The service bulletin also stated that "ASCO recommends that any plant planning to continue the use of the NP8323 reconsider this position."

\subsection{Observation of Assembly of NP 8323 Without Lubricants}

On March 14, 1995, in the presence of representatives from ASC0's quality control and LaSalie site engineering department, the NRC inspection team observed ASCO personnel assemble one of the four NP8323 SOVs intended for LaSalle. The various components for the assembly of the SOV had been retrieved from the storage bins and inspected by ASCO's quality control personnel. The inspection team observed that clean water instead of lubricants was used during the assembly and witnessed the successful operational tests performed on the SOV.

\subsection{Conclusions}

The team cannot attribute the sticking of the ASCO NP8323 SOVs at the LaSalle County Station to any one aspect; but concluded that the following factors may all play a part in the SOV failure: less frequent cycling, in conjunction with higher ambient temperatures; instrument air quality; internal oil or grease products that attract internal as well as external contaminants; fretting; and potential piping and external valve contaminants. Additionally, from observations of ASCO's assembly techniques and discussions with ASCO personne1, the team concluded that ASCO's NP8323 assembly and testing methods 
in the past could have caused some excessive or inadvertently applied silicone products to be transferred to the core and plug nut sets during some of the fabrication or operational testing activities.

\subsection{PERSONS CONTACTED}

\section{Automatic Switch Company}
M. Adase
A. Byrne
G. Laubenste in
J. Shank
K. Thomas, Jr.
D. Tompsen
G. Plechy
R. Powell
W. Prudden

\section{Commonwealth Edison Company}

D. Drankham

R. Tjerlund

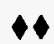

- Contacted by telephone
Assistant Engineer

Valve Service Manager

Manager, Government/Nuclear Sales

Director, New Product Design \& Development Senior Service Engineer

Director, Quality Assurance

Senior Quality Control Engineer

Senior Product Engineering Manager

Quality Control Supervisor

LaSalle Site Support Engineering

LaSalle Site Support Engineering 


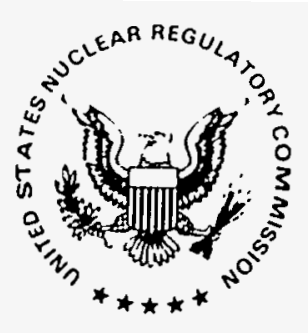

UNITED STATES

\section{NUCLEAR REGULATORY COMMISSION}

WASHINGTON, D.C. 20555-0001

June 9, 1995

Dr. Richard S. Siudek, President

Combustion Engineering, Inc.

ABB Combustion Engineering

Nuclear Operations

P.O. Box 500

1000 Prospect Hill Road

windsor, CT 06095-0500

SUBJECT: NRC INSPECTION NO. 99900538/95-01

Dear Dr. Siudek:

This letter transmits the report of the U.S. Nuclear Regulatory Commission (NRC) inspection conducted April 7 through 10, 1995, at the windsor, connecticut, facility of Asea Brown Boveri (ABB) Combustion Engineering Nuclear operations (CENO). The inspection was conducted by Robert Pettis, Jr., of the Special Inspection Branch; Jack Strosnider, Barry Elliot and John Tsao of the Materials and Chemical Engineering Branch, and Ernest wilson of NRC Region I office of Investigations.

The purpose of the inspection was to review records and obtain data and information relevant to the assessment of reactor pressure vessel integrity. Information reviewed during the inspection included the review of the Reactor Vessel Group (RVG) data base, including supporting documents and quality assurance records, plant specific summary reports, licensee correspondence and $A B B$ CENO prepared reports for the combustion Engineering Owners Group.

The inspection team held discussions with ABB CENO personnel and reviewed documentation relevant to activities performed by the RVG. On the basis of this inspection, the staff determined that ABB CENO's activities, related to the assembly and evaluation of design and fabrication records used to support assessments of reactor pressure vessel (RPV) integrity, were in compliance with the ABB CENO Quality Assurance Program Manual for Service Related Activities (QAM-100), Fourth Edition, Revision 2, and with the requirements of Appendix B to Part 50 of Title 10 of the Code of Federal Regulations. The enclosed inspection report contains a detailed discussion of the areas examined during the inspection.

The inspection also identified that although ABB CENO has data that some licensees have not acquired for use in their RPV assessments, ABB CENO does not possess all the information that licensees should have to perform a thorough RPV evaluation. 
Original fabrication records, surveillance information and research results are in the possession of various vendors, utilities, institutes and laboratories. For some RPVs, particularly older vintage, it appears that no single vendor possesses all the information relevant to performing an assessment of RPV integrity.

In accordance with 10 CFR 2.790 of the NRC's "Rules of Practice," a copy of this letter and its enclosures will be placed in the NRC Public Document Room.

Should you have any questions concerning this inspection, we will be pleased to discuss them with you. Thank you for your cooperation during this process.

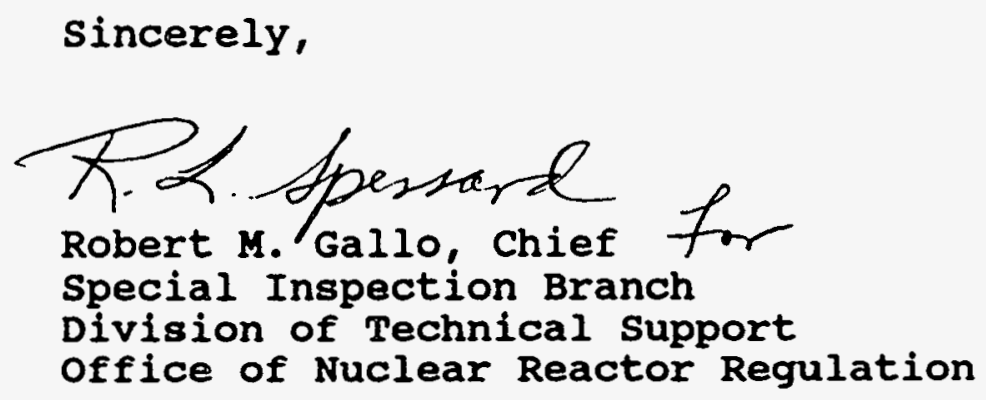

Docket No.: 99900538

Enclosure: Inspection Report No. 99900538/95-01 


\title{
U.S. NUCLEAR REGULATORY COMMISSION OFFICE OF NUCLEAR REACTOR REGULATION DIVISION OF TECHNICAL SUPPORT
}

\author{
ORGANIZATION: Combustion Engineering, Inc. \\ Asea Brown Boveri (ABB) \\ Combustion Engineering Nuclear Operations \\ REPORT NO.: \\ $99900538 / 95-01$ \\ CORRESPONDENCE \\ ADDRESS : \\ Dr. Richard S. Siudek, President \\ Combustion Engineering, Inc. \\ ABB Combustion Engineering Nuclear operations \\ P.O. Box 500 \\ Windsor, Connecticut 06095-0500 \\ ORGANIZATIONAL \\ CONTACT: \\ Ron Fitzgerald, Director \\ Nuclear Operations Quality Assurance \\ INSPECTION DATES: April 7 through 10, 1995
}

TEAM LEADER:

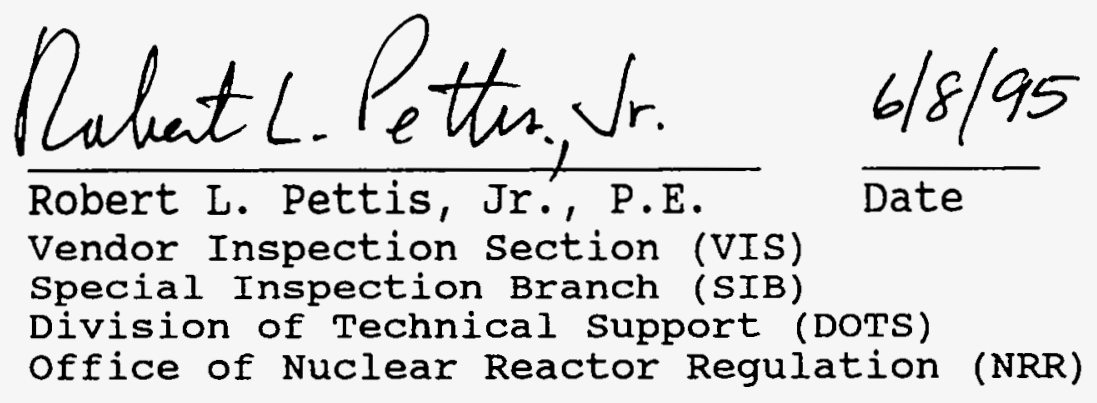

INSPECTION TEAM: Jack Strosnider, Team Manager, EMCB Barry Elliot, EMCB

John Tsao, EMCB

Ernest Wilson, Region I, OI

REVIEWED BY:

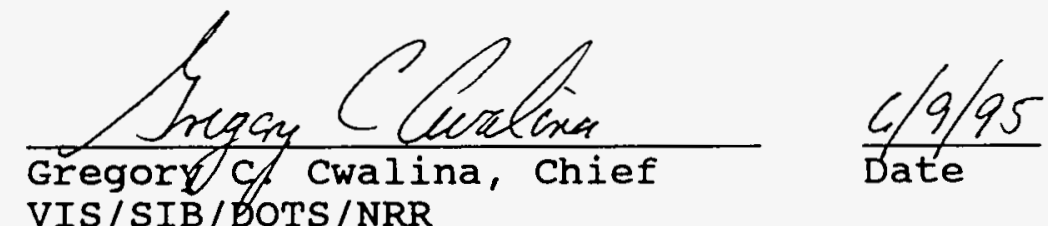

APPROVED BY:

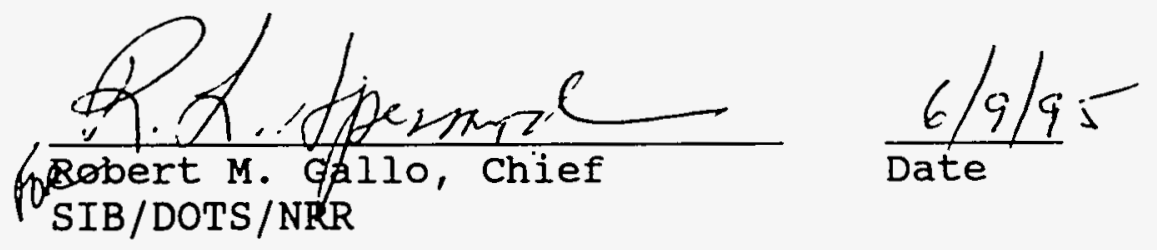


- Appendix A, "General Design Criteria for Nuclear Power Plants," General Design Criterion 10, Reactor Design, to Part 50 of Title 10 of the code of Federal Regulations (CFR).

- Appendix B to 10 CFR Part 50, "Quality Assurance Criteria for Nuclear Power Plants and Fuel Reprocessing plants."

- 10 CFR Part 21, "Notification of Failure to Comply or Existence of a Defect."

- Asea Brown Boveri (ABB) Combustion Engineering Nuclear operations (CENO), Topical Report, document CENPD-210A, Revision $7 A$, and $A B B$ CE Nuclear operations quality Assurance Manual for Service Related Activities (QAM-100), Fourth Edition, Revision 2 .

2 SUMMARY OF INSPECTION FINDINGS:

No findings were identified during this inspection.

3 STATUS OF PREVIOUS INSPECTION FINDINGS

Previous inspection findings were not addressed during this inspection.

4 INSPECTION FINDINGS AND OTHER COMMENTS

\subsection{Introduction}

On February 28 and March 6, 1992 (Revision 1), the NRC issued Generic Letter (GL) 92-01,"Reactor Vessel structural Integrity, 10 CFR 50.54(f)," which was part of a program to evaluate reactor pressure vessel (RPV) integrity, ensure that licensees are complying with the requirements of 10 CFR 50.60 and 10 CFR 50.61, and are fulfilling commitments made in response to GL $88-11$, "NRC Position on Radiation Embrittlement of Reactor Vessel Materials and its Impact on Plant Operations."

All licensees responded to the GI and provided data relevant to the assessment of their RPVs. The results of the NRC staff's review of the GL responses are documented in letters to each licensee and in NUREG-1511, "Reactor Vessel status Report," dated December 1994. The purpose of the inspection was to review records and information, determine if $A B B$ CENO has data or information relative to the assessment of RPV integrity that had not been submitted to the NRC as part of the GL responses and to determine the extent to which data were shared between $A B B$ CENO and licensees. 


\subsection{Company Background}

ABB CENO was formed in October 1993, when ABB Combustion Engineering Services and ABB Combustion Engineering Nuclear Fuel were combined. According to $A B B$ CENO, as part of the reorganization, Engineering and Development in both of the former organizations were combined into a new organization, Engineering operations. As a result of the reorganization, the major groups within the $A B B$ CENO organization include:

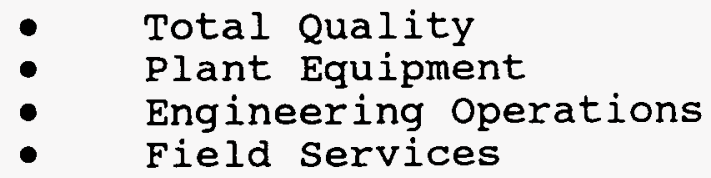

A sister company, $\mathrm{ABB}$ Atom $\mathrm{AB}$, located in Västerås, Sweden, is also involved in the activities of the U.S. nuclear industry. $A B B$ Atom is a subsidiary of Asea Brown Boveri $A B$ of the ABB Asea Brown Boveri Group.

ABB CENO (Engineering Operations) provides engineering, analysis and operations services to the nuclear power utilities. All nuclear safety-related activities are performed using controlled procedures that meet the requirements of Appendix B to $10 \mathrm{CFR}$ Part 50, NQA-1 and ABB CENO Quality Assurance Program Manual (QAM-100), which is supported by implementing procedures contained in (QAM-101). In addition, $A B B$ CENO holds an American Society of Mechanical Engineers N, NA and NPT certificates and a National Board NR certificate.

\subsection{Entrance and Exit Meetings}

During the entrance meeting in windsor, Connecticut, on April 7, 1995, the inspection team met with members of ABB CENO (Engineering Operations) management and staff, discussed the scope of the inspection and established contacts. The persons who participated in the inspection are listed in Appendix $A$ of this report. Information provided electronically to ABB CENO by the NRC on April 6, 1995, is shown in Appendix B. The inspection team conducted an exit meeting with $\mathrm{ABB}$ CENO staff and management on April 10, 1995.

\subsection{Identification of Available Information}

The information sought by the NRC staff in connection with the assessment of RPV integrity was in the form of a data base maintained by the Reactor Vessel Group (RVG) of ABB CENO. The RVG was chartered in 1991 by a group of 14 member utilities operating with ABB CENO vessels. The 14 members are all domestic utilities and are licensees for 23 RPVs. There are 70 operating reactors with RPVs that were fabricated by ABB CENO. The data base contains most of the data relevant to domestic operating 
reactors because it contains information on non-member sister vessels. ABB CENO was the original equipment manufacturer for approximately one-half of the operating reactor pressure vessels in the United States.

The objective of the RVG was to develop a verifiable data base of RPV information such as a description of the processes, procedures, chemistries and material properties for the welds, plates, forgings and cladding used in the fabrication of the RPVs of the member utilities. The assembly and evaluation of the data was performed by personnel at the $A B B$ CENO Southeast Nuclear Service Center (SNSC), located in Chattanooga, Tennessee. over 450 boxes of original vessel fabrication records and drawings were reviewed. The documents included material certifications, procedures, specifications, fabrication, laboratory log book entries, inspection and test records. Due to the complexity and technical nature of these records, several former SNSC employees were hired to participate in the interpretation and evaluation of this information. ABB CENO fabricated RPVs, steam generators and pressurizers for domestic utilities at this facility.

$A B B$ CENO collected the records for the fabrication of the RPVs for the 14 member utilities. Additional data was collected from the fabrication records of steam generators and pressurizers, if the steam generators and pressurizers were fabricated by ABB CENO. Data was also collected from non-member RPVs, steam generators and pressurizers, if the data was applicable to the member plant's RPV. As a result, the RVG data base consists of information from about 20 percent of the 450 boxes; however, it represents a larger percentage of the data of greatest interest.

The data base does not contain all surveillance data from $A B B$ CENO fabricated RPVS. The last RPV material surveillance capsule reviewed by $A B B$ CENO was in 1983. Since the data base does not contain all surveillance data and does not contain all the RPV data for non-member plants, it is not a complete data base.

The RVG data base program consisted of two phases. Phase I identified the subtasks necessary to prepare a detailed evaluation of the records. Phase II evaluated the records, which included abstracting critical data from each record selected, entered the data into the Global Data Matrix (GDM), verified the input data and provided identification of sister vessel relationships. Vessel-specific records were reviewed and prepared for each nuclear utility who participated in the project. The Phase I Final Report was issued by ABB CENO in August 1992. The Phase II Final Report is scheduled for issuance in June 1995. At the conclusion of Phase II, ABB CENO will provide each member with the results of the evaluation for each RPV owned by that member. 


\subsection{Computerized RVG Data Base}

\subsubsection{Data Abstraction Process}

As stated previously, the information which was input into the RVG data base was abstracted from the original fabrication records and documents available in Chattanooga, Tennessee. Relevant information was extracted from each document and then recorded on data entry forms which were assigned unique RVG numbers. The forms were then typed by a clerk and were verified for accuracy by a reviewer. The data entry forms were then signed by the inspector, clerk and reviewer. Each original document and the corresponding data entry forms identified by the RVG numbers, were placed in a folder prior to being input into the data base.

\subsubsection{Description of Data Base}

The RVG data base consists of 12,000 data sheets and computer files which have been input into the GDM. The software system used for storing and manipulating information in the data base is Paradox Runtime 4.5, a relational data base program. The data base consists of 54 primary, secondary and support data files. To review data stored in these files, the operator must link the. various files that contain the needed information. Hence, the operator must have a working knowledge of Paradox including the data contained in the data files.

\subsubsection{Quality Assurance of RVG Data Base}

\subsubsection{Procedures Review}

The NRC inspection team reviewed the $Q A$ activities related to the preparation of the RVG data base. ABB CENO Quality Assurance Manual (QAM) for Service Related Activities, QAM-100, Fourth Edition, Revision 2, December 21, 1994, is the upper tier quality manual which governs the activities of ABB CENO Nuclear operations. The implementing procedures required under QAM-100 are contained in ABB CENO Nuclear Services QA Procedures Manual, QAM-101, Revision 10, November 8, 1993. Quality Assurance Procedure (QAP) QAP 1.1, Revision 2, requires preparation of a Quality Plan for each project related to the supply of Quality Class 1 items or services, as defined in QAP 3.1. The plan provides specific information concerning the application of the ABB CENO quality program to the specific project.

The inspection team reviewed ABB CENO Integrated Project Quality Plan (IPQP), "Reactor Vessel Group Program for Assembly and Evaluation of Design and Fabrication Information," (Revision 6, dated January 10, 1995), which specified that experienced personnel, Eamiliar with the document contents, materials, and processes used during vessel manufacture, be selected to 
participate in this program. ABB CENO Specification MISC-MECHSP-020, "Specification for Phase I of the RVG Program," Revision 1, November 4, 1992, was prepared for Phase I of the RVG Program Plan and stated objectives and requirements for various subtasks of the program. ABB CENO Specification MISC-MECH-SP-021, "Specification for Phase II, Detailed Records Evaluation," Revision 0, November 4, 1992, was prepared for evaluation under Phase II of the project. As stated in section 3.8 of the IPQP, the provisions of 10 CFR Part 21 only apply to phase II of the project.

Other procedures prepared by $A B B$ CENO to accomplish various program tasks included RVG-PROC-92-001, "Records Rough sorting and Assembly," Revision 1, November 4, 1992, which was prepared to guide the rough sorting and inventorying effort of subtask 2, and RVG-PROC-92-002, "Abstracting of Data, Data Entry and Data Matrix Verification," Revision 0, November 5, 1992, which provided guidance for preparation and verification of data into the GDM to ensure it performed consistently. The procedure contained over 25 data forms intended to simplify the abstraction and data entry process for development of the GDM.

The procedure also included generic and plant-specific records inventory forms and document trees which show the interrelationship between the documents and assists in determining data traceability. Each form contained signature and date blocks for the abstractor and the data entry personnel along with the independent verifier for both activities.

\subsubsection{Verification and Validation of Paradox Computer Code}

Section 3.7, "QA'd Computer codes," of the IPQP requires certification of the Paradox computer code used to execute the RVG data base. Reference 2.6.1 of QAP 3.13, "Computer Software," Section 4.7 .2 (a) requires verification and validation of nonsafety-related, commercially procured software where the results are used for safety-related applications.

The inspection team reviewed the final report prepared by ABB CENO to verify and validate the latest version of the code. The report, ABB-CENO MISC-PENG-CALC-025, "Paradox and Paradox Runtime Version 4.5," February 8, 1995, contained documentation to support verification and validation of the code. Input/output functions for Versions 4.02 and 4.5 of the DOS version of Paradox were previously verified, validated and documented in ABB CENO MISC-MECH-CALC-157, Revision 0, January 27, 1994.

The methodology employed to accomplish the verification and validation of Runtime Version 4.5 was to print five existing records from the RVG data base and check that the information matched that on the input forms. This appeared adequate to the inspection team since the program's only function is to perform 
input/output related functions, not design calculations.

Additionally, the same input forms were used to generate new records in the database which were printed and compared to the output from the existing records. This verified that the paradox output matched that which was entered into the program. The file contained a completed copy of "Checklist \#3," February 7, 1995, which is required by the QAM.

\subsubsection{Indoctrination and Training of RVG Personnel}

Section 6.0, "Training and Qualification Requirements," of the IPQP references the requirement of QAP 2.1, "Indoctrination and Training," for training of personnel involved in the preparation or independent review of safety-related documentation. As stated previously, the abstraction, data entry preparation and independent verification phase of this program was performed at the SNSC facility.

The NRC inspection team reviewed the list of SNSC personnel, qualified as of August 1, 1994, which identified 12 persons and their level of qualification. The list is required to be maintained in Windsor pursuant to Paragraph 6.2.4, Revision 5, of the IPQP. Actual training records of the individuals on the list were not reviewed during the inspection.

\subsubsection{ABB CENO Performed Internal Audits}

The inspectors reviewed ABB CENO Audit Report No. ME-1093-02, November 12, 1993, which documented an internal audit performed of Mechanical Engineering, RVG Project. The purpose of the audit, conducted on october $4-6,1993$, at both the chattanooga and windsor facilities, was to verify compliance to the $A B B C E$ Nuclear QA Program, as implemented by QAM 100, Revision 1, QA Procedures Manual, QAM 101, Revision 9 and RVG IPQP NO. MISCMECH-IPQP-030, Revision 2 .

The audit identified several conditions which required corrective action. These included the lack of documentation with respect to the verification and validation of the computer program Paradox, Versions 4.0 and 4.02 , and definition of the training and experience requirements for personnel performing data extraction and independent verification activities. As a result, corrective Action Request (CAR) CAR No. AC-93-134, October 28, 1993, was generated to track closure of the items identified. ABB CENO Inter-Office Correspondence No. RVG-93-073, December 15, 1993, provided a response to the CAR and accepted its findings.

Corrective actions, which included revisions to the IPQP to address the training and experience issues (Revision 4), were completed on March 4, 1994. Verification and validation of Paradox for its initial use was documented in MISC-CALC-057, January 27, 1994, and independently verified on February 3, 1994. 
The NRC inspection team reviewed a second internal audit performed by ABB CENO on August 16-19, 1994. Audit Report No. OE/PENG(RVG)-0894-04 documented an audit of Engineering Operations, Performance Engineering and the RVG, and was performed at both the SNSC and windsor facility. The purpose of the audit was to verify compliance to the ABB CENO $Q A$ Program, as defined by the IPQP.

The audit reviewed the abstraction and transposition, including independent review, of archival reactor vessel records, data base entries including verification thereof and subsequent analysis and compilation of the data into various reports for submittal to the participants of the RVG. No findings were identified during the audit.

\subsubsection{External Audit of ABB CENO}

The inspectors reviewed a joint audit report of $A B B$ CENO which was performed by the Nuclear Procurement Issues Committee (NUPIC) on october 25-29, 1993. The audit, lead by Union Electric, and representatives from Virginia Power, Entergy, Yankee Atomic, Consolidated Edison, Consumers Power and Illinois Power, was documented in NUPIC audit report No. AG93-20, November 16, 1993.

The audit covered the supply scopes of ABB CENO's four major business units and included spare parts, commercial grade items, engineering services, design services and outage services. With respect to the activities associated with the RVG program, two observations were identified by the NUPIC inspection team which had been previously identified by $A B B$ CENO during its internal audit discussed in section 4.5 .4 .4 above.

The first observation identified that personnel performing the review of RVG data collection were not qualified as independent reviewers, as required by the IPQP. Since this requirement was viewed by $A B B$ CENO as overly restrictive, corrective actions included revising the IPQP to delete this requirement.

The second observation identified that the input/output capabilities of Paradox, the commercial software program used by Performance Engineering to access the RVG data base program, had not been validated under the requirements of the IPQP.

Performance Engineering committed to track the item under CAR No. AC-93-134, October 28, 1993, which was acceptable to the audit team. As stated previously in section 4.5.4.2 above, Paradox was verified and validated in January 1994.

\subsubsection{Current Status of the RVG Data Base}

The RVG computer files are currently in draft status and currently under review to assure that they contain all the information applicable to the member utilities. In addition to 
the electronic data base, $A B B$ CENO will be sending reports and data sheets, that contain all of the information applicable to its RPVs, to each of its member utilities.

\subsection{Plant Specific Summary Reports}

A report was prepared for each of the reactor units whose owners are participants of the RVG. The NRC inspection team requested ABB CENO to provide copies of the Maine Yankee, Fort Calhoun and Kewaunee RVG reports. Since Kewaunee was not a participant of the RVG, only the Maine Yankee and Ft. Calhoun reports were available for review. Each RVG report summarized material data for plates, forgings, welds and claddings and contained an Introduction, Vessel overview, Vessel Materials and Sister Vessel Analysis section.

The Introduction section provided a general background on fabrication methods and specifications of plates, forgings, welds, and cladding. The Vessel Overview section described the RPV materials and assembly procedures used during manufacture and included RPV diagrams. The Vessel Materials section discussed in detail the fabrication of the plates, forgings, welds and claddings and included the properties and chemical compositions of RPV materials. The Sister Vessel Analysis section provided material data from fabricated RPVs, steam generators and pressurizers that have the same heat number as the RPV materials listed in the RVG report. This section also identified selfsister materials (materials from the same heat number used at two or more locations in the same reactor vessel) and the availability of archived materials in sister plants.

The NRC inspection team identified some discrepancies in the data base. For example, there was no chemistry data for certain weld heats $(e . g ., w-5214)$ that the inspectors knew was available.

\subsection{Combustion Engineering Owners Group (CEOG) Reports}

The NRC inspection team reviewed a topical report prepared by $A B B$ CENO and the CEOG on reactor vessel integrity. The report, "Quantitative of Evaluation of Chemical Composition Variability in Reactor Pressure Vessel Welds," CE NPSD-944-P, presented test results and statistical analysis of the results of several archived surveillance specimens. The purpose of the report was to determine the range of chemical composition variability that could typically be expected for ABB CENO fabricated RPV beltline welds. Twelve archived weld seams were tested for chemical composition.

The review identified that chemistry results of the test specimens were within the expected values except for weld heat number 1P3571, flux 1092. The weld, heat number 1P3571, showed an average value of copper content of 0.363 percent with a 
standard deviation of 0.075 percent. This chemical composition showed a higher mean copper content and variability for the 1P3571 weld than had been previously reported to the NRC.

However, the data were relatively new having been generated in 1994. The chemistry data in CE NPSD-944-P had been provided to the licensees that contributed to developing the data. The report had not been provided to licensees that had not participated in the project.

\subsection{Vendor/Licensee correspondence}

The inspectors reviewed correspondence between $A B B$ CENO and the Kewaunee and Ft. Calhoun plants to verify that the data in the RVG data base was consistent with the data transmitted by $A B B$ CENO and whether relevant sister plant data existed but was not shown in the data base or the RVG report. A review of $A B B$ CENO correspondence to Kewaunee on December 4, 1985 and April 15, 1988, noted that Kewaunee was informed that the chemistry in weld heat number 1P3571, for the Kewaunee RPV, may have a higher copper content than that previously reported by Kewaunee to the NRC. ABB CENO stated in the correspondence that the copper content could be as high as 0.31 percent and the nickel content as high as 0.78 percent.

As a result of the recent CEOG study reported in $A B B$ CENO report CE NPSD-944-P, ABB CENO informed Kewaunee, on April 6, 1995, that a weld, fabricated using weld wire heat 1P3571, had an average copper content of 0.363 percent with a standard deviation of 0.075 percent. The inspectors also confirmed that the copper data that led to an average copper value of 0.363 percent was included in the RVG data base.

After reviewing the Ft. Calhoun correspondence file, the inspectors determined that $\mathrm{ABB} C \mathrm{CENO}$ informed $\mathrm{Ft}$. Calhoun that a weld, fabricated using tandem electrodes with heat numbers of 12008 and 27204, had a copper content of 0.27 percent. In response to NRC GL 92-01, Ft. Calhoun reported a copper content of 0.19 percent for the same weld heats. The inspectors were not able to confirm if the higher copper content was included in the data base the licensee used to determine the reported 0.19 percent value.

\subsection{NRC Information Obtained}

The NRC inspection team requested copies of certain information considered to have potential safety significance relative to RVG integrity assessments. This information, considered proprietary by $A B B$ CENO, included material which will be used by the NRC staff to evaluate plant-specific information requested by the staff pursuant to GL 92-01, "Reactor Vessel structural Integrity, 10 CFR 50.54(f)," Revision 1, March 6, 1992. 
With the exception of a copy of the proprietary RVG data base, which was provided to the inspection team at the exit meeting on April 10, 1995, the information requested during the inspection was provided to the NRC under separate cover on April 13, 1995. It included an affidavit which stated that the material contained in certain documents is considered proprietary and requested that it be withheld from public disclosure in accordance with the provisions of 10 CFR 2.790 .

\subsection{Summary}

An important observation of the inspection is that although $A B B$ CENO has data that some licensees have not acquired for use in their RPV assessments, ABB CENO does not possess all the information that licensees should have to perform a thorough RPV evaluation. Original fabrication records, surveillance information and research results are in the possession of various vendors, utilities, institutes and laboratories. In summary, for some RPVs, particularly older vintage, it appears that no single vendor possesses all the information relevant to performing an assessment of RPV integrity. 
PERSONS CONTACTED

ABB Combustion Engineering, Inc.

- Curtis, P.

-* Leombruni, P.

-* Ghergurovich, J.

-* Fitzgerald, R.

- Lizotte, C.

-* Toelle, S.

- * Byrne, $S$.

-* Probst, V. Bischoff, G. Gimbrone, $C$.

* Brinkman, C.
Vice President, Engineering operations Manager, Plant Components, Mechanical Project Engineer Director, CENO Quality Assurance Sr. Quality Assurance Engineer Manager, Nuclear Licensing Consultant, Primary systems Attorney ABB CEOG Representative Supervisor Manager, Washington Nuclear Operations

\section{U.S. Nuclear Regulatory Commission}

- Pettis, R.

-* Strosnider, J.

-* Elliot, B.

- Tsao, J.

-* Wilson, E.
Sr. Reactor Engineer, Team Leader, NRR Branch Chief, EMCB, NRR EMCB

EMCB

Investigator, Region I, OI

- Attended entrance meeting

* Attended exit meeting 
APPENDIX B

INFORMATION PROVIDED TO ABB COMBUSTION ENGINEERING, INC. PRIOR TO THE ONSITE INSPECTION

Prior to the start of the NRC inspection on April 7, 1995, the staff electronically forwarded the following information to $A B B$ Combustion Engineering, Inc., on April 6, 1995. The purpose was to allow ABB CENO management and staff additional time to provide responses to the information requested.

\section{INSPECTION SCOPE}

\section{General Questions}

During the entrance meeting have personnel available to address the following questions:

- Is all the data from the boxes represented in the computerized data base?

- What data in the boxes is in the data base and what data in the boxes is not in the data base?

- What is the schedule for completing the review of the boxes and placing the data in the data base?

- Describe the process of how the hard copy information and documentation in the boxes was assimilated into the computerized data base and how the information in the boxes is referenced.

- Which licensees are aware of the data and which licensee's have completed a review of the data?

- Do non-member plants know that this type of information available for their plants?

\section{General Data Request}

Provide the entire computerized RVG data base to the NRC with a users manual. Make the data base available during the inspection for review by NRC. Identify all plants for which the following information is available (including foreign plants) and provide the following data:

(a) Provide to the NRC a list of weld wire heat numbers used to fabricate the beltine welds for each commercial nuclear reactor vessel fabricated by $A B B$ CENO, 
(b) For each heat of weld wire identified in item (a), provide to the NRC all copper and nickel chemistry data and the sources of those data (including foreign reactor data),

(c) For each heat of weld wire identified in item (a), identify archival material available at $A B B$ CENO and indicate its relationship to either surveillance material or ABB CENO fabricated beltline welds,

(d) Provide to the NRC any data that demonstrates the variability of copper within welds fabricated using a single heat of weld wire or within a weld, in which the welds were fabricated by $A B B$ CENO using a submerged arc process and copper coated primary electrodes,

(e) Provide to the NRC any data that demonstrates the variability of nickel within welds fabricated using a single heat of weld wire or within a weld, in which the welds were fabricated by ABB CENO using a submerged arc process and the primary source of nickel from the primary electrodes,

(f) Provide to the NRC any data that demonstrates the variability of nickel within welds fabricated by $A B B$ CENO using a submerged arc process and the primary source of nickel from a cold nickel wire.

Describe the traceability of the data in (a) and (b) above to the boxes of stored information/data.

\section{Specific Data Review}

Have available for review the boxes of information/data and computerized database for the following sample of plants/reactor vessels.

- Kewaunee and its sister plants

- Fort Calhoun and its sister plants

Provide the number of coils of weld wire represented by the copper and nickel measurements for the weld data for Kewaunee, Fort Calhoun and their sister plants. (Note: sister plants are those plants with reactor vessels fabricated by $A B B$ CENO with the same heats of weld wire as Kewaunee and Fort Calhoun). Be prepared to provide to the NRC selected information from the boxes of information/data as identified by the NRC inspectors during the inspection.

Note: Where information/data is requested to be provided to the NRC, these data and information should be made available in a form such that NRC can arrange to take possession of the subject information and transport it to NRC headquarters in Rockville, Maryland. 


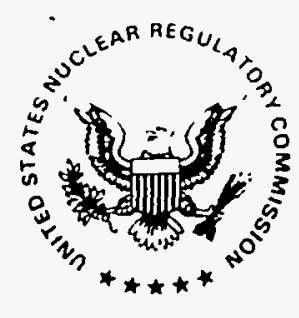

UNITED STATES

\section{NUCLEAR REGULATORY COMMISSION}

WASHINGTON. D.C. 20555-0001

May 31, 1995

Mr. Ronald J. Woodward

Director Total Quality \& Supply

Dow Corning U.S.A.

Dow Corning Corporation

Midland, MI 48686-0994

SUBJECT: $\quad$ NRC Inspection No. 99901284/95-01

Dear Mr. Woodward:

This letter transmits the report of the U.S. Nuclear Regulatory Commission (NRC) inspection of Dow Corning Corporation (Dow Corning) facilities in Midland, Michigan, and Elizabethtown, Kentucky, conducted by Messrs. P. Koltay and J. Petrosino of this office on March 23-24, 1995, and Apri1 3-5, 1995. The report also addresses the NRC staff observations on March 21-23, and April 18-21, 1995, of activities that Dow Corning performed to investigate its concern regarding cure time and flame self-extinguishing time parameters of its silicone products that are used in nuclear power plant fire barrier applications.

The inspection was conducted to evaluate Dow Corning's quality assurance program and its implementation in selected areas such as (1) manufacturing process control, (2) product design control, (3) procurement document control, and (4) a review of its program for implementing Part 21, "Reporting Defects and Noncompliance," of Title 10 of the Code of Federal Requlations (10 CFR Part 21).

As part of the inspection the inspectors examined procedures and representative records, conducted discussions and interviews with personnel, and observed several of Dow Corning silicone product manufacturing and testing processes. The inspectors observations were discussed with the Dow Corning staff at the conclusion of the inspection activities, on April 5, 1995.

Based upon the NRC staff observations and discussions during this review, it was concluded that the Dow Corning silicone products used in nuclear power plant fire barrier applications and which Dow Corning manufactures at its El izabethtown, Kentucky facility are conmercial grade items, as defined in 10 CFR $\S 21.3$. The team also concluded that al though Dow Corning's silicone products supplied for nuclear plant fire barrier applications are not subject to the NRC's Part 21 regulation, it appears to have adequately established and implemented a system which meets the intent of certain 10 CFR Part 21 requirements, such as 10 CFR $\S 21.21(\mathrm{~b})$. Areas examined during the NRC activities and our conclusions are discussed in the enclosed inspection report. 
In accordance with 10 CFR 2.790 of the NRC's "Rules of Practice," a copy of this letter and the enclosed inspection report will be placed in the NRC Public Document Room. If there are any questions concerning this inspection we will be pleased to discuss them with you. No response to this letter is required.

Sincerely,

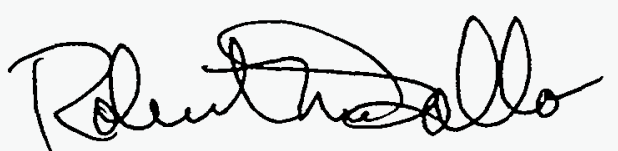

Robert M. Gallo, Chief

Special Inspection Branch

Division of Technical Support

Office of Nuclear Reactor Regulation

Docket No. 99901284

Enclosure: Inspection Report 99901284/95-01

cc: Mr. James G. Sharpe

Elizabethtown Site Manager

Dow Corning Corporation

760 Hodgenville Road

Elizabethtown, KY 42701

Mr. Robert M. Schroeder

Fire Protection Engineer

Dow Corning Corporation

2200 West Salzburg Road

Mail C043Al

Auburn, MI 48611

Mr. Christopher J. Johnson

Engineering Services

Underwriters Laboratories Incorporated

333 Pfingsten Road

Northbrook, Illinois 60062-2096 


\section{U.S. NUCLEAR REGULATORY COMMISSION \\ OFFICE OF NUCLEAR REACTOR REGULATION \\ DIVISION OF TECHNICAL SUPPORT}

ORGANIZATION:

REPORT NO.:

ORGANIZATIONAL

CONTACT:

NUCLEAR INDUSTRY ACTIVITY:

INSPECTION CONDUCTED: March 23-24; Apri1 3-5, 1995, and Apri1 18-21, 1995

Dow Corning U.S.A.

Dow Corning Corporation

99901284/95-01

Mr. Robert M. Schroeder, Fire Protection Engineer in fire barrier penetration seal assemblies for the nuclear industry. The products are sold to six tho either supply and/or develop and test the fire barrier penetration configurations before installation at nuclear power plants.
LEAD INSPECTOR:

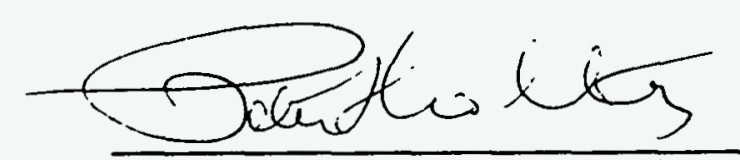

Peter S. Koltay, Team Leader

Special Inspection Section

Special Inspection Branch (TSIB)

OTHER INSPECTORS:

J. J. Petrosino

Vendor Inspection Section, TSIB

E. Conne11, PIant Systems Branch

Division of Systems Safety and Analysis

T.L. Tinkel, Brookhaven National Laboratory

REVIEWED:

APPROVED:
Manufactures commercial grade silicone products used
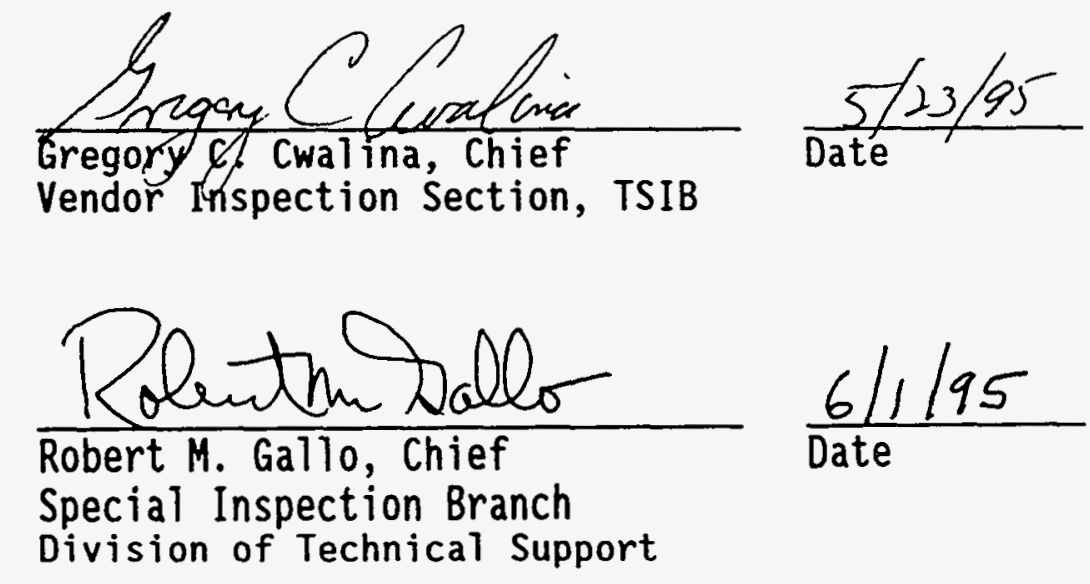
Based on the scope of this inspection, the team determined that the Dow Corning Corporation (Dow Corning) does not manufacture and supply any "basic components" as defined in Part 21, "Reporting Defects and Noncompliance," of Title 10 of the Code of Federal Regulations (10 CFR Part 21). While some customers contractually imposed the requirements of 10 CFR Part 21 on Dow Corning for silicone products supplied for use in nuclear power plant fire barrier penetration seal applications, the inspectors verified that the products met the definition of commercial grade items, as defined in 10 CFR $\$ 21.3$. Therefore, the team concluded that Dow Corning is not subject to the requirements of 10 CFR Part 21. However, the inspectors found that Dow Corning has established and implemented a program which meets the intent of certain sections of 10 CFR Part 21 , such as 10 CFR $\S 21.21$ (b). Dow Corning personnel stated to the team that although the inspectors determined that Dow Corning is not subject to the requirements of Part 21 , it will continue its existing program for meeting the intent of 10 CFR Part 21, but will discontinue issuing certifications to its customers indicating that Dow Corning products were manufactured in compliance to 10 CFR Part 21.

\section{STATUS OF PREVIOUS INSPECTION FINDINGS}

This was the first NRC staff inspection which was conducted at either of the two Dow Corning facilities discussed in this report; thus, there were no previous findings.

\section{INSPECTION FINDINGS AND OBSERVATIONS}

\subsection{Entrance and Exit Meetings}

The entrance meeting on March 23, 1995, was held at the Dow Corning Corporate headquarters in Midland, Michigan. The meeting was attended by corporate personnel responsible for the product line. The exit meeting on April 5, 1995, was held at the Elizabethtown, Kentucky manufacturing facility with the plant manager and the manufacturing team responsible for the product line in attendance. A staff attorney and the fire protection engineer responsible for product applications participated in both meetings.

\subsection{Background and Description of Facilities}

Dow Corning manufactures four products that have commercial applications and are typically used in fire barrier penetration seals at nuclear power plants, (1) Sylgard 170 Silicone Elastomer, (2) 3-6559 Cure Accelerator (typically used in conjunction with Sylgard 170), (3) 3-6548 Silicone RTV Foam, and (4) 96-081 RTV Adhesive/Sealant (typically used in conjunction with 3-6548 RTV foam). These products, available through published product description, are sold by Dow Corning to commercial customers including six customers who either supply or facilitate the installation of the materials at NRC licensees as part of fire barrier penetration seal assemblies associated with 10 CFR § 50.48, "Fire Protection." The six customers who procure the silicone products from Dow Corning are (1) Brand Fire Protection, (2) North Brothers Company, (3) Promatec, (4) PCI-ICMS, (5) Radian Corporation, and (6) Transco Products, Incorporated. 
By letter dated November 17, 1994, Dow Corning informed the NRC and their customers of a deviation which it had identified regarding sales

specifications for flame self-extinguishing time of certain lots of RTV Adhesive Sealant 96-081. The letter to the NRC stated that certain customers were being advised of a sales specification deviation on flame selfextinguishing time for 96-081 RTV Adhesive/Sealant. Dow Corning further stated that this product was supplied to certain customers under 10 CFR Part 21. In the letter sent to the customers, Dow Corning advised that tests on retained samples from three lots of the product showed a flame selfextinguishing time ranging from 35 to 130 seconds. According to Dow Corning, tests on these lots at the time they were originally produced showed a flame self-extinguishing time that met the sales specification of 10 seconds or less.

By letter dated November 28, 1994, Dow Corning informed the NRC and their customers of another deviation that it had identified regarding sales specifications for cure time of Sylgard 170 silicone elastomer. The letter to the NRC stated that certain customers of Sylgard 170 Elastomer and Sylgard 170 Fast Cure Elastomer were being advised that the cure rate for certain lots which they had received from Dow Corning was slower than the sales specification. Dow Corning further stated that these products were supplied to certain customers under 10 CFR Part 21. In the letter sent to the customers, Dow Corning advised that tests on retained samples of certain lots of material manufactured between May 1994 and November 23, 1994, indicated that the silicone products did not meet the sales specification for cure rate. According to Dow Corning, tests on these lots at the time the product was manufactured indicated the lots did meet the sales specification for cure rate. Dow Corning stated their belief that the slow cure rate was traceable to an ingredient used in Part $A$ of these materials. Dow Corning further stated that tests on retained samples of Dow Corning 3-6548 RTV Silicone Foam manufactured within the last year showed that this material met specifications and was satisfactory. Dow Corning offered to provide replacement silicone products to their customers.

\subsection{Identification of Deviations to Sales Specification}

\subsubsection{Initial Product Performance Indicators and Investigation}

In June-July 1994, Dow Corning received reports from a commercial electronics customer indicating that it had observed slower cure times of the silicone products in its electronic component applications. As a result of the customer notification, Dow Corning started an investigation to resolve the customer report. Dow Corning started its investigation by testing retained samples and determined cure times were slower than normal, but the cure times

\footnotetext{
${ }^{1}$ At the Dow Coming Elizabethtow, Kentucky silicone product manufacturing facility, it was observed by the MRC inspectors that Dow Corning typically tests each silicone product lot for its speclfication charactoristics for baseline data, and also obtains and stores samples of each silicone product lot for future analysis as required.
} 
were still within specifications. In early August 1994, Dow Corning received reports from another electronics customer regarding slow snap time on sylgard 170 fast cure. Consequently, Dow Corning performed tests on the applicable retained lot specimens and confirmed that the snap time was slower than as stated in the specification.

In mid-August 1994, additional testing by Dow Corning identified that the cure rate of Sylgard 170A was changing as the product aged, but the cure rate was still within specifications. In late August-September 1994, Dow Corning identified that a certain ingredient used in the Sylgard 170 Part A component appeared to be related to the slower cure time observed in the Sylgard 170 and the slow snap time observed in the Sylgard 170 Fast Cure. Significant variability in cure time from lot to lot was observed. In September 1994, Dow Corning observed that cure rate increased if the mixing time for the ingredient was increased. Dow Corning also determined that a certain vacuum process during the mixing of the ingredient into the Part $A$ compound also improved the cure rate. This latter observation indicated to Dow Corning that possible contaminants were affecting the cure rate. In October 1994, Dow Corning received additional reports from customers about the slow cure time of Sylgard 170, and subsequent testing on retained samples for six lots of the Sylgard 170 now showed that the cure time on two lots were out of specification.

\subsubsection{Dow Corning Investigation Findings and Corrective Actions}

As a result of inquiry letters that Dow Corning had sent out earlier to its suppliers, Dow Corning received a November 1994 letter from the supplier of the suspect ingredient stating that certain lots of the ingredient contained higher than typical levels of sulphur. Sulphur is a known contaminant that can affect the cure rate and flame self-extinguishing time of the products. Dow Corning also noted that it had not specifically required the supplier to monitor or control sulphur content in that ingredient. In November 1994, Dow Corning concluded that the slower cure rate of Sylgard 170 was related to the sulfur content of the ingredient used in the mixture and advised their customers and the NRC of the problem. Additionally, Dow Corning confirmed that varying leveis of sulphur in that ingredient appeared to correlate with the variations in Sylgard 170 cure rate. As a result, Dow Corning switched to a new manufacturer that was capable of supplying the ingredient with higher purity and less potential for sulphur contamination.

As part of its corrective action plan Dow Corning, in conjunction with Underwriters Laboratory, Incorporated (UL), engineering services staff from UL's Northbrook, Illinois facility developed a fire endurance test program of its silicone products used at nuclear power plants. Dow.Corning contracted UL to perform and monitor the fire endurance test program to determine if the manufacturing changes, that resulted in the deviations reported to the NRC and

\footnotetext{
2 Snap time is a certain point in the curing process of Sylgard 170 elastomer and 3-6548 Foam just prior to the solldification of the silicone product.
} 
licensees (self-extinguishing time and cure rate), had any significant affect upon the material's performance as a fire barrier penetration seal. The test program was developed to encompass the product sales specification parameters for each product. Dow Corning obtained sample lots from the suspect time period as well as post and pre-suspect time periods for testing. The UL testing was set up to test multiple configurations of each lot. For example, the tests at UL included four different lots of Sylgard 170 Elastomer that met Dow Corning's sales specification and three different lots of the material that deviated from it's sales specifications. The UL staff also tested one lot of 96-081 RTV Adhesive Sealant that met Dow Corning's sales specification and one lot of the material that deviated from it's sales specifications. The test program was established to ensure that it encompassed the following aspects.

- Non-suspect lots of Sylgard 170 and RTV Adhesive/Sealant 96-081 \& 3-6548 Foam 96-081 produced with the old source of the suspect ingredient

- Suspect lots of Sylgard 170 RTV Adhesive/Sealant 96-081 \& 3-6548 Foam and 96-081 which were produced with the old source of the suspect ingredient

- Lots of Sylgard 170 and RTV Adhesive/Seal in: 96-081 \& 3-6548 Foam produced with the new source of suspect the ingredient

\subsubsection{Fire Endurance Test at the UL facility in Northbrook. Ill inois}

During the week of March 20, 1995, the team observed the fabrication of the Dow Corning fire endurance test specimens, and during the week of Apri1 17, 1995, the inspector witnessed the performance of fire endurance tests for Dow Corning's 3-6548 Silicone RTV Foam, 96-081 RTV Adhesive and Sylgard 170 Elastomer. The inspector noted that the fire endurance test program was established and conducted in accordance with the requirements of ASTM E-119, "Standard Test Methods for Fire Tests of Building Construction and Materials." A total of five tests were witnessed by the inspector which encompassed all three types of materials from both the suspect group, manufactured between May 1994 and November 1994, and newly manufactured materials. Dow Corning conducted a total of approximately 25 fire tests under this effort. No variations or anomalies of significance were observed in the fire barrier performance of penetration seals constructed with materials from the suspect lots and the newly manufactured materials. Dow Corning completed its test program on Apri1 29, 1995.

\subsection{Procurement Document Control and Product Data Sheets}

\subsubsection{Procurement Document Control}

On March 23-24, 1995, the team reviewed a sample of Dow Corning customer procurement records associated with the six suppliers identified in

Section 3.2. The team reviewed some recent customer purchase orders (POS) and discussed the process with the Dow Corning personnel who are actually 
responsible for receiving and processing the nuclear customer orders. The inspectors observed that none of the customer's POs imposed any nuclear power plant safety-related design, qualification, manufacturing, test or other unique nuclear requirements upon Dow Corning. The team found that two of the six customers contractually imposed the provisions of 10 CFR Part 21 on Dow Corning, while the other four customers did not impose 10 CFR Part 21 requirements on Dow Corning. All of the customer POs which were reviewed by the inspectors ordered Dow Corning products by silicone product name and formulation number, such as "Sylgard 170 (fast Cure Silicone Elastomer), Part B," and did not specify any nuclear design or specification requirements. Some POs required Dow Corning to have an "approved quality assurance [QA] program" for the manufacture of its silicone products.

The typical Dow Corning nuclear customer PO package also contained a Dow Corning "certificate of analysis." A review of several certificates of analysis by the inspectors, for both commercial customers and nuclear customers noted only one difference between the nuclear and commercial certificates for like-products. The certificates that were in the PO package for the customers who imposed 10 CFR Part 21 contained a note which stated, "Complies With 10 CFR 21;" the others did not. The inspectors informed Dow Corning staff that its note certifications that stated compliance with Part 21 were not applicable, since Dow Corning manufactured and supplied commercial grade items for nuclear power plant use. The Dow Corning staff stated that they would discontinue issuing the certificates of analysis stating compliance with 10 CFR Part 21.

\subsubsection{Product Data Sheets}

The NRC inspectors reviewed several Dow Corning product data sheets, application guide specifications, and silicone foam cell structure and color comparison charts. The product data sheets reviewed were for, Sylgard 527 primerless silicone dielectric gel; 3-6548 silicone RTV foam; 96-081 RTV adhesive/sealant; and Sylgard 170 A \& B silicone elastomer. None of the Dow Corning specification sheets indicated any specific end-use applications or industry specific use, such as chemical or nuclear.

\subsection{CFR Part 21 \& Associated Programs}

The inspectors reviewed the program that Dow Corning had adopted to implement the provisions of 10 CFR Part 21, and evaluated the applicability of 10 CFR Part 21 to Dow Corning in regard to the silicone products used at nuclear power plants. The inspectors found that Dow Corning had developed procedures to address the provisions of 10 CFR Part 21, "Dow Corning Corporation Standard 071, "Reporting of Deviations and Noncompliance as Required by Federal Regulation 10 CFR Part 21," and had also established an associated quality system which ensured that the subject deviations were reported to its customers. Since Dow Corning was not subject to Part 21 , the inspectors did not verify compliance with the provisions of 10 CFR Part 21 . However, the inspectors did verify that the established Dow Corning program met the intent of certain elements of the Part 21 regulation, such as 10 CFR $\S 21.21$ (b), which requires that vendors inform its customers of deviations and failures to comply with regulations. 
The NRC inspectors also reviewed associated quality systems that typically would interface and provide input into a 10 CFR Part 21 program. The team concluded that Dow Corning's International Organization for Standardization (ISO) 9002 quality system controls regarding customer complaints appeared to ensure that the 10 CFR $\S 21.21$ (b) aspect of informing customers of deviations to procurement specifications was effectively executed. For example, the subject deviations initially were received from customers who used the silicone products in their commercial electronics applications, and the problems were documented and logged into the customer complaint system by the Dow Corning customer service personnel. Once the problems were documented and logged into the Dow Corning quality system, an investigation of the potential product problems were initiated. As a result, Dow Corning found that the problem was generic to certain lots, was caused by sulfur in a particular ingredient, and customers were informed.

Therefore, the team concluded that the quality system controls which Dow Corning had established would appear adequate to meet the intent of certain provisions of 10 CFR Part 21, such as 10 CFR § $21.21(\mathrm{~b})$.

\subsection{Manufacturing Process Control and Product Design Control}

The NRC inspectors conducted discussions, reviewed documents and observed manufacturing process controls related to the Dow Corning silicone products used at nuclear power plants. No difference was identified by the inspectors between the commercial and nuclear products or their associated design or manufacturing processes.

\subsection{Inspection Team Conclusions}

The team concluded that the silicone products which are procured from Dow Corning by its six nuclear customers identified in Section 3.2 are commercial grade items as defined in 10 CFR § 21.3. Further, the team noted to Dow Corning that a commercial grade item can not be transformed into a basic component, as defined in 10 CFR $\S 21.3$, merely by imposing the provisions of Part 21 in a PO without imposing other unique nuclear requirements for the design, manufacturing, testing and supply of that item.

Based upon the document reviews, observations by the team, and discussions with Dow Corning manufacturing and corporate personnel the inspectors also concluded that Dow Corning satisfactorily performed its investigative and corrective actions of its silicone product concerns regarding cure time parameters of its silicone products that are used in nuclear power $\mathrm{plant}$ fire barrier applications. Additionally, the portions of Dow Corning's quality system controls reviewed by the inspectors were found to be effectively executed. 


\subsection{PERSONNEL CONTACTED}

Dow Corning Corporation Corporate office

R. Woodward

J. Boone

R. Schroeder

R. Loveland

L. Krauss, Esq.

R. McKellar, Esq.

M. Gill

M. Heminger

L. Bergman

M. Ladenburger
Total Quality \& Supply

Total Quality \& Supply

Fire Protection

Building Materials

Legal

Legal

Customer Service

Customer Service

Product Steward

Product Line

Dow Corning Elizabethtown Manufacturing Facility

J. Sharpe

H. Chapman

P. Alexander

W. Clark

G. Dehli

F. Nass

J. Thomas

T. Vessels
P1 ant Manager

Technical Development Quality Engineer Technology/Quality Product Team Leader ISO-Audits

QA Data Center QA Laboratory

Underwriters Laboratory. Incorporated

C. Johnson

A. Hauser

S. St. Pierre
Engineering Services Engineering Services Laboratory Technician 


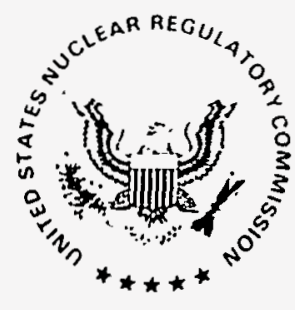

\section{UNITED STATES}

\section{NUCLEAR REGULATORY COMMISSION}

WASHINGTON, D.C. 20555-0001

May 16, 1995

Mr. John M. Cooper, Executive Vice President

Dresser Industries, Inc.

Industrial Valve Operation

Dresser Valve \& Controls Division

P.0. Box 1430

Alexandria, Louisiana 71309-1430

SUBJECT: $\quad$ NRC INSPECTION NO. 99900054/95-01

Dear Mr. Cooper:

This letter transmits the report of the U.S. Nuclear Regulatory Commission (NRC) inspection of Dresser Industries, Inc., Industrial Valve Operation (Dresser), Alexandria, Louisiana, conducted by Robert Pettis, Richard McIntyre and Billy Rogers, of this office, on March 13-16, 1995. The NRC inspection team conducted an evaluation of the Dresser quality program and the implementation of that program as it relates to the manufacture of safetyrelief valves and spare parts supplied to the nuclear industry.

The NRC inspection team reviewed documentation, procedures, and representative records, conducted interviews and held discussions with members of Dresser's staff. On the basis of this inspection, the inspection team determined that the implementation of the Dresser quality assurance program complies with the requirements of Appendix $B$ to Part 50 of Title 10 of the Code of Federal Regulations. The enclosed inspection report contains a detailed discussion of the areas examined. No response to this letter or its enclosure is required.

In accordance with 10 CFR 2.790 (a) of the NRC "Rules of Practice," a copy of this letter and its enclosure will be placed in the NRC Public Document Room.

Should you have any questions concerning this report, we will be pleased to discuss them with you. Thank you for your cooperation.

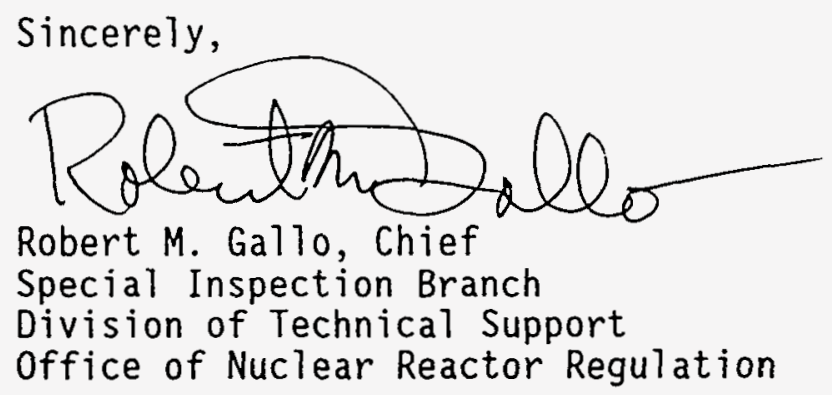

Docket No.: 99900054

Enclosure: Report No. 99900054/95-01 
U.S. NUCLEAR REGULATORY COMMISSION

OFFICE OF NUCLEAR REACTOR REGULATION

DIVISION OF TECHNICAL SUPPORT

REPORT NO.:

ORGANIZATION:

ORGANIZATIONAL

CONTACT:

NUCLEAR INDUSTRY

ACTIVITY:

INSPECTION DATES:

LEAD INSPECTOR:

REVIEWED BY:

APPROVED BY:
$99900054 / 95-01$

Dresser Industries, Inc.

Industrial Valve Operation

Dresser Valve and Controls Division

P.0. Box 1430

Alexandria, Louisiana 71309-1430

John W. Richardson

Manager, Quality Assurance

Manufacturer of various model safety and pressure relief valves supplied to the nuclear industry.

March 13-16, 1995

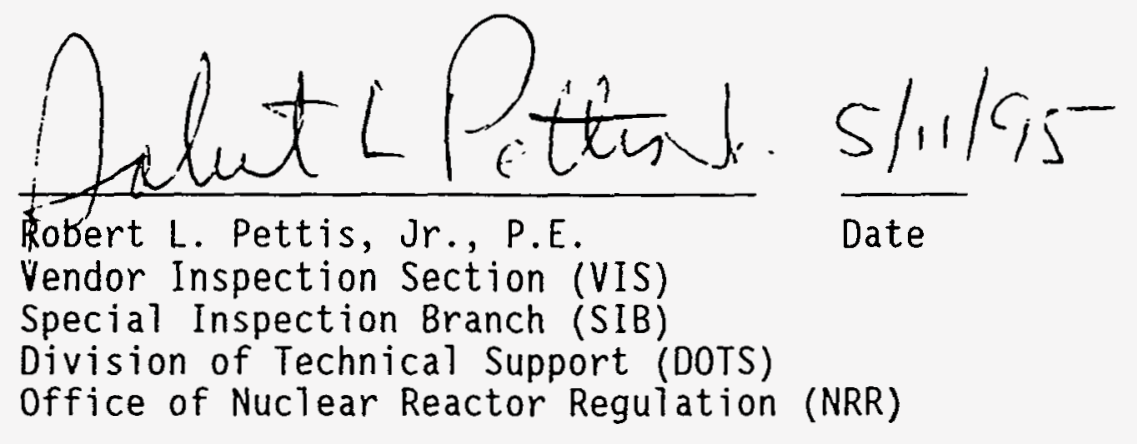

Richard P. McIntyre, VIS/SIB/DOTS/NRR

Billy H. Rogers, VIS/SIB/DOTS/NRR
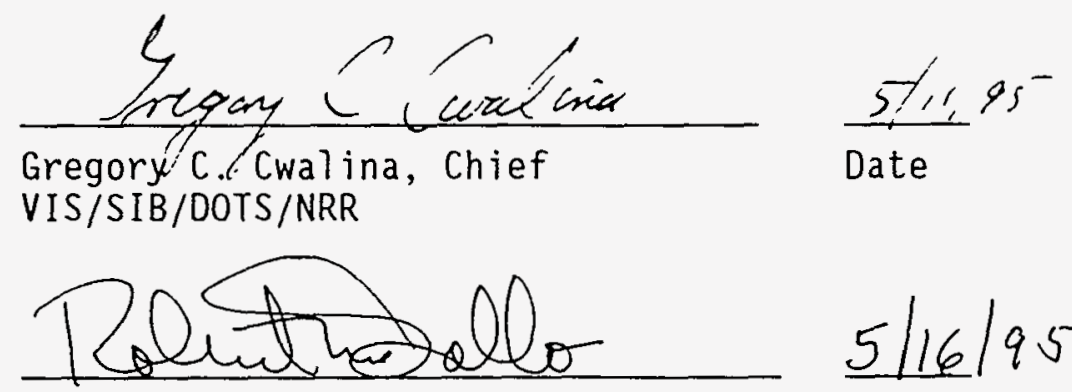

Robert M. Galio, Chief SIB/DOTS/NRR
$5 / 16 / 95$

Date 
During this inspection, the NRC inspection team evaluated the implementation of the Dresser Industries, Incorporated, Industrial Valve Operation, (Dresser) quality assurance program related to the manufacture of various model safetyrelief valves supplied to the nuclear industry. The inspection was conducted to determine Dresser's compliance with the requirements of Appendix B to Part 50 of Title 10 of the Code of Federal Regulations (Appendix $B$ ) and the provisions of 10 CFR part 21. The inspection team reviewed technical information, procedures and representative records, conducted interviews, held discussions and observed manufacturing activities. No violations or nonconformances were identified during this inspection.

\section{STATUS OF PREVIOUS INSPECTION FINDINGS}

None were reviewed during this inspection.

\section{INSPECTION FINDINGS AND OTHER COMMENTS}

\subsection{Background}

Dresser Industries, Inc., has served the power industry since 1880. Today, Dresser Industries has more than 100 manufacturing plants and sales, service and other facilities in some 50 countries around the world. The nuclear industry product line includes various safety and pressure relief valves manufactured to the overpressure protection requirements of Sections I and VIII of the American Society of Mechanical Engineers (ASME) Boiler and Pressure Vessel Code, and to an ASME Section III approved Quality Assurance Program which also meets the requirements of Appendix B. The power industry continues to rely on these types of valves to provide overpressure protection suitable for the high pressure and temperature applications required by modern power generation equipment. All valves are flow tested by Dresser in accordance with ASME Code rules to establish rated capacities and have been certified by the National Board of Boiler and Pressure Vessel Inspectors. Dresser Industries' world headquarters is located in Dallas, Texas.

\subsection{Entrance and Exit Meetings}

During the entrance meeting, held on March 13, 1995, the NRC inspection team met with members of Dresser management and staff, discussed the scope of the inspection, and established organizational contacts. During the exit meeting, held on March 16, 1995, the inspection team summarized its findings with Dresser management and staff. The Appendix of this report 1 ists the persons contacted during the inspection.

\subsection{Review of 10 CFR Part 21}

The inspection team reviewed Dresser Quality Assurance Procedure (QAOP) 1-9, "Evaluating and Reporting of Deviation and/or Noncompliance Affecting Safety Related to NRC Regulation 10 CFR Part 21, "Revision 2, March 1, 1995, which was well written and appeared to be properly implemented. In addition, the inspection team observed Dresser's 10 CFR Part 21 posting as required by 10 CFR 21.6. Dresser had posted Section 206 of the Energy Reorganization Act of 1974 (Section 206) and a notice which described 10 CFR Part 21 and QAOP 1-9 and to whom reports could be made. The inspection team noted a weakness in 
the posting regarding the location where QAOP $1-9$ and 10 CFR Part 21 could be examined and other minor discrepancies between the notice and QAOP 1-9.

Dresser indicated that the notice would be revised to be in agreement with the current revision of QAOP 1-9 and to indicate where 10 CFR Part 21 and QAOP 1-9 could be examined.

The inspection team reviewed Dresser's records associated with 10 CFR Part 21 evaluations performed from 1990 to 1995. During this period, Dresser had performed 13 evaluations and made one report to the NRC. The evaluations appeared to have been performed in a thorough and timely manner with one exception. The inspectors noted that 10 CFR Part 21 file 94-02 indicated an evaluation which lasted from May 19, 1994, until July 28, 1994, in excess of the 60 days allowed by Part 21 . Dresser indicated that the basis for the listed evaluation completion date was the issue date of Dresser Report SRV237A, "Review of Published Adjusting Ring Positions Given In Service Manuals for 1900 Safety Relief Valves Nuclear Plants," Revision 0, dated July 30, 1994, which discussed aspects of the 10 CFR Part 21 evaluation but also supported additional work. Based on review of SRV-237A and associated supporting documentation and discussions with Dresser, the inspection team concluded that the actual evaluation completion date (during which it was determined that a defect did not exist) was on or about May 19, 1994, and that no violation of Part 21 had occurred. Dresser also indicated that the file would be corrected to indicate the actual completion date. The inspection team discussed the importance of accurately documenting 10 CFR Part 21 evaluations and reporting activities and concluded that this was a weakness in the implementation of Dresser's 10 CFR Part 21 evaluation program.

\subsection{Dedication Activities}

The inspection team reviewed Dresser Procedure EG37, "Quality Classification of Nuclear Pressure Relief Valve Parts, "Revision 12, August 18, 1994. The procedure is used to establish the quality classification for valve parts supplied to licensees and provides instruction on the use of commercial grade items (CGIs) when installed in valves classified as safety-related.

Appendix A of the procedure, "Commercial Grade and Non-Safety-Related Items Quality Class C and D Parts," provides information for establishing the suitability of using CGIs in a safety-related valve. The procedure also establishes definitions for acceptance methods, basic component, CGI, critical characteristics, dedication, safety-related and safety function. It also provides specific examples of how the definitions are applied to Dresser valves and the dedication of CGIs used in a safety-related application. The dedication process includes performance of a technical evaluation and the determination of the appropriate acceptance method(s).

The technical evaluation assured that the specification requirement for the CGI were adequately translated into the procurement document. The acceptance methods were documented in the Nuclear Standard Master Control Document, assigned to the applicable utility, and the applicable assembly instruction. The acceptance methods included material verification, documentation of traceability and dimensional inspection. The inspection team concluded that the procedure effectively implemented the Dresser requirement of performing 100 percent inspection and testing of all parts used in safety-re]ated valves. 


\subsection{Internal Audits and Corrective Actions}

The inspection team reviewed Section 16, "Corrective Action," and Section 18, "Audits," of the Dresser "Quality Assurance Manual (QAM) For Section III Nuclear Valves," Revision 23, June 5, 1992; Quality Assurance Operating Procedures (QAOP) 1-6, "Internal Audits, " and QAOP 1-7, "Corrective Action," both Revision 17, March 1, 1995. The requirements stipulated that the quality assurance (QA) program would be audited at least annually by a panel of at least four representatives from various departments. Also, monthly audits were scheduled in one or more of the sections of the QA Program. These monthly audits were conducted using checklists for each section of the QA program and cover the following four product areas:

- ASME Section III Nuclear Valves

- NR - Nuclear Repair/ ASME Section XI

- ASME Section I, IV, VIII - Non Nuclear

- VR - Non Nuclear Repair

The inspection team reviewed the reports for the "Annual Review of the Quality System Status and Adequacy of QA Programs Valves and Parts" performed for 1990 through 1993 (the report for 1994 had not yet been completed). These reports included a list of closed and outstanding corrective actions for audit findings identified during the monthly audits. The inspection team noted that several audit findings had been open for several years. Dresser stated that some issues were being reviewed by special task groups and others were left open to reverify implementation of corrective actions over a period of time.

The inspectors selected a sample issue to review from the 1 ist of corrective actions. Corrective Action Request (CAR) QA-92-21, June 6, 1992, documented a finding concerning safety-relief valves being assembled without the use of torque wrenches for the bonnet bolting as required by Assembly Instruction AS132. The issue concerned the use of a new style bonnet, shaped differently than the original bonnet, which did not provide adequate clearance for a torque wrench without additional actions such as machining (the original bonnet had provided adequate clearance). Dresser stated that the new bonnet was used only on commercial valves and had not been used on any nuclear valves and AS-132 was not applicable to nuclear valves.

The valves, which were sold as nuclear safety-related, were manufactured and assembled separately from the commercial product line using different assembly and test instructions and procedures.

The inspection team reviewed EG-34, Revision 7, March 8, 1995, "Nuclear Installations Pressure Relief Valves, "which is the Engineering Instruction (EI) that 1 isted all of Dresser's nuclear customers and the valves sold to them by model number along with the accompanying Master Control Document (MCD). The inspection team reviewed a sample of 16 valves representing 11 different nuclear utilities. The review of the MCD verified that it properly identified the instructions and procedures to be used during manufacturing that were specific to the nuclear product line. 
The inspection team also reviewed EG-2, Revision 8, March 6, 1995, "Nuclear Application Manual," which lists all the instructions and procedures that are applicable for the nuclear product line. These included, but were not limited to:

- Assembly Instructions

- Cleaning Instructions

- Functional Testing Instructions

- Hardsurfacing instructions

- Heat Treatment Instructions

- Hydrostatic Testing Instructions

- Mechanical Testing Procedure

- Nondestructive Testing Procedure

- Purchasing Specification

- Repair Instructions

- Welding Instructions

- Master Control Documents (Nuclear Standard)

The inspection team did not identify any instances where nuclear valves were assembled or tested using a commercial product line instruction such as AS-132. A11 MCDs reviewed by the inspection team contained the appropriate reference to an EI or procedure contained in EG-2. The inspectors verified that valves manufactured on the nuclear product line were manufactured using nuclear specific instructions and procedures, that the applicable instructions and procedures required bonnet bolting, and that adequate documentation existed to support the required torque.

\subsection{Analysis of Gasketed Joints}

The inspection team reviewed the engineering basis which supports gasket integrity and bolt stress calculations for the joint between the valve body and the bonnet. To accomplish this, Dresser developed a computer program called GENFLG which analyzes the joint in accordance with the requirements of ASME Section III and customer specifications. The program calculates the resulting bolt stress from input loadings obtained from each customer's piping stress analysis which is supplied to Dresser.

The program has been used at Dresser since 1972 and uses valve input data from various tables in the American National Standards Institute (ANSI) ANSI B16.5, "Pipe Flanges and Flanged Fittings," ANSI B16.34, "Valves-Flanged, Threaded, and Welded End," and ASME Section III. For example, values for various gaskets, identified as $M$ and $Y$ values in ANSI B16.5, are used to approximate the compressive strength of the gasket based on its material.

The program performs a structural analysis of the joint in accordance with Appendix II of Section VIII of the ASME Code. External loading in the form of forces and moments are input into the program which results in the calculation of bolt forces and stresses. Natural frequency calculations are performed 
using the Dresser computer program VIB, which calculates the first mode natural frequency of the SRV.

The inspection team reviewed joint calculations for customer purchase order (P0) No. 18-62951-0, Arizona Public Service Company (APSC), Palo Verde Nuclear Plant, Units 1,2 and 3 , August 30,1991 . The order was for eight, ASME Section III, Class 2, 6-inch, 150-pound ANSI rated SRVs. The PO invoked the provisions of 10 CFR Part 21 and APSC Design Specification No. 13-JN-6918, Revision 1. The general design features of the SRV, its component identification, materials and valve application data were provided in Dresser Contract Document $3 \mathrm{NC}-3112$. The file and its supporting documentation appeared complete and in accordance with Dresser QA procedures. Dresser issued APSC a Certificate of Compliance on November 22, 1991.

\subsection{Quality Improvement Team Activities}

Dresser established a Quality Improvement Team (QIT) to review processes or situations where improvements could be made and to make recommendations on methods of achieving those improvements. The inspection team reviewed the conclusions of one such QIT, the Safety Relief Valve (SRV) team, and discussed with its members the origin of the SRV team, its composition, the methods used, the conclusions drawn, and implementation of improvements based on the conclusions. The SRV team had been assembled by Dresser management in 1991 to review the circumstances of a high rejection rate of commercial SRVs during final production testing. The rejection rate applied to commercial SRVs being tested as a part of confirmation of the production process prior to shipment of the SRVs to customers. If the commercial SRV did not pass the production test it was reworked on the production line and retested as required prior to shipment.

The SRV team's conclusions and recommendations, documented in a February 1993 report, were accepted by management and incorporated into the commercial SRV production activities. Dresser indicated that the rejection rate of commercial SRVs had been significantly reduced and that a constant review of commercial SRV production resulted in the low failure rate.

The inspection team verified that the activities of the SRV review team only applied to the commercial valve product $l$ ine and that a separate set of production methods and procedures are used for nuclear SRVs. Commercial SRVs are typicaliy manufactured one hundred at a time and inspected on a sample basis, while nuclear SRVs are manufactured one or two at a time and individually inspected. The primary distinction between the nuclear and the commercial manufacturing operations is that additional time is allotted for performing the same operation for the nuclear line.

For example, the machining of an interior angle in the valve body would typically take 15 minutes for a commercial SRV using numerical control machining, contrasted with 60 minutes for a nuclear SRV using manual machining. The inspection team reviewed the results of the SRV team, discussed the issue with SRV team members and Dresser management, reviewed the applicable commercial and nuclear procedures, and concluded that the earlier SRV rejection rate did not apply to nuclear SRVS and that there were no concerns identified with nuclear SRVs. 


\section{APPENDIX}

\section{PERSONS CONTACTEO}

The following persons were contacted during the inspection and except as noted, attended both the entrance and exit meetings.

Dresser:

$\begin{array}{ll}* & \text { J. Cooper } \\ * \quad & \text { R. Danzy } \\ * \quad \text { T. Bordelon } \\ \text { J. Richardson } \\ \text { A. Casler } \\ \text { J. Hatz } \\ \text { R. Huffman } \\ \text { D. Sharma } \\ +\quad \text { R. Warrington } \\ \text { R. Thomas } \\ +\quad \text { R. Maxey }\end{array}$

Executive Vice President and General Manager

Vice President, Engineering

Vice President, Sales and Marketing

Manager, Quality Assurance

Manager, Quality Processes

Principal Quality Assurance Engineer

Senior Product Engineer

Supervisor, Application Engineering

Industria] Engineer

Quality Assurance Engineer

U.S. Nuclear Regulatory Commission:

R. Pettis

G. Cwal ina

R. McIntyre

B. Rogers

Team Leader

Chief, Vendor Inspection Section

Senior Reactor Engineer

Reactor Engineer

* Attended exit meeting only 


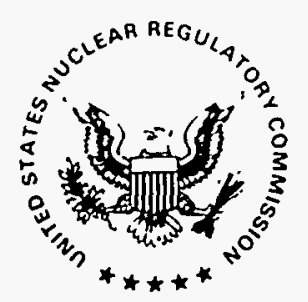

\author{
UNITED STATES \\ NUCLEAR REGULATORY COMMISSION \\ WASHINGTON, D.C. 20555-0001 \\ June 14, 1995
}

Mr. Mark T. Capallo, President

Energy \& Process Corporation

2146-B Flintstone Drive

Tucker, GA 30084-5000

SUBJECT: NRC INSPECTION NO. 99900866/95-01

Dear Mr. Capallo:

This letter addresses the U.S. Nuclear Regulatory Commission (NRC) inspection of your facility at Tucker, Georgia, conducted by Messrs. U. Potapovs and L.L. Campbell of this office on May 8 through 11, 1995, and the discussions of their findings with you and members of your staff at the conclusion of the inspection. The inspection was conducted to evaluate your quality assurance program and its implementation in selected areas such as (1) control of purchased material and services, (2) material traceability control, (3) upgrading of material purchased from non-qualified sources (commercial grade item dedication), and (4) a review of your program for implementing Part 21, "Reporting Defects and Noncompliance," of Title 10 of the Code of Federal Regulations (10 CFR).

Areas examined during the NRC inspection and our findings are discussed in the enclosed inspection report. This inspection consisted of an examination of procedures and representative records, discussion, and observations by the inspectors.

Our review of your activities in these areas indicated that, although your quality assurance program and its implementation adequately addressed material supplied under the rules of the ASME Code, it failed to meet certain NRC requirements applicable to your commercial grade item dedication practices utilized when supplying material under the quality requirements of 10 CFR Part 50, Appendix B. Specifically, your quality assurance program failed to provide adequate instructions or procedures for controlling the commercial grade item dedication process and also failed to provide a documented basis to substantiate that your sampling $\mathrm{plans}$ for verifying critical characteristics provided reasonable assurance that the dedicated items met the applicable procurement document requirements. Deficiencies were also identified in your methods of manufacturing tensile test specimens used in the dedication process. The specific findings and references to the pertinent requirements are identified in the enclosures to this letter.

Please provide us within 30 days from the date of this letter a written statement in accordance with the instructions specified in the enclosed Notice of Nonconformance. We will consider extending the response time if you can show good cause for us to do so. 
The responses requested by this letter and the enclosed Notice are not subject to the clearance procedures of the Office of Management and Budget as required by the Paperwork Reduction Act of 1980, Public Law No. 96-511. In accordance with 10 CFR 2.790 of the NRC's "Rules of Practice," a copy of this letter and the enclosed inspection report will be placed in the NRC Public Document Room.

If there are any questions concerning this inspection we will be pleased to discuss then with you.

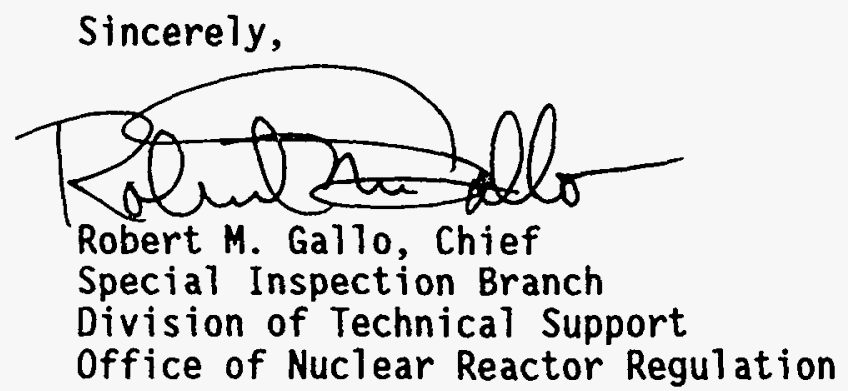

Docket No.: 99900866

Enclosures: 1. Notice of Nonconformance

2. Inspection Report $99900866 / 95-01$ 
Based on the results of an NRC inspection conducted on May 8 through 11, 1995, it appears that certain of your activities were not conducted in accordance with NRC requirements.

A. Criterion V, "Instructions, Procedures, and Drawings," of Appendix B to Title 10 of the Code of Federal Requlations (10 CFR) Part 50 requires, in part, that activities affecting quality shall be accomplished in accordance with instructions, procedures, or drawings.

Contrary to the above, Energy \& Process Corporation (EP) had not developed instructions or procedures that provided requirements for controlling commercial grade item (CGI) dedication activities such as (a) selecting critical characteristics to be verified, (b) identifying proper verification methods for confirming the acceptability of critical characteristics, and (c) ensuring heat or lot traceability to manufacturer's certification. (Nonconformance 99900866/95-01-01).

B. Criterion VII, "Control of Purchased Material, Equipment and Services," of Appendix $B$ to 10 CFR Part 50 requires, in part, that measures shall be established to assure that purchased material conforms to procurement documents.

Contrary to the above, EP had not established a documented bas is to substantiate that its destructive testing and dimensional inspection sampling plans for verifying critical characteristics provides reasonable assurance that dedicated CGIs supplied met applicable procurement documentation requirements (Nonconformance 99900866) 95-01-02).

C. Criterion V, "Instructions, Procedures and Drawings," of Appendix B to 10 CFR Part 50 requires, in part, that activities affecting quality shall be accomplished in accordance with instructions, procedures, or drawings.

Section 26.0.2 of EP Procedure QCP 26, "Tensile Testing Procedure" states that tensile testing shall be performed in accordance with Specification A/SA 370, "Specification for Test Methods and Definitions for Mechanical Testing of Steel Products".

Section 6.3, "Procurement of Test Specimens," of ASTM Specification A 370 , requires, in part, that when test specimens are manufactured, care shall be taken to remove by machining all cold worked areas from the section used in evaluating the test.

Contrary to the above, the method used to manufacture tensile specimen from a stainless steel elbow supplied under Virginia Power $C_{0}$. purchase 
order CNT 479183 produced a test section containing cold worked areas which may have contributed to unusually high yield strength recorded for this elbow. (Nonconformance 99900866/95-01-03).

Please provide a written statement or explanation to the U.S. Nuclear Regulatory Commission, ATTN: Document Control Desk, Washington, D.C. 20555, with a copy to the Chief, Special Inspection Branch, Division of Technical Support, Office of Nuclear Reactor Regulation, within 30 days of the date of the letter transmitting this Notice of Nonconformance. This reply should be clearly marked as a "Reply to a Notice of Nonconformance" and should include for each nonconformance: (1) a description of steps that have been or will be taken to correct these items; (2) a description of steps that have been or will be taken to prevent recurrence; and (3) the dates your corrective actions and preventive measures were or will be completed.

Dated at Rockville, Maryland

this 14th day of June, 1995 
U.S. NUCLEAR REGULATORY COMMISSION

OFFICE OF NUCLEAR REACTOR REGULATION

DIVISION OF TECHNICAL SUPPORT

REPORT NO.:

$99900866 / 95-01$

ORGANIZATION:

Energy \& Process Corporation

2146-B Flintstone Drive

Tucker, GA 30084

ORGANIZATIONAL

CONTACT:

Charles. E. Thornton, Manager

Quality Assurance

NUCLEAR INDUSTRY

ACTIVITY:

Energy \& Process Corporation is a supplier of metal products to the nuclear industry.

INSPECTION DATES: $\quad$ May 8 through 11, 1995

LEAD INSPECTOR:

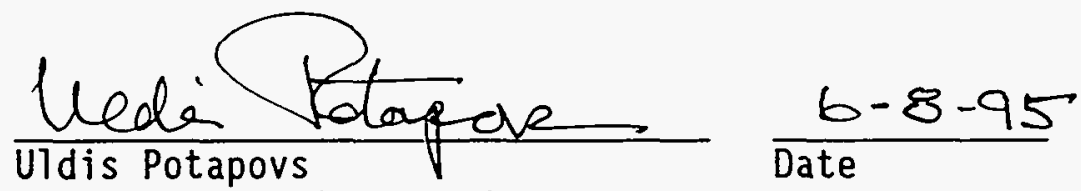

Vendor Inspection Section (VIS)

Special Inspection Branch (TSIB)

OTHER INSPECTORS: Larry L. Campbell

Quality Assurance and Safety Assessment Section

Quality Assurance and Maintenance Branch

REVIEWED BY:

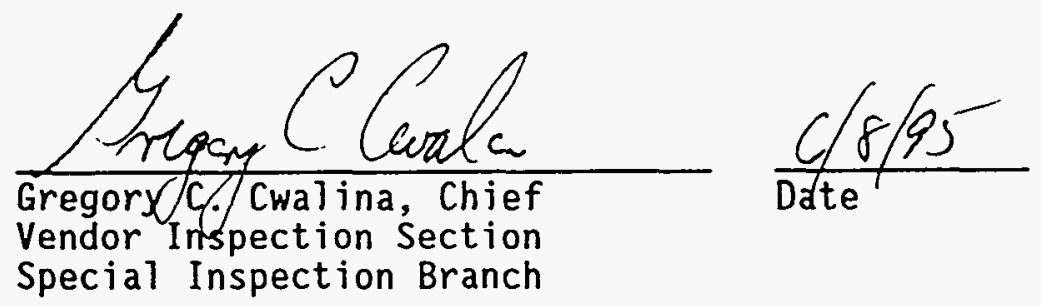

APPROVED BY:

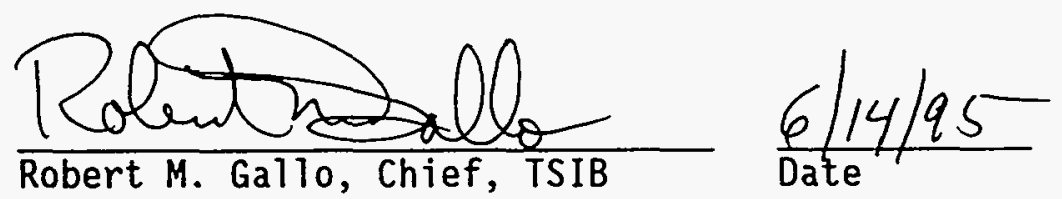


During this inspection, the NRC inspectors evaluated Energy \& Process's (EP's) implementation of quality assurance measures for those activities which directly affected the quality and performance capability of their product. These activities included the control of purchased material and services, material traceability control, and commercial grade item (CGI) dedication. The team also reviewed EP's program for implementing Part 21, "Reporting Defects and Noncompliance, " of Title 10 of the Code of Federal Requlations (10 (FR).

The inspection basis consisted of the following:

- Appendix B, "Quality Assurance Criteria for Nuclear Power Plants and Fuel Reprocessing Plants," to Part 50 of Title 10 of the Code of Federal Regulations (10 CFR Part 50)

- 10 CFR Part 21

- Section III of the ASME Boiler and Pressure Vessel Code (Code)

- EP's Quality Systems Manual, Revision 0, dated November 24, 1993

\subsection{Violations}

No violations were identified during this inspection.

\subsection{Nonconformances}

\subsubsection{Nonconformance 95-01-01}

This nonconformance, described in Sections 3.4.2.1 and 3.4.2.4 of the report identifies EP's failure to develop appropriate instructions or procedures that provide requirements for controlling commercial grade dedication activities such as selecting critical characteristics to be verified, identifying acceptable verification methods, or assuring material traceability.

\subsubsection{Nonconformance 95-01-02}

This nonconformance, described in Section 3.4.2.4 of the report identifies EP's failure to establish a documented basis for substantiating that its material sampling plans for verifying critical characteristics provide reasonable assurance that the dedicated CGIs supplied to their customers meet applicable procurement specification requirements.

\subsubsection{Nonconformance 95-01-03}

This nonconformance, described in Section 3.4.2.3.3 of the report identifies an instance where the method used to manufacture a tensile test specimen failed to meet the applicable specification requirements. 


\section{STATUS OF PREVIOUS INSPECTION FINDINGS}

This was the first NRC inspection of Energy \& Process Corporation

\section{INSPECTION FINDINGS AND OBSERVATIONS}

\subsection{Entrance and Exit Meetings}

During the entrance meeting on May 8, 1995, the NRC inspectors discussed the inspection scope and developed general information about EP's products and activities. During the exit meeting on May 11, 1995, the NRC inspectors discussed their findings and observations with EP's management.

\subsection{Description of Facilities}

EP has been accredited by the American Society of Mechanical Engineers (ASME) as a material supplier of ferrous and nonferrous bars, threaded fasteners, castings, forgings, plate, seamless fittings, flanges, NPT stamped tubular products, structural shapes, welding material, standard supports, and similar items. The scope of their Quality Systems Certificate (QSC) also includes the qual ification of material manufacturers and suppliers of subcontracted services as well as upgrading of stock material. EP has also been accredited as a material manufacturer of ferrous and nonferrous threaded fasteners, seamless fittings and flanges. Their QSC's expire on April 28, 1996.

According to EP management, approximately $85 \%$ of their products are supplied for nuclear applications. Approximately $65 \%$ of their nuclear orders are supplied under their ASME quality systems program and certified under their QSCS, with the remaining $35 \%$ supplied under 10 CFR Part 50 , Appendix B quality assurance requirements. Most of the Appendix $B$ material is purchased as commercial grade items and dedicated.

EP does not perform any material manufacturing operations at their facility. EP has the capability to perform limited threading operations and material subdividing. A material test laboratory is located on site and is capable of performing chemical analyses (optical emission spectrometer), as well as tensile and hardness testing.

\subsection{CFR Part 21 Program}

\subsubsection{Implementing Procedures.}

The NRC inspectors determined that EP maintained the required 10 CFR Part 21 postings in a conspicuous place. EP prepared QCP 16, "Reporting of Defects and Noncompliance," dated January 7, 1994, to implement the provisions of 10 CFR Part 21. The NRC inspectors reviewed QCP 16 for compliance with the requirements of Section 21.21 , "Notification of failure to comply or existence of a defect and its evaluation," of 10 CFR Part 21 and identified several weaknesses. Specifically: 
- QCP 16, for the most part, only referenced the use of 10 CFR Part 21 and did not contain the prescriptive text required by Section 21.21 of 10 CFR Part 21.

- QCP 16 stated, in part, that "Should the evaluation conclude that the condition is reportable under 10 CFR Part 21, the QA Manager shall notify all affected customers after tracking the shipments of the applicable material." The NRC identified to EP that if it concludes that the condition is reportable, in addition to notifying its customers, it must also notify the NRC in accordance with the requirements of Section 21.21 of 10 CFR Part 21.

EP informed the NRC inspectors that its 10 CFR Part 21 implementing procedures would be would be revised to address the weaknesses identified in this inspection report.

\subsubsection{EP Procurement Documents}

The NRC inspectors examined the EP Approved Vendor List for companies that were approved Appendix B material suppliers and that provided calibration and nondestructive evaluation services. The NRC inspectors reviewed documentation for material and services provided by three companies and found that EP had imposed the requirements of 10 CFR Part 21 and 10 CFR Part 50, Appendix B, and that the companies had acknowledged acceptance of these requirements.

\subsubsection{Notification Concerning Deviating material}

On January 25, 1994, PECO Energy Company (PECO) issued a corrective action request (CAR) to EP concerning 150 ASME SA 194, Grade 7, heavy hex nuts which were supplied by EP in May 1993. The CAR was issued after PECO's chemical analyses for 143 of the 150 nuts did not agree with the values shown on the certified material test report (CMTR) suggesting a loss of heat traceability. The CAR also noted that the manufacturer's and grade markings of the 143 nuts appeared different (stamped) than those of the remaining 7 nuts (raised).

The nuts were originally purchased from A\&G Engineering Co. II, Inc. (A\&G) by Hub Inc. (now EP) in 1986. At the time of the procurement, A\&G was an ASME QSC holder and the material was procured under their ASME Certificate.

However, A\&G declared bankruptcy in 1993 and is no longer in business. In February 1995, the NRC issued Information Notice 95-12, to alert 1icensees that $A \& G$ may have supplied nonconforming fasteners.

In response to PECO's CAR, EP performed chemical analyses on several nuts from the same heat of material and determined that the carbon contents of these nuts was below the specification requirements. EP advised PECO that, since the material supplier was no longer in business, the root cause of the deviation could not be determined and issued a return authorization for these nuts. EP also notified other recipients of nuts from the same heat of material that their testing of these nuts had identified carbon contents below the minimum allowed for SA 194 Grade 7 material. Subsequent7y, EP issued a 
follow up to the customer notifications suggesting that the low carbon values may be attributed to a decarburization zone caused by heat treatment and that retest results with the material surface layer removed showed carbon contents within specification.

The inspectors determined that EP's disposition of the reported deviation was consistent with the requirements of 10 CFR Part 21.

\subsection{Quality Assurance Program Implementation}

\subsubsection{Material Supplied to ASME Code Requirements}

\subsubsection{Program Controls}

EP's program for supplying ASME Code material is described in their Quality Systems Manual(QSM), Revision 0, dated November 24, 1993 which is committed to meeting the requirements of ASME Section III, NCA 3800 as well as the applicable portions of ANSI N45.2, ISO 9002, 10 CFR 50, Appendix B, and NQA-1 Basic Requirements. The program controls are described in the manual and in referenced implementing procedures. Selected areas of the manual and its implementing procedures were examined during this inspection.

EP's QSM and its implementing procedures require that purchase orders for ASME Code material be placed only with vendors appearing on EP's Approved Vendor List (AVL). Vendors are placed on the AVL based on holding a valid ASME QSC or following the completion of a satisfactory survey by EP in accordance with the requirements of Subarticle NCA 3800 of the ASME Code, Section III. Provisions for upgrading of stock (Commercial grade) material were reviewed and determined to be in compliance with the applicable ASME Code requirements. These procedures require the performance of all tests specified in the applicable material specification and in the Code on each piece of the stock material or, when material traceability is established by audit, the performance of the required tests on one sample of each heat of material. Chemical analysis is required on each piece of the stock material in either case.

The NRC inspectors reviewed several recent customer purchase orders and accompanying data packages and determined that in most instances the material appeared to have been supplied in accordance with the applicable QSM provisions. Sufficient documentation was generally available to demonstrate compliance with customer purchase order and ASME Code requirements. The document review identified two areas where the bases for acceptability of material from EP suppliers did not appear to be fully supported. One of these relates to inadequate verification of compliance with specific EP purchase order requirements during material receiving inspection as shown in the following example:

On February 23, 1995, TVA issued a purchase order to EP for $1 / 2$ inch $x$ $3 / 8$ inch 3000 ib couplings to be supplied in accordance with ASME 182 , TP316L. EP ordered the material from Alloy Stainless who is a qualified 
supplier and specified in their purchase order that mill test reports and certificate of compliance must be provided with the material.

Instead of providing mill test reports, Alloy Stainless supplied (and EP accepted) this material with "Test Report Certification" on Alloy Stainless letterhead.

While the acceptance of this material does not violate the currently applicable ASME Code or specification requirements, it suggests confusion over the definition of terms or inadequate guidance for material acceptance. Several other packages contained similar inconsistencies.

The second area involved the acceptance of manufacturer's letter as apparent basis for not performing hydrostatic test on pipe which was purchased as stock material as summarized below:

On December 2, 1994, Florida Power \& Light Co. issued a purchase order to EP which included 96 feet of 4 inch diameter schedule 40 , SA 106 , Grade B, seamless pipe to the 1989 edition of ASME Code. EP ordered the pipe from Marmon/Keystone who, in turn, obtained it from US Steel. Upgrading by EP included performance of chemical analyses, tensile, and flattening tests.

Instead of performing a hydrostatic test to verify compliance with the material specification, EP accepted a statement on US Steel Co.

letterhead noting that they hydrotest all seamless standard and line pipe to the requirements of the applicable material specification.

The inspectors noted that basing the acceptance of stock material on certification by the supplier in lieu of test may not fully comply with the material upgrading requirements of the ASME Code. The above examples were identified to EP as weaknesses in the implementation of their ASME QSM.

3.4.2 Non Code material, Supplied to 10 CFR 50, Appendix B Requirements (Commercial Grade Dedication)

\subsubsection{Program and Procedures}

The documented requirements for EP's dedication process were limited to the following text in Section 6.7 of the EP Quality Systems Manual.

Stock (commercial grade) material may be used for safety-related, non-ASME Section III purchase orders provided selected tests are made to verify compliance with the applicable material

specification. Such tests are conducted per heat or lot. Results of the testing shall be passed on to the customer.

The NRC inspectors determined that EP had developed procedures that controlled activities supporting the dedication process including (1) processing incoming orders, (2) receiving inspection, (3) laboratory testing, (4) audits and 
surveys, and (5) quality control inspector training and certification. However, EP informed the inspectors that it had not developed procedures for controlling commercial grade item (CGI) dedication activities such as selecting and verifying critical characteristics. The implementation of EP's dedication activities was reviewed and is discussed in Sections 3.4.2.3 and 3.4.2.4 of this report.

The NRC inspectors determined that incoming customer purchase orders (POs), were initially reviewed by the EP's sales department and the need for purchasing material testing services was identified and placed in a hold status until the material was receipt inspected. Receiving inspection and the need for testing to support the dedication of CGIs were being documented on Form 105, "QC Inspection PIan," and Form 113, "Material Cutting Ticket."

Additionally, the NRC inspectors determined that EP screens all incoming CGIs by reviewing the material certifications provided by the nonqualified supplier for compliance to the applicable material specification and by verifying markings or tagging provided with the CGIs. The NRC inspectors determined that the selection and verification of critical characteristics, at times, appeared to be based on performing the tests that could be performed on a CGI rather than those tests that should be performed (see section 3.4.2.3.2 of this report). The test methods, at times, also appeared to be based on EP's judgement rather than accepted test methods (see section 3.4.2.3.3 of this report). EP informed the NRC inspectors that it had issued an E-Mail, dated January 11, 1995, increasing the sampling size of the chemical analyses required for CGI dedication. This E-Mail was issued to employees involved in CGI dedication activities and identified that the number of chemistry analyses to be performed would be in accordance with the sampling plan presently being used for performing dimensional inspection, Attachment 20.1, "Lot Sampling Plan," of QCP 20, "Receiving Inspection," dated January 7, 1994 and Attachment 5.1 "Lot Sampling Plan" in QCP 5, "Quality Control Inspection" dated January 7, 1994. EP's use of sampling is further discussed in Section 3.4.2.4 of this report.

EP's failure to establish a documented CGI dedication program or procedures for the selection of critical characteristics and identification of appropriate verification methods to confirm the acceptability of critical characteristics was identified as a nonconformance with Criterion $V$ of 10 CFR 50, Appendix B (Nonconformance 99900866/95-01-01).

\subsubsection{Dedication Process Strengths and Weaknesses}

The NRC inspectors determined that even though EP's CGI dedication program did not have procedures or instructions for the identification and verification of critical characteristics, the dedication practices reviewed included a number of the essential elements of CGI dedication. EP's practice of attempting to obtain the original mill test reports of commercial grade material was identified as a strength in their CGI dedication process. EP's well equipped and staffed material testing laboratory was also identified as a significant positive factor. 
However, in addition to the nonconformances identified in Section 1.2 of this report, the inspectors also observed several program/process weaknesses which are summarized below.

- The technical bases for not verifying certain material specification requirements such as hydrostatic testing of dedicated CGI pipe and certain material mechanical properties of CGIs that are too small for the manufacture of a test specimen were not required to be documented.

- Laboratory test results were accepted as meeting the material specification requirements without questioning what effects these results have on other material specification requirements not verified during the dedication process. This is of concern when the other material requirements, not verified, are considered critical characteristics or when there are questionable differences between the EP test results and the test results provided by the material supplier.

- The NRC inspectors questioned EP's practice of including unvalidated supplier material certifications (stamped "QA OK" during the initial screening of incoming commercial grade items) in documentation packages supplied to customers when, at times EP's confirmatory material property overchecks clearly show that the supplier's or EP's certification was questionable (also see Section 3.4.2.4 of this report).

\subsubsection{Review of Dedication Packages}

The NRC inspectors reviewed the following completed CGI dedication packages to determine if critical characteristics for the items had been properly identified and verified, and if adequate procedural controls were in place.

3.4.2.3.1 Virginia Electric and Power (Virginia Power) purchase order (P0) No. CNT 486707, dated December 12, 1994 with a Revision, dated January 10, 1995, Item No. 3, was issued to EP for the supply of 9 each, $11 / 2$ inches, chrome-moly, American Society for Testing and Materials (ASTM) A 182, Grade F22, 90 degrees, pipe elbows. EP issued PO No. E256-00823, to a nonqualified supplier, Pennsylvania Machine Works (PMW), and purchased 10 commercial grade pipe elbows for this Virginia Power PO. EP verified that markings on the tees were correct, reviewed the nonqualified manufacturer's material test report for conformance with the material specification requirements, performed a hardness check, chemistry analyses, and tensile test (including elongation and reduction of area), on 1 of the tees, and dimensional inspections on 4 of the tees. The results of the overchecks performed by EP indicated that the attributes tested were in compliance with ASTM A 182, Grade F22, Class 1, specification requirements. The sampling used for inspections and tests performed on the dedicated items is discussed in Section 3.4.2.4 of this inspection report.

3.4.2.3.2 Virginia Power Purchase Order PO No. CNT 494177, dated March 2, 1995, Line Item No. 7, was issued to EP for the supply of 20 each, $11 / 2$ inches, chrome-moly, ASTM A 182, Grade F22, 3000 pounds, pipe tees. EP issued 
P0 No. E256-01402, dated March 8, 1995, to a nonqualified supplier, PMW and purchased 25 commercial grade pipe tees for this Virginia Power PO. EP verified that markings on the tees were correct, reviewed the nonqualified manufacturer's material test report for conformance with the material specification requirements, performed a hardness check and chemistry analyses on 5 of the tees, and dimensional inspections on 4 of the tees. The results of the overchecks performed by EP indicated that the attributes tested were in compliance with ASTM A 182, Grade F22, C1ass 3, specification requirements. The sampling used for inspections and tests performed on the dedicated tees is discussed in Section 3.4.2.4 of this inspection report.

The NRC inspectors discussed the dedication of the tees with EP and identified an inconsistent selection of tests to verify compliance to A 182 material specification requirements. Previously, EP supplied Virginia Power

ASTM A 182, Grade F 22, 90 degrees, elbows (see Section 3.4.2.3.1 of this report) and performed the following additional tests to verify compliance to the A 182 material specification requirements: (a) tensile testing of the material to determine the material's tensile and yield strength, and (b) elongation and reduction of area tests to determine the material's ductility.

Based on discussions with EP, it appears that EP does not always select the tests used to dedicate an item based on ensuring that the dedicated item was in compliance with the applicable material specification. At times, it appears that the selection of tests was based on convenience. According to $E P$, tensile tests were not performed on the tees because tensile test specimens could not be obtained from the tees. The NRC inspectors informed EP that the inability to obtain test specimens from the tees was not an adequate basis for not verifying the material's strength and ductility. The inspectors noted that the observed inconsistencies in selection and verification of critical characteristics appeared to be attributed to EP's failure to develop written procedures or instructions that provided requirements for determining the types of tests to be selected and appropriate verification methods to be used to ensure that a dedicated CGI was in compliance with applicable material specification and customer requirements (see Section 3.4.2.1 of this report). EP informed the NRC inspectors that, on occasion, it has contacted customers and informed them that certain tests, required by the material specification, could not be performed. The NRC inspectors noted that customer waivers of required testing were considered a part of the CGI dedication package and needed to be documented.

\subsection{Virginia Power Purchase Order PO No. CNT 479183, dated September} 21, 1994, Line Item No. 3, was issued to EP for the supply of 4 each, 1 inch, schedule $10 \mathrm{~S}$, belled ends, ASTM A 403, Type 304L, stainless steel, 90 degrees, elbows. EP issued PO No. 98177, dated June 6, 1992, to a nonqual ified supplier, Bestweld Inc. (Bestweld), for the manufacture of 19 commercial grade pipe elbows for this Virginia Power PO. EP supplied Bestweld pipe used for manufacturing these elbows. EP purchased the pipe used to manufacture the elbows from Sandvik Steel (Sandvik), a qualified EP supplier. Sandvik, an 
ASME Quality Systems Certificate Holder, supplied the pipe in accordance with the requirements of Specification ASTM/SA A-312, Type 304L, as ASME Section III, Class 2, material.

EP verified that markings on the elbows were correct, reviewed the nonqual ified manufacturer's (Bestweld's) material test report for conformance with the material specification requirements, and performed a chemical analyses and tensile test (tensile strength, yield strength, and elongation) on one elbow. The sampling used for inspections and tests performed on the dedicated items is discussed in Section 3.4.2.4 of this inspection report.

Although the elbow tensile test results met the requirements of Specification A 403, Type 304L, the NRC inspectors questioned EP's acceptance of these test results. The pipe used to manufacture the elbows was subjected to a final annealing heat treatment at a temperature of 1900 degrees $F$ minimum followed by rapid water quench to below 800 degrees $F$ in less than three minutes. This treatment resulted in the pipe having a yield strength of 42,200 psi. According to the certification received from Bestweld, the elbows were bright annealed at 1925 degrees $F(t,-25$ degrees $F$ ) and, as permitted by Specification A 321 , Bestwell certified that the yield strength was essentially the same as reported by Sandvik because Bestweld subjected the elbows to the same annealing temperature as Sandvik. However, when EP performed its independent tensile test on one of the elbows, a reported yield strength of 73,000 psi was obtained. Because the Bestweld material certification listed a yield strength for the elbows as $42,200 \mathrm{psi}$ and the EP test identified a yield strength of $73,000 \mathrm{psi}$, the NRC inspectors questioned the validity of this test for demonstrating adequacy of Bestweld's manufacturing process.

The NRC inspectors determined that EP appears to have manufactured the tensile test specimen from one of the elbows improperly. EP's Tensile Testing Procedure, QCP 26 requires tensile tests to be performed in accordance with specification A/SA 370, "Specification for Test Methods and Definitions for Mechanical Testing of Steel Products." The test specimen was obtained by cutting a strip from the outer radius of the elbow and then flattening the cut strip and machining/cutting the strip to the correct dimensions to form the test specimen. It appeared that the requirements of Section 6.3, "Procurement of Test Specimens," of A 370 were not followed by EP. Section 6.3 requires, in part, that when test specimens are manufactured care shall be taken to remove by machining all cold worked areas from the section used in evaluating the test. In this instance, EP appeared to have cold-worked, by flattening the outer radius of the elbow, the test specimen over its entire length. The cold working could have resulted in EP reporting a yield strength that may not be representative of the actual yield strength of the elbows supplied. The NRC inspectors concluded that EP failed to comply with $A 370$ requirements in manufacturing the tensile specimen. (Nonconformance 99900866/95-01-03).

EP informed the NRC inspectors that originally it had requested Bestweld to subject a piece of the supplied pipe to the same heat treatment that the elbows received. However, this piece of pipe was lost and according to EP, 
the only way to verify that Bestweld, a nonqualified supplier, had properly manufactured and heat treated the elbows was to perform a tensile test on an elbow. The NRC inspectors expressed concern that, because the piece of pipe had been lost, and the tensile test could not be performed in accordance with Specification A 370 requirements, EP attempted to verify the item's tensile properties using a nonconforming specimen. It was further discussed that EP has no procedural guidance for determining the proper methods for verifying critical characteristics.

The NRC inspectors also determined that EP does not compare any of its test results to the nonqualified supplier's material certifications and bases its certification on the test results meeting the applicable material specification requirements. EP informed the NRC inspectors that it considers the items received from a nonqualified supplier to be of one heat or lot and only performs tensile tests on one item from the nonqualified heat or lot. The NRC inspectors expressed concern over EP practice of not comparing its test results to those received from the nonqualified supplier. EP's definition and use of nonqualified supplier's heat and lots and its failure to compare the nonqualified supplier's material certification to its test results as part of its dedication process is discussed in Section 3.4.2.4 of this inspection report.

The NRC inspectors also determined that EP had supplied an additional 5 elbows for Virginia Power PO CNT 492269 using the same tensile test results supplied with Virginia Power PO CNT 479183.

\subsection{Tennessee Valley Authority (TVA) P0 P-93N3F-41823E-002, dated} February 22, 1995, Item 1 , was issued to EP for the supply of $3 / 4$ inch diameter, 40 feet total, A 276, Type 304, cold finish, round metal bar. EP issued PO No. E256-01313, dated February 23, 1995, to a nonqual ified supplier, Centerless Grinding Service (Centerless), and purchased 48 feet ( 4 each, 12 feet lengths) of the $3 / 4$ inch diameter A 276, Type 304, commercial grade round metal bar. Centerless purchased the bars from Green Bay Supply Company which had purchased the bars from Huta Baildon, a Polish bar manufacturer. EP verified markings and performed dimensional checks on each bar, reviewed the nonqualified distributor's, supplier's and manufacturer's certifications, performed chemical analyses on 2 of the bars, and performed tensile tests and an intergranular corrosion susceptibility test on one bar. Two of the bars were not subjected to any material overchecks. The results of the overchecks performed by EP indicated that the attributes tested were in compliance with $A$ 276, Type 304, requirements. The sampling used the tests performed on the dedicated bars is discussed in Section 3.4.2.4 of this inspection report.

3.4.2.3.5 Virginia Power PO No. CNT-485585, dated November 29, 1994, Item 3, was issued to EP for the purchase of 1 piece of 1 inch thick $X 48$ inches $X$ 48 inches, A 516, Grade 70, plate. EP issued PO No. E256-00778, dated December 5, 1994, to a nonqualified supplier, Ferro Union, for a piece of 1 inch thick $\times 48$ inches $\times 96$ inches A 516, Grade 70 piece of plate. Ferro Union purchased the plate from Highveld. EP performed a visual and dimensional inspection on the plate received from Ferro Union and cut a 
48 inches $X 48$ inches piece for shipment to Virginia Power and performed a chemical analyses and tensile tests on another piece cut from the plate received from Ferro Union. The results of the overchecks performed by EP indicated that the attributes tested were in compliance with A 516, Grade 70 , requirements.

\subsubsection{Material Sampling and Traceability}

EP informed the NRC inspectors that CGIs purchased from nonqualified suppliers and dedicated as basic components were inspected and tested by EP in accordance with the following sampling plans.

- Visual inspection is performed on 100 percent of the CGI items received.

- Dimensional inspection is performed in accordance with Attachment 5.1, "Lot Sampling Plan," to EP Procedure No. QCP 5, "Quality Control Inspection," dated January 7, 1994 and Attachment 20.1 "Lot Sampling Plan" of QCP 20, "Receiving Inspection", dated January 7, 1994. The NRC inspectors discussed with EP that this sampling plan appeared to have been taken from Table 7-2, "Single-Sampling Plans for Normal

Inspection," of MIL-STD-105D, "Sampling procedures and Tables for Inspection by Attributes" with an Acceptable Quality Level (AQL) of 10.

$\begin{array}{lccc}\text { BATCH SIZE } & \text { SAMPLE SIZE } & \text { ACCEPT } & \text { REJECT } \\ 2 \text { T0 } 8 & 2 & 1 & 2 \\ 9 \text { to } 15 & 3 & 1 & 2 \\ 16 \text { to } 25 & 5 & 1 & 2 \\ 26 \text { to } 50 & 8 & 2 & 3 \\ 51 \text { to } 90 & 13 & 3 & 4 \\ 91 \text { to } 150 & 20 & 5 & 6 \\ 151 \text { to } 280 & 32 & 7 & 8 \\ \text { etc. } & -- & - & - \\ \text { etc. } & -- & - & - \\ 3201 \text { to } 10,000 & 200 & 21 & 22\end{array}$

The NRC inspectors questioned the use of an AQL of 10 because, for example, this sampling plan would permit a sample size of 3 for a batch of 11 items to be accepted even though one of the items sampled is rejected. EP could not provide the NRC inspectors with the basis for its selection of this sampling plan or the selection of an AQL of 10 . EP informed the NRC inspectors that even though QCP 5 permits the acceptance of a batch of items having one or more items rejected, its practice was to reject the entire batch or to inspect each remaining item when one of the items sampled was rejected.

- According to Section 6.7 of the EP Quality Systems Manual, stock material may be used for safety-related, non-ASME Section III purchase orders, provided selected tests are made to verify compliance with the applicable material specification. Section 6.7 continues by stating 
that such tests are conducted per heat or lot. However, for the dedication of material to be supplied under Appendix $B$, no surveys or audits are performed to verify heat traceability. EP informed the NRC inspectors that it performs one tensile test on each heat or lot of CGIs to be dedicated. EP further informed the NRC inspectors that it intends to follow its lot sampling plan in QCP 5 for the performance of chemical analyses. According to EP, its destructive sampling plans for dedicating CGIs are used for ali dedications regardiess of the size or type of product, or whether the CGIs were purchased directly from the manufacturer or through a distributor.

The NRC inspectors discussed the use of EP's sampling methodology in detail during the inspection and asked EP to provide the bases for its destructive sampling $\mathrm{plans}$ as providing reasonable assurance that the CGIs not tested had the required material chemistry and strength and other properties required by the applicable material specification. EP informed the NRC inspectors that it had not established a quantitative basis, such as by the use of statistics, for its destructive sampling plan.

The NRC inspectors noted that Appendix $B$ requires, in part, that a quality assurance program be established to provide controls over activities affecting quality of components and that compliance with this criterion would generally require EP to impose applicable provisions of Appendix $B$ on their suppliers and to assure their compliance with these provisions. Maintaining material heat traceability to assure representative sampling is considered an activity affecting quality. The inspectors also noted that, for certain applications, the NRC staff has accepted commercial grade dedication as an alternative method to the programmatic quality assurance measures of Appendix B for assuring that items purchased from commercial sources will meet the applicable purchase specification requirements. When the dedication process is based on sampling of material to verify critical characteristics, the sampling plan is expected to have an adequate technical basis and to provide a high level of assurance of the dedicated item's suitability for service.

The inspectors concluded that, without material traceability verification, EP's sampling practice for dedication of commercial grade material does not provide reasonable assurance that such material will conform to the specification requirements. (Nonconformance 9990866/95-01-02)

The NRC inspectors discussed the overall effectiveness of the dedication process including the utilization of supplier performance history in development of sampling strategies and the evaluation of product markings as indicators of material heat homogeneity. It was also noted that product screening by chemical analys is of unqualified material and comparison of such analyses with the mill test report can be a valuable tool for validating material traceability. 
The NRC inspectors also discussed with EP the evaluation of EP's tensile, chemistry, hardness, and other test results when they vary from those identified on the nonqualified supplier's material certification. The NRC inspectors determined that there are no requirements in EP's dedication program for comparing and evaluating EP's test results to the vendor-supplied test reports, and for identifying questionable vendor test reports when they are being supplied to a customer. The NRC inspectors reviewed several documentation packages for dedicated material forwarded by EP to its customers and determined that the nonqualified supplier's certification used for the initial EP screening of material was included in these packages. The NRC inspectors noted that EP's practice of including the unvalidated supplier certification (stamped "QA OK" during the initial commercial grade material screening process) in the documentation packages supplied to customers without identifying to its customers what the "QA OK" stamped certification represented could mislead the customers to assume that EP had verified the authenticity and accuracy of these certifications.

The NRC inspectors concluded that EP had not developed adequate procedures or instructions to assure that items received from a nonqualified supplier were from the same manufacturer's heat or lot that was identified on the supplier's material certification. (Nonconformance 99900866/95-01-01)

\subsection{Nuclear Utilities Procurement Issues Committee (NUPIC)}

\subsubsection{NUPIC Audit at EP}

The NRC inspectors determined that NUPIC had performed an audit of EP, formerly HUB Incorporated, Energy \& Process Division (HUB/EP), on September 27 through October 1, 1993. The NUPIC lead audit utility was Public Service Electric Gas Company (PSE\&G) with auditors from Wolf Creek Nuclear Operating Company and Pacific Gas \& Electric Company. The summary section of the NUPIC Audit Report for HUB/EP, dated November 1, 1993, states, in part, that the audit team concluded that HUB/EP "has demonstrated their Revision 13, dated 213-93 of their Quality System Manual and implementing procedures are in compliance with the applicable provisions of 10 CFR 50 Appendix B, ANSI N45.2, 10 CFR Part 21, ISO 9002, ASME Section III, NCA 3800, and EPRI 5652."

The NUPIC audit report continued by further addressing commercial grade dedication and stated, in part, that HUB/EP had established an acceptable traditional commercial grade dedication program and that items procured commercial grade from unaudited/unsurveyed suppliers were dedicated for safety-related use by inspecting outbound material using an established lot sampling plan specified in Procedure QCP-5, Revision 7, and by performing tests on one sample from each heat or lot. The NUPIC audit report also 
indicated that specific critical characteristics for various items supplied by HUB/EP were provided to NUPIC auditors by several 1icensees. There were no findings identified in the NUPIC audit report.

\subsubsection{NRC Comments on NUPIC's Evaluation of EP's CGI dedication Program}

EP informed the NRC inspectors that the requirements in Section VI, "Examination, Tests, and Reports," of its Quality Systems Manual, and QCP 5, "Quality Control Inspection," for commercial grade dedication and sampling were the same during the conduct of the NRC inspection as when NUPIC performed its audit in 1993. Information, such as the following, was not provided in the NUPIC audit report and may be beneficial to NUPIC members (NRC 1 icensees) in evaluating the use of items, dedicated by EP, in safety significant/critical plant applications.

- The NUPIC audit report did not provide any details of the sampling plan in QCP 5. The sampling plan in QCP 5 appeared to be taken from MIL-Std1050 , and to have an $A Q L$ of 10 which permits accepting the lot of items with 1 or more of the sampled items being rejected. As discussed in Section 3.4.2.4 of this report, this sampling plan did not appear to provide a high level of assurance of the dedicated item's suitability for service. HUB/EP had no documented basis for this sampling plan and could not provide the NRC inspectors its rationale for selecting a sampling plan having an AQL of 10 .

- HUB/EP had not established a documented basis to substantiate its assumption that a heat or lot of items supplied by a nonqualified manufacturer or distributor is a valid heat or lot and that testing only one item from each heat and lot provides reasonable assurance that the dedicated CGIs not tested met applicable procurement documentation requirements.

- The NUPIC audit report stated, in part, that HUB/EP commercial grade dedication program met EPRI NP 5652, "Guideline for the Utilization of Commercial Grade Items in Nuclear Safety Related Applications (NCIG-07)." However, as discussed in this inspection report, HUB/EP had not developed procedures that provided requirements for controlling CGI dedication activities such as (a) selecting critical characteristics to be verified, (b) identifying proper verification methods for confirming the acceptability of critical characteristics, and (c) ensuring that a heat or lot received from a nonqualified supplier was a valid heat or lot.

\section{PERSONS CONTACTED}

The NRC staff participating in the inspection and EP personnel contacted during the inspection are listed below. 


\section{Energy \& Process Corporation}

+* Capal10, M

$t^{*}$ Thornton, Jr., C

President and General Manager

$+*$ Walker, C

+ Kennedy, K

+ Buffington, $R$ Prasad, A

Quality Assurance Manager

Operations Manager

Sales

Quality Control Inspector

Laboratory Manager

+* Wolfe, C

QC Inspector Trainee

\section{U.S. NUCLEAR REGULATORY COMMISSION}
+* Potapovs, U
+* Campbe11, L
Team Leader, VIS/TSIB
Reactor Engineer, TQMB
* Attended the entrance meeting
+ Attended the exit meeting 


\section{UNITED STATES \\ NUCLEAR REGULATORY COMMISSION \\ WASHINGTON, D.C. 20555-0001}

June 20, 1995

Mr. Mark Van Sloun, Vice President and General Manager

Rosemount Nuclear Instruments, Incorporated 12001 Technology Drive

Eden Prairie, Minnesota 55344-3695

SUBJECT: NRC INSPECTION NO. 99900271/95-01

Dear Mr. Van Sloun:

This letter transmits a corrected copy of the subject report. The enclosed corrected copy replaces U.S. Nuclear Regulatory Commission (NRC) Inspection Report 99900271/95-01 in its entirety for the NRC inspection activity that was conducted at the Rosemount Nuclear Instruments, Incorporated (Rosemount), Eden Prairie facility on January 23 through January 26, 1995.

After reviewing the initial NRC inspection report, the Dow Corning Corporation (Dow Corning) informed the NRC, by letter dated May 2, 1995, of a

misunderstanding that occurred during a telephone discussion and provided clarification of their comments that were contained in the report. The staff has corrected the affected section, on page 8 of the report, and identified the revised section with a vertical line in the margin of page 8 . The NRC staff also reviewed the revised report and determined that the revised section of NRC report 99900271/95-01 did not affect any conclusions regarding the Rosemount sensor cell oil crystallization issue.

In accordance with 10 CFR 2.790(a) of the NRC "Rules of Practice," a copy of this letter and its enclosure will be placed in the NRC Public Document Room. No response to this letter or its enclosure is required. Should you have any questions concerning this report, we will be pleased to discuss them with you.

Sincerely,

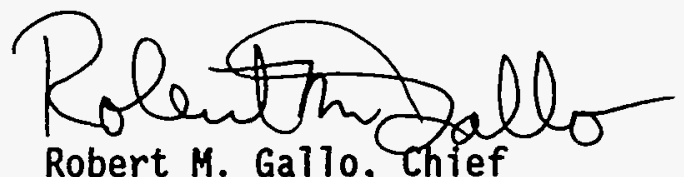

Robert M. Gallo, Chief

Special Inspection Branch

Division of Technical Support

Office of Nuclear Reactor Regulation

Docket No.: 99900271

Enclosure: As stated

cc: See next page 
Mr. Kenneth E. Ewald

Business Unit Manager

Rosemount Nuclear Instruments, Incorporated 12001 Technology Drive

Eden Prairie, Minnesota 55344-3695

Mr. Arnold R. Huntress

Associate Process Consultant

Materials Development

Dow Corning Corporation

Midland, Michigan 48686-0995

Mr. Paul Blanch

135 Hyde Road

West Hartford, Connecticut 06117

Ernest Hadley, Esquire

414 Main Street

Post Office Box 3121

Wareham, Massachusetts 02571 
REPORT HO.:

ORGANIZATION:

ORGANIZATIONAL

CONTACT:

NUCLEAR INDUSTRY

ACTIVITY:

INSPECTION DATE:

LEAD INSPECTOR:

OTHER INSPECTORS:

REVIEWED BY:

APPROVED BY:
U.S. NUCLEAR REGULATORY COMMISSION

OFFICE OF NUCLEAR REACTOR REGULATION

DIVISION OF TECHNICAL SUPPORT

99900271/95-01

Rosemount Nuclear Instruments, Incorporated 12001 Technology Drive

Eden Prairie, Minnesota 55344-3695

Mr. Kenneth E. Ewald, Business Unit Manager (612) 828-8241

Designer, manufacturer, and supplier of temperature detectors and sealed gage, differential, and high-line differential pressure transmitters used extensively in nuclear safety-related applications.

January 23-27, 1995
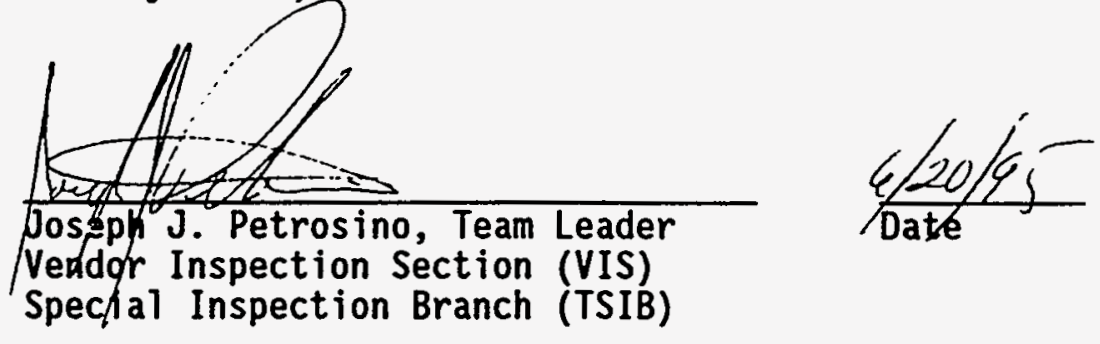

Shashikant V. Athavale Instrumentation and Controls Branch Division of Reactor Control and Human Factors

K. I : Parczewski

Materials and Chemical Engineering Branch Division of Engineering
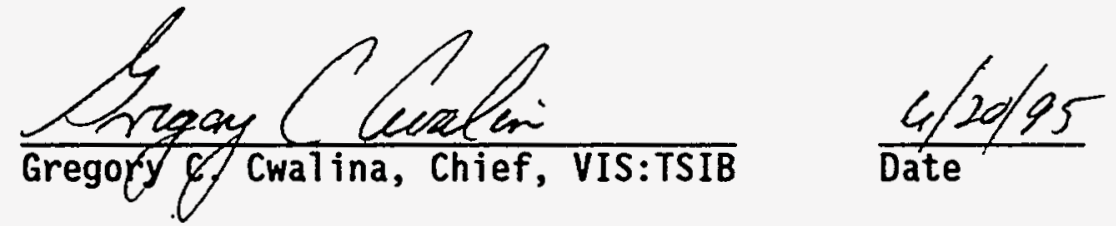

Enclosure 


\section{SUMMARY OF INSPECTION FINDINGS}

During this inspection, the NRC inspection team evaluated the adequacy of the process that Rosemount Nuclear Instruments, Incorporated (Rosemount), established related to the use and conditioning of the Dow Corning 704 (DC 704) silicone fluid that is used by Rosemount for its Models 1153 and 1154 safety-related pressure transmitters. The inspection was conducted in conjunction with an NRC Headquarter's staff review to assure that Rosemount's applicable safety-related pressure transmitters supplied to the U.S. nuclear industry would perform their safety function within their designed operating parameters with little probability of a potential for silicone oil crystallization below $70^{\circ}$ Fahrenheit (F) applications.

The inspection basis consisted of the following:

- Rosemount Nuclear Quality Manual (NQM), Document Number D9000115, Revision C, dated June 1, 1994

- Appendix B, "Quality Assurance Criteria for Nuclear Power Plants and Fuel Reprocessing Plants," to Part 50 of Title 10 of the Code of Federal Regulations (10 CFR Part 50)

- Part 21, "Reporting of Defects and Noncompliance," of 10 CFR

No violations or nonconformances were identified by the NRC inspection team during this inspection.

\subsection{Inspector Fol low-Up Item 99900271/95-01-01}

As discussed below in Section 2.2, the NRC staff will review Chanhassen's procedure which it adopted to implement the provisions of 10 CFR Part 21 during a future NRC inspection. (95-01-01)

\subsection{Inspector Follow-Up Item 99900271/95-01-02}

As discussed below in Section 3.10, the team had some concerns regarding the quality assurance (QA) program requirements imposed and implemented by the Rosemount transmitter sensor cell manufacturing activities at the Chanhassen facility which will be reviewed during a future NRC inspection. (95-01-02)

\section{STATUS OF PREVIOUS INSPECTION FINDINGS}

During an inspection of Rosemount conducted on February 1 through 4, and March 8 through 12, 1993, the NRC inspection team determined that certain of Rosemount's activities were in violation of NRC requirements, as specified in NRC inspection Report 99900271/93-01 and associated transmittal letters. Additionally, the inspection team found several weaknesses in Rosemount's QA program in both QA program establishment and implementation as required by NRC requirements contractually imposed on Rosemount by purchase orders (POs) from nuclear power reactor utilities. The adequacy of Rosemount's corrective actions for the following violations and nonconformances were reviewed, evaluated and dispositioned as stated below. 


\subsection{Violation 99900271/93-01-EA94-049 (CLOSED)}

Contrary to Section 21.21, "Notification of failure to comply or existence of a defect and its evaluation," of the version of 10 CFR Part 21 in effect from January 1978 until July 1991, the Measurement Division of Rosemount, Incorporated (Rosemount), failed to adequately establish and implement a procedure to effectively implement the provisions of 10 CFR Part 21 . The Rosemount procedure, Quality Implementation Procedure (QIP) 126(N), "Potential Defect or Deviation in Products for Nuclear Application, "issued March 18, 1981 , did not ensure that deviations, as defined in 10 CFR $\$ 21.3$ (e), about which Rosemount did not have adequate knowledge of each of the applications at NRC licensee facilities, were either evaluated or transmitted to the applicable customer or licensee for evaluation. Specifically, between 1984 and December 1988, Rosemount failed to properly inform licensees of a potential for a sensor cell oil-loss problem that could occur in its nuclearsafety-related 1150-series pressure transmitters which could have caused safety limits to be exceeded or caused substantial safety hazards to exist at licensee facilities.

The NRC inspectors verified that Rosemount's Procedure N-1626, "Implementation of 10CFR Part 21 for Deviations and Failures to Comply in Nuclear Products," Revision D, dated May 27, 1994, had been appropriately revised since the last NRC staff inspection at the Rosemount facility. Additionally, Rosemount committed to ensure that its communications with the NRC and its licensees are more complete and candid as indicated in its December 14, 1994, letter to NRC staff. As discussed in our February 15, 1994, letter, the NRC inspectors concluded that the applicable provisions of 10 CFR Part 21 should be effectively executed as a result of the revised Rosemount program controls.

\subsection{Violation 99900271/93-01-01 (CLOSED)}

Contrary to Section 21.21, "Notification of failure to comply or existence of a defect and its evaluation," of 10 CFR Part 21, Rosemount failed to establish or implement a procedure to ensure that the provisions of 10 CFR Part 21 were executed at its Chanhassen facility. As discussed below in Section 3.1, the Chanhassen, Minnesota, facility is currently a separate corporate entity from the Eden Prairie, Minnesota, facility. That is, Chanhassen is pait of the Rosemount Measurement Division (RMD) of Rosemount Corporation and the Eden Prairie nuclear activities are under Rosemount Nuclear Instruments, Incorporated. However, at the time of the identification of the violation, Eden Prairie was part of RMD and was responsible for ensuring that Chanhassen had adopted procedures to effectively implement the provisions of 10 CFR

Part 21. Since Eden Prairie is now a separate corporate entity from Chanhassen, it would not be responsible for ensuring the adequacy of Chanhassen's 10 CFR Part 21 procedure.

However, during the NRC staff review of the circumstances surrounding violation 99900271/93-01-01, the team reviewed a copy of the procedure which Chanhassen has adopted to implement the provisions of 10 CFR Part 21, Pressure Department Procedure (PDP)-1320-3, "Nuclear Sensor Part 21 Reporting," 
Revision E, dated January 19, 1995. Since the Chanhassen facility is now a separate corporate entity, Procedure PDP-1320-3 will be reviewed during a future NRC inspection at Chanhassen and is identified as NRC inspector followup item 99900271/95-01-01.

\subsection{Violation 99900271/93-01-02 (CLOSED)}

Contrary to Section 21.6, "Posting requirements, " the 10 CFR Part 21 posting at Rosemount's Eden Prairie and Chanhassen facilities did not adequately describe the 10 CFR Part 21 regulation or the procedure adopted to implement 10 CFR Part 21. In addition, the postings were found to contain outdated names and telephone numbers of personnel to whom reports were to be made. The inspectors verified that the postings at the Eden Prairie facility were in accordance with 10 CFR \& 21.6 ; therefore, this issue is closed.

\subsection{Violation 99900271/93-01-03 (CLOSED)}

Contrary to Section 21.51, "Maintenance and inspection of records, " of 10 CFR Part 21, Rosemount records regarding a review of suspect resistors used in Rosemount 710 DU products did not contain adequate information to enable the team to determine whether Rosemount customers were appropriately informed of the deviation. During this 1995 inspection, the team reviewed the documents which Rosemount discussed in its April 1, 1994, response letter to the NRC letter, dated March 4, 1994, which transmitted the Notice of Violations. The April lst letter refuted violation 93-01-03. Based on its record review, the team concluded that Rosemount appropriately informed their customers of the subject deviation. Therefore, as discussed in NRC's response dated June 13, 1994, to Rosemount, this violation has been withdrawn and is closed.

\subsection{Nonconformances 99900271/93-01-04 - 99900271/93-01-09 (OPEN)}

These nonconformances were not reviewed by the NRC inspection team during this inspection activity; therefore, each nonconformance will remain open and will be reviewed during a future inspection.

\subsection{Inspector Follow-Up Items $99900271 / 93-01-10$ - 99900271/93-01-15 (OPEN)}

These inspector follow-up items were not reviewed by the NRC inspection team during this inspection activity; therefore, each inspector follow-up item will remain open and will be reviewed during a future inspection.

\section{INSPECTION FINDINGS AND OTHER COMMENTS}

\subsection{Rosemount Companies}

In the February-March 1993 time period, the Chanhassen and Eden Prairie facilities were both a part of the Rosemount Corporation's Measurement Division. Subsequent to the 1993 inspection, the responsibility of the safety-related transmitter came under Rosemount Nuclear Instruments, Incorporated (Rosemount) and the Chanhassen facility remained part of RMD. During the 1993 inspection, Chanhassen manufactured the pressure transmitter's (1) safety-related sensor cell, and (2) the nuclear printed circuit (PC) card 
assembly (basic components as defined in 10 CFR $\S 21.3$ ). The safety-related sensor cell was manufactured at the Chanhassen facility and the nuclear PC card assembly was being manufactured by Rosemount Aerospace, now a Division of the B.F. Goodrich Company, during the performance of the January 1995 NRC staff inspection. Therefore, Chanhassen (part of RMD) and Rosemount Aerospace were characterized and treated by Rosemount as separate sub-tier manufacturers of "basic components." Rosemount located its nuclear power plant business

activities at the Eden Prairie facility where it procures pressure transmitter parts; and assembles, tests and supplies Rosemount safety-related pressure transmitter Models 1152, 1153 and 1154 to the nuclear industry.

\subsection{Entrance and Exit Meetings}

The NRC inspectors conducted an entrance meeting on January 23, 1994, with Rosemount staff and discussed the scope of the inspection. On January 26 , 1994, the team leader discussed the NRC inspection results.

\subsection{Background}

The silicone oil used in the Rosemount pressure transmitter Models 1153 and 1154 sensor cells is a Dow Corning Corporation silicone oil. During a May 1994 review of Rosemount's response to NRC staff inspection findings delineated in Inspection Report $999000271 / 93-01$, the staff identified a cautionary note in the DC 704 product data sheet which stated: "Caution: Dow Corning 704 diffusion pump fluid may crystallize if subjected to temperatures below $21^{\circ} \mathrm{C}\left(69.8^{\circ} \mathrm{F}\right)$. If crystallization occurs, two hours of $50^{\circ} \mathrm{C}\left(122^{\circ} \mathrm{F}\right)$ temperature will return the fluid to its original state." However, in conflict with the Dow Corning cautionary note, the NRC staff found that the Rosemount transmitter Models 1153 and 1154 product data sheets stated that the transmitter's lower operating design limit was $+40^{\circ} \mathrm{F}$ and its lower qualified storage limit was $-40^{\circ} \mathrm{F}$. Therefore, since the Rosemount operating and storage lower limits were below the crystallization temperature which Dow Corning stated in its DC 704 data sheet, the NRC staff initiated a review.

The staff's concern was based on the postulated consequence that potential silicone oil crystallization in a safety-related transmitter could render the transmitter inoperable and compromise safety, depending on the number and location of affected transmitters. A Rosemount September 28, 1994, letter to the NRC forwarded Rosemount's August 12, 1994, analysis of the matter (Rosemount Report D9400078). Based on its analysis, Rosemount concluded that DC 704 was still the most appropriate fluid for use in the Model 1153 and 1154 transmitters. The Rosemount analysis discussed Rosemount's initial engineering actions in 1980 regarding the DC 704 oil's potential for crystallization and referenced its engineering report, Rosemount Report No. $11805 \mathrm{~A}$, which addressed and summarized the DC 704 crystallization issue. The Rosemount 1980 report concluded that crystallization was not a concern as long as certain conditions were met. As a result of the NRC staff review of the September 28, 1994, Rosemount letter, the NRC concluded in a December 9, 1994, letter to Rosemount that the manufacturing process (DC 704 preconditioning) used by Rosemount will prevent crystallization of the $0 i 1$ in the transmitters 
prior to shipment. Further, Rosemount's analysis of the transmitter oil crystallization concern acceptably demonstrated that the potential problem is adequately addressed by initial and periodic transmitter performance testing by the licensees.

\subsection{Sensor Cell Operation}

Rosemount uses the DC 704 oil in its transmitter's sealed sensor cell diaphragm compartments. Every sensor cell has two separate oil compartments which are separated by a center diaphragm (sensing diaphragm), with isolating diaphragms at each end of the cylindrical sensor cell. Each of the three diaphragms are circumferentially welded to form the diaphragm's seal. In operation, process pressure is transmitted through either of the isolating diaphragms to the DC 704 oil which then displaces the sensing diaphragm in the center of the sensor cell. The movement and position of the sensing diaphragm is detected by capacitor plates located on both sides of the sensing diaphragm and a differential capacitance between the sensing diaphragm and the capacitor plates is converted to an electrical signal. The amount of sensor cell fill fluid on either side of the sensing diaphragm is equal to approximately three drops of DC 704 oil. As a result, the properties of the fill fluid (viscosity, dielectric constant and density) are important to the performance of the transmitter.

\subsection{704 Associated Process Controls}

The NRC staff inspectors observed the Rosemount manufacturing process controls associated with DC 704 and reviewed the procedures used to control the processes. The inspectors noted that the procedure used to "condition" Dow Corning silicone oil (DC200 was the first silicone oil to be outgassed), was initially written in 1979. Rosemount Procedure 01153-3045, "Outgas Procedure," Revision L, dated June 4, 1992, delineates the oil processing steps which are performed by Rosemount on all DC 704 silicone diffusion pump fluid received for use in its Models 1153 and 1154 pressure transmitters. According to Rosemount staff, the main purpose of the outgassing process is to ensure maximum noncompressability, improve the dielectric characteristics and to filter out any contaminants. According to the Rosemount staff, moisture is removed and the potential for crystallization of silicone oil is greatly reduced as a benefit of the outgassing process.

In the DC 704 conditioning process, the $0 i 1$ is maintained at $150^{\circ} \mathrm{F}$ for approximately 16 hours under a partial vacuum condition at a specific pressure. The oil is continuously stirred during the heating and evacuating process and the outgassed DC 704 oil is later piped in to sensor cells which have been vacuum evacuated at a specific temperature and pressure for several hours. After the sensor cells are filled with the DC 704, their fill oil tubes are crimped and welded. The team noted that all of the identified procedures for the DC 704 oil and the filling of oil in to the transmitter cell were in accordance with Rosemount's stated program in their letter to the NRC. The team concluded that the procedures have adequate guidance for the Rosemount technicians to accomplish the DC 704 oil conditioning to ensure that dissolved gases and moisture were removed from the oil. It appeared that 
Rosemount's process was well established, the operator was aware of the procedural requirements and the intent of the process control. Additionally, all activities that were witnessed appeared to be accomplished in accordance with the established procedures.

\subsection{Rosemount Report 11805A}

The team reviewed the Rosemount engineering report, Rosemount Report 11805A, "Re-evaluation of Suitability of Dow Corning $7040 i 7$ for Use in Model 1152 or 1153 Pressure Transmitters," to assess its validity and soundness. According to the scope, this report described the results of an engineering evaluation undertaken to determine if a problem existed with the use of DC 704 fluid in pressure transmitters qualified for Class $1 \mathrm{E}$ applications in nuclear power plants. The report stated that the response of the transmitter depended on fluid movement within the transmitter, that the $0 i l$ volume was very small and fluid viscosity is important. Viscosity of the oil would increase at low temperatures and result in slow response. Crystallization or incipient crystallization (irreversible long-range order) would also show up at low temperature as an increase in apparent viscosity which would not disappear when the oil returns to room temperature. Measurement of the time constant of the transmitter unit therefore provides the prime measure of the occurrence of crystallization. Additionally, the report stated that if there were a marked change of density due to crystallization, the dielectric characteristics would al so change resulting in a marked zero or span shift as a second indication of the occurrence of crystallization. The report concluded that none of its testing observations indicated any effect which could be interpreted as due to crystallization of DC 704 oil.

The Rosemount Report stated that, crystallization was not a matter for concern when using DC 704 oil as a pressure transfer fluid for nuclear qualified pressure transmitters, so long as: (a) operating temperature is greater than $40^{\circ} \mathrm{F}$ and (b) the present fill method, which insures the absence of air and moisture, is maintained. The report indicated that the only time condition (a) might be violated would be during storage before installation. As stated in the Report, this possibility was tested on a non-operational basis during a storage temperature-aging program where Rosemount took 6 Model 1153 Series B transmitters (use DC $704 \mathrm{oil}$ ) and exposed them to 20 cycles vec...en $-55^{\circ} \mathrm{F}$ and $+135^{\circ} \mathrm{F}$ with one cycle equal to 3 hours at $-55^{\circ} \mathrm{F}$ and 3 hours at $135^{\circ} \mathrm{F}$. Rosemount did not identify any anomalies attributed to the cycling, and maximum zero or span shift after cycling was approximately one percent. Rosemount identified that these test results were within the expected shift.

\subsection{Discussion with Dow Corning Corporation Staff}

On January 25, 1995, the NRC inspectors conducted a telephone discussion with a Dow Corning Corporation technical representative who has been associated with the initial research, development and production of Dow Corning silicone fluids since the $1950 \mathrm{~s}$. The Dow Corning technical representative provided the team members with the history of the DC 704 silicone oil development and experience over the approximate 40 year existence of the fluid. For example, the Dow Corning technical representative indicated that little is known about the mechanism of crystallization of the DC 704 fluid, but in their opinion, 
moisture is the suspected cause for oil crystallization due to a molecular alignment or orientation. The Dow Corning technical representative stated that agitation and geometry of the vessel containing the fluid may have some effects, but they are of lesser importance. The team noted that agitation as a possible factor for crystallization was addressed in Rosemount's engineering analyses, D9400078, Revision A, dated August 12, 1994, and D9400129, Revision A, dated November 22, 1994, but was not confirmed by either the experiments conducted by Rosemount or Dow Corning.

The Dow Corning technical representative stated that crystallization can be eliminated by heating the oil at or above $122^{\circ} \mathrm{F}$ for 2 hours and DC 704 fluid has a very high thermal stability and heating it to $150^{\circ} \mathrm{F}$, as Rosemount does, for an extended period of time would not cause degradation. The effects of gamma radiation on DC 704 were also discussed with the Dow Corning technical representative and he stated that polymerization would be expected to occur upon exposure to radiation in proportion to radiation dose, and that a high dose would be required to cause a noticeable change. However, the possibility of crystallization is very unlikely. The Dow Corning technical representative also stated that DC 704 fluid has high stability to radiation and formation of large polymerized molecules which could act as crystallization seeds is not very probable.

In summary, the Dow Corning technical representative indicated that the probability that a clean (filtered), conditioned DC 704 silicone oil will crystalize is very small. That is, the potential of crystallization disappears if moisture is outgassed prior to use of the DC 704 and there is no implication of any higher probability of crystallization when used in pressure transducers. The Dow Corning technical representative also stated that if there was an initiation of a fluid phase change in which the DC 704 molecules oriented themselves in a crystal lattice pattern prior to being received by the end user, such as Rosemount, the heating and outgassing at $150^{\circ} \mathrm{F}$ for 16 hours that Rosemount performs would return the fluid back to a normally stable state.

\subsection{Functional Testing of Model 1153 \& 1154 transmitters}

The team reviewed Rosemount's production test procedures and test logs. The team noted that since 1979, Rosemount has been performing functional aycle testing of its Model 1153 and 1154 pressure transmitters. The team noted that Rosemount procedures require a minimum temperature test cycle at $40^{\circ} \mathrm{F}$. The lower end $40^{\circ} \mathrm{F}$ test temperature is lower than the identified crystallization threshold temperature of $69.8^{\circ} \mathrm{F}$. The NRC team observed one of Rosemount's lower end testing activities and reviewed the test results. No anomalies were noted by the team. Rosemount has computerized its pressure transmitter test chamber program and assemblies. The program is tied into a Rosemount mainframe computer system which allows various monitoring and technical data retrieval.

\subsection{Tracking for Future Failures due to 0il Crystallization}

Rosemount, in their letter to NRC dated September 28, 1994, committed that they would send copies of their analysis to each of their customers to inform them about the potential of oil crystallization. The inspection team verified that Rosemount informed their customers and made them aware of this problem by 
their customer transmittal letters, dated December 1, 1994. In its letter to the NRC, Rosemount indicated that it intended to monitor and track future problems relating to oil crystallization. The team reviewed Rosemount's procedures for tracking identified crystallization problems and its associated failure analysis form. The team found that Rosemount's measures that it has established to track fill oil crystallization failures appeared adequate.

\subsection{Sensor Cell Manufacturer}

The team reviewed Rosemount procurement document $Q A$ requirements which were applicable to the sensor cell manufacturing activities at the Chanhassen facility and identified a concern regarding the adequacy of the quality assurance (QA) requirements that Chanhassen had applied to its sensor cell manufacturing activities. The team found that the quality requirements imposed on Chanhassen by Rosemount procurement specification NPS-01 required Chanhassen to establish and maintain a quality assurance program that complies with the requirements of NPS-01. However, Rosemount allowed an exemption to Sections 1 and 10 which dealt with QA program organization and inspection, respectively. The team also noted that Chanhassen has adopted International Standard IS0-9001, "Quality systems Model for quality assurance in design-development, production, installation and servicing," Section 4, "Organization," of which requires that inspection, test and monitoring be performed by "personnel independent of those having direct responsibility for the work being performed." Appendix B has similar requirements. Rosemount staff indicated that Chanhassen had not implemented that requirement. It was not clear to the team whether Rosemount's procurement document $Q A$ requirement exemptions took precedence over Chanhassen's quality system requirements or Appendix $B$ to 10 CFR Part 50 requirements. The inspectors will examine the basis for Rosemount's acceptance of Chanhassen's lack of implementation of independent inspection and adequacy of its overall program related to sensor cell manufacturing during a future NRC staff inspection.

Additionally, an NRC letter dated March 4, 1994, transmitting a Notice of Violation (Report 99900271/93-01), indicated that Rosemount did not establish or implement an independent $Q A$ inspection or verification function in its sensor cell and printed circuit (PC) card manufacturing areas at the Chanhassen facility. Since the current absence of independent inspection at Chanhassen may be related to lack of adequate corrective action, the NRC staff will review the adequacy of the overall QA program corrective action which Rosemount has performed. These issues are identified above as inspector follow-up item 95-0102 , and will be reviewed during a future inspection.

\subsection{Demonstration of Crystallization}

On January 23, 1995, the NRC inspectors requested Rosemount staff to demonstrate crystallization of a DC 704 oil sample and the Dow Corning Corporation recommended method of returning the DC 704 oil back to its original state. On January 24, 1995, Rosemount staff scraped a few specks of a Dow Corning provided sample of crystallized DC 704 and placed the specks in a glass bottle which contained a sample of approximately three ounces of new DC 704. The NRC inspectors placed the sample in a styrofoam container surrounded by ice cubes to reduce the temperature. Within a few minutes, crystallization started to occur and within 75 minutes the DC 704 was completely crystallized. The sample became 
solid and semi-transparent. At the end of 75 minutes, the crystallized DC 704 sample was removed from the ice bath and placed on the inspectors conference room table for approximately four hours at room temperature. The sample did not fully restore to its pre-crystallization state, but became mushy and appeared to be cloudy. Later, the sample was heated at approximately $127^{\circ} \mathrm{F}$ for 2 hours. At the end of two hours, the oil became fluid, clear and it appeared to have returned to its original state. The sample was than placed in a refrigerator overnight at a maintained temperature of approximately $43^{\circ} \mathrm{F}$. On January 25,1995 , the team noted that the sample had not returned to the crystallized state and appeared to be in its original clear fluid condition.

This demonstration indicated that the $D C 704$ fluid can be returned to its original state with as 1 ittle as two hours of approximately $127^{\circ} \mathrm{F}$ temperature and that recrystallization is not easily obtainable. Although this was only a demonstration, it would suggest that performing the Dow Corning recommendation would reduce the possibility of future crystallization.

\subsection{Conclusions}

Based on the team's review of the Rosemount procedures, manufacturing process and personal interviews with the Rosemount manufacturing and engineering staff, the NRC staff concluded that Rosemount's actions in 1980 regarding the DC 704 cautionary note adequately addressed its 10 CFR Part 21 responsibilities and its engineering basis for its Model 1153 and 1154 design low temperature operation were valid. Additionally, the team determined that Rosemount provided their customers a summary of their engineering analysis that was provided to the NRC and Rosemount had its applicable manufacturing process controls appropriately implemented. The team also concluded that Rosemount's conditioning of the DC 704 oil before its use should remove any existing seeds which could cause crystallization. Although complete immunity from crystallization may not be achievable, the information provided by Dow Corning and the Rosemount testing and industry historical data indicate that there is little probability of crystallization of DC 704 oil.

PERSONS CONTACTED

Rosemount Nuclear Instruments, Incorporated

G.D. Anderson

T. Beaudette

Stuart C. Brown

Marc Bumgarner

Ken Ewald

Tim Layer

Rob Lind

Jerry Valley

Mark Van Sloun
Nuclear QA Supervisor. Instrument Builder

Engineering Supervisor Product Design Engineer

Business Unit Manager

Marketing Manager

Manufacturing Engineer

Nuclear Q.A. Manager

Vice President and General Manager

\section{Dow Corning Corporation}

Arnold R. Huntress (by telephone)
Associate Process Consultant Materials Development 


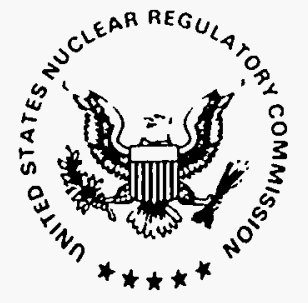

UNITED STATES

NUCLEAR REGULATORY COMMISSION

WASHINGTON. D.C. 20555-0001

June 16, 1995

Mr. Kris Weger

Senior Vice President

and General Manager

Unistrut Corporation

$35680 \mathrm{Cl}$ inton Street

Wayne, Michigan 48184

Dear Mr. Weger:

SUBJECT: NOTICE OF VIOLATION AND DEMAND FOR INFORMATION:

NRC INSPECTION REPORT 99900362/90-01 AND

REPORT OF INVESTIGATION CASE NO. 4-89-016

This letter transmits a Notice of Violation based on the results of the U.S. Nuclear Regulatory Commission (NRC) inspection of Unistrut Corporation (UC), conducted at your facility in Wayne, Michigan, on December 10-14, 1990, the inspection report, and the synops is of an investigation conducted from approximately November 1989 unt il August 1992. The NRC, as part of an ongoing scrutiny of fasteners being supplied to the nuclear industry, received information that raised concerns pertaining to safety-related basic components that UC supplied to the nuclear industry. Therefore, the NRC conducted the subject inspection and investigation.

During the inspection, the NRC staff determined that UC failed to perform the required evaluation of deviations or to inform NRC 1 icensees or purchasers so that they could perform or cause an evaluation to be performed pursuant to the provisions of Part 21 of Title 10 of the Code of Federal Requlations (10 CFR Part 21). This failure to comply constitutes a violation of NRC regulatory requirements and, therefore, we are issuing a Notice of Violatis..

(Enclosure 1). The team also identified several nonconformances related to the implementation of the UC quality program; these are discussed later in this letter. The inspection report (Enclosure 2) contains a detailed discussion of the areas examined during the inspection and our findings.

The Office of Investigations (OI) also examined those concerns, as described in the enclosed synopsis taken from OI's Report of Investigation Case No. 4-89-016 (Enclosure 3). The OI investigation and other reviews associated with UC actions have recently been completed; the enclosed inspection report and Notice of Violation are being issued herewith.

On the basis of an OI interview on June 13, 1990, with UC management (Vice President and General Manager, Production Engineering Manager, and Quality Assurance Manager), the NRC staff advised UC that certificates of conformance, issued with fasteners supplied to the nuclear industry as safety-related basic components, contained invalid certification statements. The fasteners were supplied by UC as safety-related basic components certified to comply with NRC regulatory requirements when, in fact, the fasteners were commercial-grade because UC had not dedicated them for use as basic components. As a result of 
this NRC action, on June 21, 1990, UC advised all of its authorized service centers that on June 15, 1990, UC had suspended certification of products as complying with 10 CFR Part 50, Appendix B and 10 CFR Part 21. According to UC, changes were made to its quality program and on September 26, 1990, UC advised all of its nuclear customers that its quality program (which UC asserted complied with Appendix B to 10 CFR Part 50) for safety-related metal framing products was "back on line."

Subsequent1y, in December 1990, an NRC inspection team, led by Steven M. Matthews and comprising the other inspectors named in the report, conducted the subject inspection to determine whether the products supplied to the U.S. nuclear industry actually complied with the regulatory requirements for basic components. The products were supplied with UC certificates of conformance that certified compliance with the requirements of 10 CFR Part 50 , Appendix $B$ and 10 CFR Part 21. During this inspection, the team also reviewed other areas related to UC's manufacturing and quality assurance process.

The most significant inspection finding, as described in the enclosed Notice of Violation, was the failure of UC to perform the required evaluation of deviations or to inform licensees or purchasers so they could perform or cause an evaluation to be performed pursuant to the provisions of 10 CFR Part 21. The team reviewed a number of purchase orders (POS) for fasteners, issued to UC from 1 icensees, which imposed on UC the requirements of 10 CFR Part 50, Appendix $B$ and 10 CFR Part 21. UC supplied those customers with fasteners which bore certificates of conformance that certified compliance with the licensees $P O$ requirements.

UC advised the team during the inspection that in October 1990, UC met several times with its sole fastener supplier, General Fastener Company (GF) of Livonia, Michigan, to discuss the capability of GF to supply UC safety-related fasteners that comply with NRC requirements. On October 26, 1990, GF decided that it could not supply fasteners to UC certified as safety related because, according to GF, it did not have, nor had it ever had, a quality program that complied with 10 CFR Part 50 , Appendix $B$. UC subsequently decided it could not continue to supply fasteners to the nuclear industry that would be certified to comply with NRC requirements for safety-related basic components.

Although UC stated during the inspection that it had not supplied fasteners certified as safety related to the nuclear industry since 0ctober 26, 1990, UC had also neither informed 1 icensees of this decision nor rescinded its letter of September 26, 1990. Moreover, as of December 14, 1990, UC had neither evaluated its departure from the technical requirements of the 1icensee POS for the fasteners supplied before October 26, 1990, nor had UC informed licensees or purchasers of the deviations. This situation constituted a violation of NRC requirements and, furthermore, demonstrated UC's apparent lack of regard for NRC requirements.

You should be aware that the NRC considers a willful violation to be a significant regulatory concern. Following the events described above, the NRC issued the regulation in 10 CFR 50.5 that provides for enforcement actions 
against any individual who, through deliberate misconduct, places or could have placed an NRC licensee in violation of NRC requirements. You should be aware that, should you engage in deliberate misconduct in the future, you may be subject to individual enforcement action pursuant to 10 CFR 50.5.

He have since observed that, even though you stated during the inspection that UC had not supplied fasteners certified as safety related to the nuclear industry since October 26, 1990, UC was 7 isted under the headings "Products and Services" (including the categories of bolts, cable tray hangers and supports, fasteners, fittings, nuts, pipe hangers, and studs) and "Suppliers," in addition, a full-page advertisement on page 18 in the October 1991 issue of Nuclear Plant Journal, Volume 9, No. 6, and under the same headings and categories, UC continues to be listed in the November 1994 issue, Volume 12, No. 6. Therefore, further information is needed to enable us to determine if there is reasonable assurance that UC is conducting these activities under NRC jurisdiction in accordance with NRC requirements. Accordingly, pursuant to Sections 161c and 1610 of the Atomic Energy Act of 1954, as amended; Section 206(d) of the Energy Reorganization Act of 1974, as amended; and 10 CFR 2.204, you are required to

(1) Inform the NRC whether or not UC has reentered the business of supplying basic components as defined in 10 CFR Part 21 for any period of time since October 26, 1990, and if it has, give the extent and nature of such business activity, including the dates of such activity.

(2) If UC has supplied basic components as defined in 10 CFR Part 21 since October 26, 1990, submit a detailed explanation of the actions taken to ensure that the basic components comply with NRC requirements; include an explanation of UC compensatory actions taken to correct the invalid certificates of conformance issued before October 26, 1990, as described above.

(3) If UC has not supplied basic components pursuant to 10 CFR Part 21 since October 26, 1990, submit a one-time. written notice at least 30 days before it resumes such activities to the U.S. Nuclear Regulatory Commission, ATTN: Document Control Desk, Washington, D.C. 20555-0001 with a copy to the Chief, Special Inspection Branch, Division of Technical Support, Office of Nuclear Reactor Regulation, U.S. Nuclear Regulatory Commission, Washington, D.C. 20555-0001.

(4) If UC does not agree to submit the notice specified in (3) above, it should so state and provide the basis for not submitting the notice.

You are required to respond to this Demand for Information in accordance with 10 CFR 2.204 within 30 days of the date of this letter.

In accordance with the "General Statement of Policy and Procedures for NRC Enforcement Actions," 10 CFR Part 2, Appendix C (1990), Violation 90-01-01 described in the enclosed Notice of Violation has been classified as a Severity Level III violation (Supplement VII, Subsection C.5) because UC 
failed to evaluate its departure from the technical requirements of the licensee POS, such that, if an appropriate evaluation had been made as required, a 10 CFR Part 21 report would have been made.

Even though other violations related to 10 CFR Part 21 were noted by the team in Report 99900362/90-01, only violation 90-01-01 is cited in the Notice of Violation for the following reasons:

(1) The NRC has adequately addressed the safety issues through its issuance, on April 1, 1991, of Information Notice 91-25, "Commercial-Grade Structural Framing Components Supplied As Nuclear Safety-Related Equipment."

(2) The actions of UC preceded the NRC issuing guidance on commercial-grade dedication in Generic Letter 91-05, "Licensee Commercial-Grade Procurement and Dedication Programs," on April 9, 1991.

(j) Neither the OI investigation nor the ARC inspection of UC documented in Report 99900362/90-01 identified any substandard fasteners.

(4) Compared to the safety significance of the violation cited in the Notice of Violation, the other violations had relatively lower safety significance, and we believe, little purpose would be served in this case by citing the less significant violations.

During this inspection, the team also found that other elements of your quality program did not meet NRC requirements and resulted in the identification of several nonconformances described in Report 99900362/90-01. The inspection identified that, contrary to the requirements of $10 \mathrm{CFR}$ Part 50, Appendix $B$, UC had not established adequate measures to control the dedication of commercial-grade material. As a result, commercial-grade products were supplied to the nuclear industry as safety-related basic components and were certified by UC as complying with 10 CFR Part 50, Appendix $B$ and 10 CFR Part 21. The specific findings and references to the pertinent requirements for all nonconformances are described in the enclosed inspection report.

A notice of nonconformance for the findings is not being issued for the same reasons described above for issuing only Violation 90-01-01. Additionally, the staff recognizes that at the time of this inspection neither NRC licensees nor their suppliers had a clear understanding of commercial-grade dedication. However, if UC has resumed business with the nuclear industry pursuant to 10 CFR Part 21, the staff expects UC to carefully review the information in the enclosed inspection report and take actions, as appropriate, to correct the nonconformances identified and to prevent recurrence and, as part of the response required below, provide a summary of your corrective actions taken.

You are required to respond to this Notice of Violation within 30 days of the date of this letter by filing a written response under oath and affirmation. You should follow the instructions specified in the enclosed Notice of 

K. Weger
$-5-$

Violation when preparing your response. In addition to the instructions specified in the enclosed Notice of Violation, send copies of your response, at the same address, to the Director, Office of Enforcement, and to the Assistant General Counsel for Hearings and Enforcement.

After reviewing your responses to the Demand for Information and Notice of Violation, including your proposed corrective actions, the staff will determine whether further action is necessary to ensure compliance with NRC regulatory requirements.

In accordance with 10 CFR 2.790(a) of the NRC "Rules of Practice," a copy of this letter and its enclosures will be placed in the NRC Public Document Room. The responses directed by this letter and its enclosures are not subject to the clearance procedures of the Office of Management and Budget as required by the Paperwork Reduction Act of 1980, Public Law No. 96-511.

Should you have any questions concerning this action, we will be pleased to discuss them with you.

$$
\text { Sincerely, }
$$

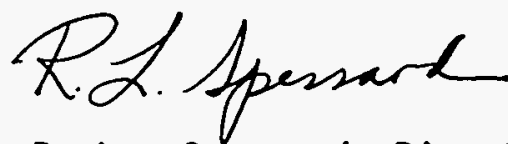

R. Lee Spessard, Director

Division of Technical Support

Office of Nuclear Reactor Regulation

Docket No. 99900362

EA-91-020

Enclosures:

1. Notice of Violation

2. Report No. $99900362 / 90-01$

3. Synopsis: Report of Investigation Case No. 4-89-016 


\section{NOTICE OF VIOLATION}

Unistrut Corporation

Hayne, Michigan
Docket No. 99900362

Report No. 90-01

EA-91-020

During an NRC inspection conducted on December 10-14, 1990, violations of NRC requirements were identified. In accordance with the "General Statements of Policy and Procedures for NRC Enforcement Actions," 10 CFR Part 2, Appendix C (1990), the most significant violation is listed below:

Section 21.21, "Notification of failure to comply or existence of a defect," of 10 CFR Part 21 (in effect at the time of this inspection), Subsection (a) (1) required, in part, that each individual, corporation or other entity subject to the regulations adopt appropriate procedures for either evaluating deviations or informing the licensee or purchaser of the deviation.

Contrary to the above, two examples were identified in which Unistrut Corporation (UC), an entity subject to 10 CFR Part 21 , failed to perform an evaluation of a deviation (i.e., a departure from the technical requirements included in a procurement document), or inform 7 icensees or purchasers so they could cause an evaluation to be performed.

Specifically, in the following instances, UC procured commercial-grade fasteners from the General Fastener Company (GF) of Livonia, Michigan and, without dedicating the commercial-grade fasteners for use as basic components, supplied them to the nuclear industry as safety-related basic components, issuing certificates of conformance to NRC licensees which certified that the fasteners complied with NRC regulatory requirements.

(90-01-01)

(1) For Gulf States Utilities Company, River Bend Station purchase order (P0) 89-4-77172, dated August 25, 1989, issued to UC for safety-related ASTM A307, Grade A, galvanized, hex head bolts, 3/8-inch-16 x 2-1/2 inch that imposed on UC the requirements of 10 CFR Part 50, Appendix $B$ and 10 CFR Part 21; UC supplied River Bend Station with commercial-grade hex head bolts (since UC did not dedicate the fasteners) and a certificate of conformance dated October 5, 1989, which certified that the fasteners met the requirements of the licensee PO, 10 CFR Part 50, Appendix $B$ and 10 CFR Part 21.

(2) For Consumers Power Company, Palisades Plant, Bechtel Constructors Corporation issued PO 20557-F1020-Q to UC for safety-related ASTM A307, grade $A$, hex head cap screws, 3/8-inch-16 $\times 3 / 4-$ inch that imposed on UC the requirements of 10 CFR Part 50, Appendix $B$ and 10 CFR Part 21; UC supplied Bechtel Constructors Corporation--Palisades Plant with commercial-grade hex head cap screws (since UC did not dedicate the fasteners) and a certificate of conformance dated October 4, 1990, which certified that the fasteners met the requirements of the licensee P0, 10 CFR Part 50, Appendix B and 10 CFR Part 21. 
These instances have been classified as a Severity Level III Violation (Supplement VII).

Pursuant to the provisions of 10 CFR 2.201, UC is hereby required to submit a written statement or explanation to the U.S. Nuclear Regulatory Commission, ATTN: Document Control Desk, Washington, D.C. 20555-0001 with a copy to the Chief, Special Inspection Branch, Division of Technical Support, Office of Nuclear Reactor Regulation, within 30 days of the date of the letter transmitting this Notice of Violation. This repiy should be clearly marked as a "Reply to Notice of Violation" and should include for the violation (a) the reason for the violation, or, if contested, the basis for disputing the violation; (b) the corrective steps that have been taken and the results achieved; (c) the corrective steps that will be taken to avoid further violations; and (d) the date when full compliance will be achieved. Your response may reference or include previous docketed correspondence if the correspondence adequately addresses the required response. Where good cause is shown, consideration will be given to extending the response time. Under the authority of Section 182 of the Act, 42 U.S.C. 2232, this response shall be submitted under oath or affirmation.

Dated at Rockville, Maryland this 16th day of June, 1995 
ORGANIZATION: UNISTRUT CORPORATION

WAYNE, MICHIGAN

REPORT

NO.: $99900362 / 90-01$

INSPECTION

INSPECTION

DATE: DECEMBER $10-14,1990$

ON-SITE HOURS: 93

$\begin{aligned} \text { CORRESPONDENCE ADDRESS: } & \text { Unistrut Corporation } \\ & 35660 \text { Clinton St. } \\ & \text { Wayne, Michigan } 48184\end{aligned}$

ORGANIZATIONAL CONTACT: Kris Weger, Vice President and General Manager

TELEPHONE NUMBER:

(313) $721-4040$

NUCLEAR INDUSTRY ACTIVITY: Unistrut Corporation (UC) is a manufacturer/supplier of continuous slotted metal channel products, general fittings, fasteners, and mechanical accessories used to create structural framing systems. These structural framing systems are supplied as safety-related components and are used to support safety-related pipes, duct work, cable trays, and conduit. Approximately 10 percent of UC's business is with the nuclear industry.

ASSIGNED INSPECTOR:

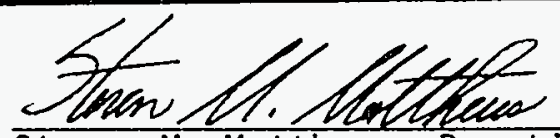

Steven M. Matthews, Reactive Inspection Section Date No. 1 (RIS-1) Vendor Inspection Branch (VIB)

OTHER INSPECTOR(S): Ann M. Fitzgerald, NRC Stewart L-: Magruder, NRC

APPROVED BY:

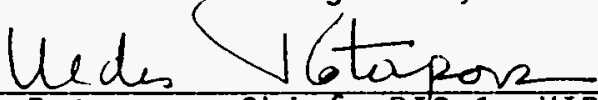
UTdis Potapovs, Chief, RIS-1, VIB $\frac{2-19-91}{\text { Date }}$

\section{INSPECTION BASES AND SCOPE:}

A. BASES: 10 CFR Part 50, Appendix B and 10 CFR Part 21

B. SCOPE: To assess the UC quality program and its implementation in selected areas such as: control of procurement; design control; and control of purchased material, equipment and services.

PLANT SITE APPLICABILITY: All nuclear power plants with UC products. 
REPORT

NO.: $999000362 / 90-01$

INSPECTION

RESULTS:

PAGE 2 of 27

A. VIOLATIONS:

1. Contrary to Section 21.21, "Notification of Failure to Comply or Existence of a Defect," of 10 CFR, two examples were identified where UC failed to perform an evaluation or to notify the licensees or purchasers so they could perform or cause an evaluation to be performed regarding commercial-grade fasteners supplied to the nuclear industry as safety-related with Certificates of Conformance (C of C) that certify compliance with regulatory requirements. (90-01-01)

a. UC supplied commercial-grade fasteners to the River Bend Nuclear Station with a $C$ of $C$ which certified compliance with the licensee's PO, Appendix B to 10 CFR Part 50, and 10 CFR Part 21.

b. UC supplied commercial-grade fasteners to the Palisades Nuclear Plant with $C$ of $C$ which certified compliance with the licensee's PO, Appendix B to 10 CFR Part 50, and 10 CFR Part 21.

2. Contrary to Section 21.31, "Procurement Documents," of 10 CFR, a review of documentation packages revealed two examples where UC issued purchase orders (POS) to suppliers for safety-related components and failed to invoke the requirements of 10 CFR Part 21 on the POs. $(90-01-02)$
a. UC failed to invoke the requirements of 10 CFR Part 21 on P0 No. P-03779, October 4, 1990, issued for safety-related fasteners.

b. UC failed to invoke the requirements of 10 CFR Part 21 on PO No. P-03791, October 8, 1990, issued for safety-related fasteners.

3. Contrary to Section 21.21, "Notification of Failure to Comply or Existence of a Defect," of 10 CFR, UC procedure in Section F, "10 CFR Part 21 Reporting of Defects and Non-Compliance," of the Unistrut Diversified Products Quality Assurance Manual (QAM), Revision No. 3, September 4, 1990, did not (1) define the term "potential reportable events;" therefore, UC staff did not know what conditions to report to their supervisors; (2) ensure the evaluation of deviations or departures from the technical requirements included in procurement documents; and (3) describe the process or bases of performing evaluations for reporting defects to the Nuclear Regulatory Conmission (NRC) or notifying customers of deviations. (90-01-03) 
ORGANIZATION:

UNISTRUT CORPORATION

WAYNE, MICHIGAN

REPORT

NO.: $999000362 / 90-G 1$

INSPECTION

RESLLTS:

PAGE 3 of 27

B. NONCONFORMANCES:

1. Contrary to Criterion II, "Quality Assurance Program," of Appendix B to 10 CFR Part 50, and Section II, "Quality Assurance Program," of the QAM, the NRC inspectors reviewed certain sections of the UC QAM and determined that UC failed to establish and implement a program, for the quality criteria reviewed, that included those planned and systematic actions necessary to provide adequate confidence that basic components such as structural framing channel, fasteners, general fittings, and mechanical accessuries will perform their safety-related function. Specifically, UC failed to prescribe the following:

(1) the controls necessary for the completion of internal audit

corrective actions to assure the quality of impacted products; (2) the quality requirements to be imposed in POs to vendors of safety-related products; (3) the controls necessary to assure that UC supplied materials met licensee-imposed material specifications; and (4) the criteria used by UC to review the licensees' POs to establish acceptance of the order and to ensure UC's compliance with the quality and technical requirements of the licensees' P0s. (90-01-04)

2. Contrary to Criterion II, "Quality Assurance Program," of Appendix B to 10 CFR Part 50, UC failed to establish and implement a program, before November 1990 to provide for the indoctrination and training of personnel performing activities affecting quality in the requirements of 10 CFR Part 21 and Appendix B to 10 CFR Part 50. This is another occurrence of Nonconformances 86-01-08 and 86-01-09, identified by the NRC during the previous inspection and documented in Inspection Report (IR) No. 99900362/86-01. (90-01-05)

3. Contrary to Criterion III, "Design Control," of Appendix B to 10 CFR Part 50, UC failed in Section III, "Design Contro1," of the UC QAM, and Quality Assurance Procedure (QAP) No. 20-01-038, "Commercial-grade Dedication Program," Revision No. 0, September 4, 1990, to establish adequate measures for the dedication of commercial-grade materials that were supplied to the nuclear industry as safety-related. Specifically, UC (1) had not established an adequate basis for accepting the material certifications from its suppliers; (2) did not verify the chemical and physical properties of coil material by performing chemical and physical tests; (3) until recently, UC did not maintain traceability on material in the press shop; (4) did not perform testing traceable to each coil of material used in the fabrication of channel products; and (5) except for channel nuts and 
REPORT

90-degree angle fittings, did not perform any testing on products produced in the press shop. Therefore, UC supplied inadequately dedicated parts such as structural framing channel, channel nuts, screws, nuts, washers, general fittings, and mechanical accessories as safety-related components to the nuclear industry. (90-01-06)

4. Contrary to Criterion III, "Design Control," and Criterion IV, "Procurement Document Control," of Appendix B to 10 CFR Part 50, UC's requirements in Section III, "Design Control," and Section IV, "Procurement Document Control," of the UC QAM and QAP No. 20-01-010, "Control of Purchased Materials, Products, and Services," Revision No. 4, November 9, 1990, failed to establish measures to ensure that regulatory requirements imposed in licensees' POs are established and translated into documents that ensure adequate quality is achieved. Moreover, UC failed to ensure that compliance to imposed regulatory requirements had been achieved before issuing $C$ of $C$ that certified compliance. This condition led UC to make unsubstantiated certification staterients ull $C$ it $C$ issued to licensees. Specifically, UC routinely failed to perform the following: (1) control the receipt and review of POs from licensees in order to establish the requirements imposed on UC; (2) establish measures necessary to translate the requirements imposed in POS from licensees into specifications or procedures; (3) assure compliance to the requirements imposed in POS from licensees prior to issuing $C$ of $C$ that certified compliance; (4) verify UC's compliance prior to revising previously issued $C$ of $C$; and (5) impose 10 CFR Part 50, Appendix B or similar quality requirements in POs to suppliers of safety-related fasteners. (90-01-07)

5. Contrary to Criterion VII, "Control of Purchased Material, Equipment and Services," of Appendix B to 10 CFR Part 50, UC's requirements in Section VII, "Control of Purchased Materials and Services," of the UC QAM and QAP No. 20-01-007, "Vendor Qualifications and Audit Requirements," Revision No. 3, August 1, 1990, failed to establish adequate measures to assess and document the effectiveness of the quality programs of vendors supplying materials and services. Specifically, the UC audits failed to discover that the quality program of their fastener suppiier did not meet 10 CFR Part 50, Appendix B requirements. In addition, UC did not audit their commercial-grade suppliers of steel coil material, which furnished material certifications used by UC in the conmercial-grade dedication process. This is another occurrence of Nonconformance 86-01-05, identified by the NRC during the previous irspecioion and documented in IR No. 99900362/86-01. (90-01-08) 
ORGANIZATION: $\quad$ UNISTRUT CORPORATION

WAYNE, MICHIGAN

REPORT

NO.: $\quad 999000362 / 90-01$

INSPECTION

RESULTS:

PAGE 5 of 27

C. UNRESOLVED ITEMS:

NONE

D. STATUS OF PREVIOUS INSPECTION FINDINGS:

1. (CLOSED) Violation 86-01-01

Contrary to 10 CFR 21.6, UC did not post 10 CFR Part 21 procedures for the evaluation of deviations, Section 206 of the Energy Reorganization Act of 1974, and the regulations of 10 CFR Part 21.

The NRC inspectors determined that UC had properly posted the required documents and that corrective actions taken to prevent recurrence were adequate.

\section{2. (CLOSED) Violation 86-01-02}

Contrary to 10 CFR 21.21, UC's procedure, "Processing of Reportable Events," did not specify or identify a time limit for notification or method of notifying the NRC of a defect.

The NRC inspectors determined that UC's corrective actions taken to prevent recurrence were inadequate. Violation 90-01-03, identifies additional examples where UC failed to establish adequate procedures for the evaluation of deviations. This previous inspection finding will now be tracked under Violation 90-01-03.

3. (CLOSED) Violation 86-01-03

Contrary to 10 CFR 21.31, UC failed to impose the requirements of 10 CFR Part 21 in POs to suppliers of safety-related materials and services.

The NRC inspectors determined that UC's corrective actions taken to prevent recurrence were inadequate. Violation 90-01-02, identifies additional examples where UC issued safety-related POs to niaterial suppliers and failed to imposed the requirements of 10 CFR Part 21. This previous inspection finding will now be tracked under Violation 90-01-02.

\section{4. (CLOSED) Nonconformance 86-01-04}

Contrary to Criterion $V$ of 10 CFR Part 50, Appendix B and QAP No. 20-01-003, "Receiving Inspection of Customer Returned Material," of the QAPM, UC failed to properiy segregate rejected material. 
ORGANIZATION:

REPORT

NO.: $999000362 / 90-01$

INSPECTION

RESULTS:

PAGE 6 of 27

The NRC inspectors reviewed the control of rejected material identification and segregation during a plant tour and determined that the corrective actions taken to prevent recurrence were adequate.

5. (OPEN) Nonconformance 86-01-05

Contrary to Criterion $V$ of 10 CFR Part 50, Appendix B and Section XIX, "Audits," of the QAM, UC failed to perform external audits of certain vendors.

The NRC inspectors determined that external vendor audits are currently performed at scheduled intervals. However, other concerns were raised regarding the adequacy and completeness of vendor audits, which are discussed in Section E.8.0 of this report and identified as Nonconformance 90-01-08.

\section{6. (CLOSED) Nonconformance 86-01-06}

Contrary to Criterion V of 10 CFR Part 50, Appendix B and Section XIX, "Audits," of the QAM, UC failed to perform required internal audits according to schedule.

The NRC inspectors determined that internal audits are currently perforned at scheduled intervals and that the corrective actions taken to prevent recurrence were adequate.

\section{7. (CLOSED) Nonconformance 86-01-07}

Contrary to Sriterion $V$ of 10 CFR Part 50, Appendix B and Section XII, "Test Control," of the QAM, and QAP No. 20-01-031, "Qualification of NDE (PT) Personnel," of the QAPM, UC failed to document objective evidence of the annual eye examination for an NDE Level II and a Level III examiner.

The NRC inspectors found that QAP No. 20-01-031, as described above, had been deleted from the UC QAPM and Section IX, "Control of Special Processes," of the QAM did not address nondestructive examinations. UC decided that the requirements for NDE examinations were no longer necessary and the quality program had been revised accordingly. The NRC inspectors determined that the corrective actions taken were adequate.

\section{8. (OPEN) Nonconformance 86-01-08}

Contrary to Criterion $V$ of 10 CFR Part 50, Appendix B and QAP No. 20-01-024, "Quality Personnel Selection and Training," of the QAPM, UC failed to 
REPORT

document objective evidence of the indoctrination and training of a UC inspector or maintain complete qualification files for other UC inspectors.

The NRC inspectors determined that the corrective actions taken to prevent recurrence regarding indoctrination ard craining of personnel was inadequate, as evidenced by Nonconformance 90-01-05, which identifies other inadequacies regarding indoctrination and training described in Section E.5.0 of this report.

\section{9. (OPEN) Nonconformance 86-01-09}

Contrary to Criterion $V$ of 10 CFR Part 50, Appendix B and QAP No. 20-01-030, "Auditor Qualifications," of the QAPM, UC fajled to document objective evidence of communication: skills, attendarice at an audit training course, and fulfiiling audit participation requirements for several lead auditors.

The NRC inspectors determined that corrective actions taken to prevent recurrence regarding indoctrination and training of lead auditors was inadequate, as evidenced by Nonconformance 90-01-05, which identifies other iriadequacies regardirg incioctrination and training described in Section E.5.0 of this report.

\section{E. INSPECTION FINDINGS AND OTHER COMMENTS:}

\subsection{Entrance and Exit Meetings}

The Nuclear Regulatury Commission (NRC) inspectors informed UC staff of the scupe of the inspection, outlined areas of concern, and established working interfaces during the entrance meeting on December 10, 1990. On December 14, 1990, the NRC inspectors summarized the inspection findings, observations, and concerns to UC management during the exit meeting.

\subsection{Background}

UC manufactures safety-related continuous slotted metal channel products used to create many different structural framing systems to support safety-related items. These systems are supplied through a network of nationwide Authorized Service Centers, which are either owned and operated by UC or inciependently owned. The framing systems supplied to the nuclear industry consist generally of $1-5 / \varepsilon$ inch width channel, channel nuts, fasteners, fittings, and pipe clamps. These are used to support safetyrelated components such as pipes, duct work, cable trays, and conduit. 
REPORT

UC has been supplying structural framing products to the nuclear industry since 1975, however, UC staff claimed that they have not always certified their products as safety-related. Determining the initial date certification to 10 CFR Part 50, Appendix B and 10 CFR Part 21 began was of interest to the NRC inspectors. UC staff told the NRC inspectors that based on UC's review, it had determined that UC first began issuing $C$ of $C s$ to the requirements of 10 CFR Part 21 and Appendix B to 10 CFR Part 50 in August 1988. The NRC inspectors, however, identified safety-related POs in July and September of 1982 with UC C of Cs that certified compliance with the customer's PO, which imposed 10 CFR Part 21 and 10 CFR Part 50, Appendix B. This issue is discussed in more detail in Section E.7.0 of this report.

\subsection{Inspection of 10 CFR Part 21 Compliance}

During an interview with UC's Vice President and General Manager, Production Engineering Manager, and Quality Assurance Manager conducted by NRC staff on Jurie 13, 1990, UC was made aware, by NRC staff, that it had supplied safety-related fasteners to the nuclear industry with invalid $C$ of C's certifying that the safety-related fasteners supplied met the requirements of 10 CFR Part 21 and Appendix B to 10 CFR Part 50. As a result, on June 21, 1990, UC advised a 11 UC Authorized Service Centers that on June 15, 1990, UC had suspended certificarion of products as complying with Appendix B to 10 CFR Part 50 and 10 CFR Part 21. After making changes to the UC QAM and QAPM, UC advised a 11 nuclear customers on September 26, 1990, that UC's 10 CFR Part 50, Appendix B program for safety-related metal framing products was, "back on line."

UC held several meetings with their only fastener supplier, General Fastener Co. (GF) of Livonia, Michigan, in October 1990 to discuss GF's ability to supply safety-related fasteners that fully comply with NRC requirements. On October 26,1990 , GF decided that it could not supply safety-related fasteners because it did not have, nor had it ever had, a quality program that complied with 10 CFR Part 50, Appendix B or 10 CFR Part 21. UC subsequently decided it could not continue to supply safetyrelated fasteners to the nuclear industry in compliance with NRC requirements. As of December 14, 1990, UC had not notified licensees of this decision or rescinded the letter of September 26, 1990. UC has not supplied fasteners, certified as safety-related, to the nuclear industry since October 26, 1990.

The NRC inspectors reviewed UC's implementation of and compliance with 10 CFR Part 21 requirements for 1 icensees' procurement of basic components. During this review three violations of NRC requirements were identified. The violations are discussed separately as follows. 
ORGANIZATION: $\quad$ UNISTRUT CORPORATION

WAYNE, MICHIGAN

REPORT

NO.: $999000362 / 90-01$

INSPECTION

RESULTS:

PAGE 9 of 27

\subsection{Evaluation and Notification of Deviations}

The following two examples were identified where UC was aware of a departure from the technical requirements of licensees' safety-related POs and failed to either evaluate the deviation or inform the licensee or purchaser of the deviation so they could perform or cause an evaluation to be performed. As a result, Violation (90-01-01) was identified in this area of inspection.

a. Gulf States Utilities Co. issued P0 No. 89-4-77172, August 25, 1989, for safety-related ASTM A307, grade A, galvanized, hex head bolts, $3 / 8$ inch - $16 \times 2-1 / 2$ inch, with special head marking symbol "U", to supply the River Bend Nuclear Station and imposed the requirements of Appendix B to 10 CFR Part 50 and 10 CFR Part 21. UC purchased the bolts from GF with PO No. P-02694, September 18, 1989, as commercial-grade. UC'S PO No. P-02694 to GF changed the licensee's procuremerit liaterial specifications and ordered SAE-J429, grade 2, hex head cap screws with the special head marking.

GF has been UC's only supplier of fasteners and UC staff told the NRC inspectors that the requirements of Appendix B to 10 CFR Part 50 and 10 CFR Part 21 were not imposed in the PO to GF because UC had developed an understanding with GF that all fasteners supplied by GF were nuclear safety-related. The relationship and bases for the understandings between UC and GF are discussed in Section E.8.0 of this report.

The NRC inspectors determined, through interviews with GF staff, that with regard to supplying fasteriers to UC, GF did not, as of December 12 , 1990, nor has it ever had a quality program that it believed complied with the NRC requirements in 10 CFR Part 50, Appendix B or 10 CFR Part 21.

GF issued a C of C of September 20, 1989, to UC certifying that the products met the requirements specified in PO No. P-02694. UC did not dedicate the bolts, that are in fact commercial-grade, prior to certifying them as meeting the requirements of Gulf States Utilities Co.'s PO, 10 CFR Part 21, and Appendix B to 10 CFR Part 50, as stated on the UC C of $C$ of October 5, 1989. UC certified that the fasteners met the licensee's required specification, ASTM A307, grade A, even though UC ordered them to $S A E-J 429$, grade 2, and received the fasteners from GF with a $C$ of $C$ that they met $S A E-J 429$, grade 2 . UC had never performed a commercial-grade dedication of the fasteners purchased from GF. 
REPORT

The NRC inspectors requested UC's evaluation of this deviation to determine (1) when GF began supplying commercial-grade fasteners that UC believed to have been supplied as safety-related; (2) which licensees' POs are impacted by this condition; and (3) which licensees or purchasers must be notified of the deviation. As of December 14, 1990, UC had not performed an evaluation of the deviation, which it was made aware of on June 13, 1990, or informed licensees or purchasers of the deviation so they could perform or cause an evaluation to be performed.

b. Bechtel Constructors Corp. issued PO No. 20557-F1020-Q to UC for safety-related ASTM A307, grade $A$, hex head bolts, 3/8- $16 \times 3 / 4$ inch, and $3 / 8$ inch flat washers. The PO was issued to supply the Palisades Nuclear Plant and imposed the requirements of 10 CFR Part 21 and $10 \mathrm{CFR}$ Part 50, Appendix B. UC purchased the items from GF with PO No. P-03779, October 4, 1990.

UC ordered the items from GF using an "N" prefix to their standard catalog number which, UC claims, designates the items as nuclear safety-related. UC staff told the NRC inspectors that GF knew that the new "N" prefix, introduced by UC in September 1990, indicated that the fasteners were designated as nuclear safety-related. UC'S PO No. P-03779 to GF did not impose the requirements of 10 CFR Part 21 , Appendix $B$ to 10 CFR Part 50 , or any other quality requirements. UC'S PO No. P-03779 to GF changed the licensee's procurement material specificatiuns and ordered SAE-J429, grade 2 , hex head cap screws.

GF issued $C$ of $C$ of October 9,1990 , to UC certifying that the fasteners for PO No. P-03779 complied with UC'S PO, the mater:-? ipecification SAE-J429, grade 2, and a quality program which conforms to ANSI N45.2 and 10 CFR Part 50, Appendix $B$ and that 10 CFR Part 21 applied to this order. UC then issued $C$ of $C$ to Bechtel Constructors Corp. on October 10, 1990, certifying that the fasteners met ASTM A307, grade A, and were processed in accordance with the purchaser's P0, ANSI N45.2, Appendix $B$ to $10 \mathrm{CFR}$ Part 50, and that $10 \mathrm{CFR}$ Part 21 applied to this order.

GF subsequently advised UC on 0ctober 26,1990 , that in fact, GF's $C$ of $C$ of October 9, 1990, were not valid because the fasteners were not processed in accordance with Appendix B to 10 CFR Part 50 and that 10 CFR Part 21 requirements were not applied to this order. Since UC did not perform a commercial-grade dedication of these items, the UC C of $C$ of October 10, 1990, issued to Bechtel Constructors Corp. were not valid. 
ORGANIZATION: $\quad$ UNISTRUT CORPORATION

WAYNE, MICHIGAN

REPORT

N0.: $999000362 / 90-01$

INSPECTION

RESULTS:

PAGE 11 of 27

The NRC inspectors requested UC's evaluation of the deviation or evidence that Bechtel Constructors Corp. had been notified of the deviation. As of December 14,1990, UC had not performed an evaluation of the deviation, which it was made aware of on 0ctober 26 , 1990 , or informed the purchaser of the deviation so they could perform or cause an evaluation to be performed.

\subsection{Procurement Documents Incorporation of 10 CFR Part 21}

The inspectors reviewed UC's implementation of Section 21.31, "Procurement Documents," of 10 CFR and found two examples where UC POS to a supplier of safety-related components did not specify that 10 CFR Part 21 would apply. As a result, Violation (90-01-02) was identified in this area of inspection.

a. On October 4, 1990, UC issued PO No. P-03779 to GF for part No. NHCS037075, $3 / 8$ inch - $16 \times 3 / 4$ inch, hex head cap screws, per ANSI B18.2.1, SAE-J429, grade 2, and part No. NFLW037 EL, $3 / 8$ inch flat washers, type A plain (wide) per ASTM F944-83, and ANSI B18.22.1-81. The new " $N$ " prefix to the UC part No. designates the parts as nuclear safety-related items. These fasteners were supplied to the Palisades Nuclear Plant. UC did not invoke the requirements of 10 CFR Part 21 and 10 CFR Part 50, Appendix B in the safety-related order to GF.

b. On October 8, 1990, UC issued PO No. P-03791 to GF for part No. NHCSO50125, 1/2 inch - $13 \times 1-1 / 4$ inch, hex head cap screws, per ANSI B18.2.1, SAE-J429, grade 2. The "N" prefix to the UC part No. designates the parts as nuclear safety-related items. UC did not invoke the requirements of 10 CFR Part 21 and 10 CFR Part 50, Appendix $B$ in the safety-related order to GF.

\subsection{CFR Part 21 Procedures Implementation}

The inspectors reviewed Section $F$ of the Unistrut Diversified Products Quality Assurance Manual (QAM) Revision No. 3, September 4, 1990. Section F, "10 CFR Part 21 Reporting of Defects and Non-Compliance," of the QAM is the UC procedure that implements the requirements of Section 206 of the Energy Reorganization Act of 1974 and Section 21.21, "Notification of Failure to Comply or Existence of a Defect," of 10 CFR. This review concluded that Section F of the UC QAM failed to comply with the requirements of Section 21.21 of 10 CFR as described below. As a result, Violation (90-01-03) was identified in this area of the inspection. 
REPORT

NO.: $999000362 / 90-01$
INSPECTION

RESULTS:

a. Section $F$ requires that all employees should notify their immediate supervisor of, "potential reportable events." However, Section F did not define what constitutes a "potential reportable event" nor did UC provide training for employees that defined the term. Therefore, employees did not know what conditions to report to their immediate supervisors.

b. Section $F$ failed to ensure the evaluation of deviations or departures from the technical requirements included in procurement documents.

c. Section $F$ failed to prescribe the process or bases of performing evaluations for reporting defects to the NRC or notifying custcmers of deviations.

\subsection{Inspection of 10 CFR Part 50, Appendix B, Compliance}

This area of the inspection focused on UC'S QAM and QAPM. UC established the QAM and QAPM to meet the quality assurance criteria requirements of 10 CFR Part 50, Appendix B for safety-related components such as structural framing charinel, channel nuts, screws, nuts, washers, general fittings, and mechanical accessories supplied to the nuclear industry. Implementation of the UC QAM is supplemented by the QAPM. The NRC inspectors reviewed only certain sections of the QAM and QAPM. The review was conducted to determine whether or not UC had established and implemented a program, for the quality criteria reviewed, that comprises all those planned and systematic actions necessary to provide adequate confidence that components supplied to the nuclear industry will perform satisfactorily in service.

The QAM sections reviewed prescribe only generalized responsibilities and purposes and did not prescribe details of a quality program that adequately established measures that comply with NRC requirements. The NRC inspectors determined from this review that the sections of the QAM, as supplemented by the QAPM, did not adequately establish those planned and systematic actions necessary to assure the safety and reliability of the components and identified the following examples.

a. The QAM requires in Section II, "Quality Assurance Program," paragraph 2.7, that the status and adequacy of this program will be determined through the review of internal audits, and Section XVIII, "Internal/ External Audits," paragraph 18.4 provides for the completion of corrective action requested within a reasonable time, and QAP No. 20-01-027, "Internal Audits," Revision No. 1, July 6, 1987, also provides for the completion of corrective action requested within a 
REPORT

NO.: $999000362 / 90-01$

reasonable time. The QAM and its supplements did not adequately prescribe controls for the completion of internal audit corrective actions that are necessary to assure that the adequacy of the quality of safety-related products, impacted by the corrective actions, is achieved.

b. The QAM requires in Section IV, "Procurement Document Control," paragraphs 4.2 and 4.4 , that when safety-related products are specified (on licensee's POs), this information shall also be called out on the PO to the supplier. However, the QAM did not prescribe the quality and technical requirements necessary for safety-related POs issued to vendors. The QAM referenced QAP No. 20-01-010. The NRC inspectors concluded that QAP No. 20-01-010, "Control of Purchased Materials, Products, and Services," Revision No. 4, November 9, 1990, did not prescribe the quality and technical requirements to be imposed on POs to suppliers of safety-related products, inclusive of imposing the requirements of 10 CFR Part 21 , and did not ensure that the inaterial specifications imposed on suppliers are the same or equivalent to material specifications required by the licerisees' POs.

c. The QAM requires in Section IV, "Procurement Document Control," paragraphs 4.7 arid 4.8 , that customers' POs requiring certifications will not be accepted by Customer Service without written approval from the Quality Assurance Department. However, the QAM did not prescribe the controls for nuclear safety-related POs. The QAM referenced QAP No. 20-01-034. The NRC inspecturs concluded that QAP No. 20-01-034, "Customer Purchase Order Review," Revision No. 1, October 22, 1990, did not include the PO review criteria to meet regulatory requirements, inclusive of verifying whether or not 10 CFR Part 21 was imposed by the licensees' POs.

The inspectors concluded from this review that the QAM, supplemented by the QAPM, did not prescribe a quality program in certain sections that provides adequate control over those activities affecting the quality of the components to the extent consistent with their importance to safety as required by regulatory requirements imposed on UC by licensees' POS. Specifically, UC failed to prescribe the following: (1) the controls necessary for the completion of internal audit corrective actions to assure the quality of inipacted products; (2) the quality requirements to be imposed in POs to vendors of safety-related products; (3) the controls necessary to ensure that UC supplied materials met licensee-imposed material specifications; and (4) the criteria used by UC to review the licensees' POS to establish acceptance of the order and to ensure UC's 
ORGANIZATION: $\quad$ UNISTRUT CORPORATION

WAYNE, MICHIGAN

REPORT

NO.: $999000362 / 90-01$

INSPECTION

RESULTS:

PAGE 14 of 27

compliance with the quality and technical requirements of the licensees' P0s. As a result, Nonconformance (90-01-04) was identified in this area of inspection.

\subsection{Indoctrination and Training}

The NRC inspecturs reviewed the training records for UC Quality Control Inspectors. The first training session that included 10 CFR Part 21 and 10 CFR Part 50, Appendix B, for UC personnel whose activities affect quality, was held on November 8,1990 . There were no records of training that included the requirements of 10 CFR Part 21 and 10 CFR Part 50, Appendix B before November 1990.

Compliance with 10 CFR Part 21 and Appendix B to 10 CFR Part 50 was required by the procurement documents of licensees. Training in 10 CFR Part 21 responsibilities is necessary to ensure that deviations are identified and evaluated. Unistrut personnel were never trained, before November 1990, in the definition of a deviation as described in 10 CFR Part 21 or in the quality requirements of 10 CFR Part 50, Appendix $B$. Therefore, Unistrut personnel who performed activities affecting quality did not have the training necessary to identify a deviation as a departure from the technical requirements of the procurement documents.

UC failed to establish and implentent a program, before November 1990, to provide for the indoctrination and training of personnel performing activities affecting quality in the requirements of 10 CFR Part 21 and Appendix $B$ to 10 CFR Part 50. This is arother occurrence of Nonconformances 86-01-08 and 86-01-09, identified by the NRC during the previous inspection and documented in IR No. 99900362/86-01. As a result, Nonconformance (90-01-05) was identified in this area of the inspection.

\subsection{Dedication of Commercial-Grade Items}

The dedication process, consisting of the measures UC uses to select and review for suitability of application those materials, parts, equipment and processes that are essential to the safety-related functions of the ir products, as required by Criterion III, "Design Control," of Appendix B to 10 CFR Part 50, was reviewed. The inspectors evaluated the entire dedication process which encompasses audits of suppliers, receipt inspection, in-process inspection, traceability control, and testing. To this end, the inspectors were given a detailed plant tour during which they had the opportunity to observe in-house processes and talk with several inspectors. 
GRGANIZATION: $\quad$ UNISTRUT CORPORATION

WAYNE, MICHIGAN

REPORT

NO.: $999000362 / 90-01$

INSPECTION

RESULTS:

PAGE 15 of 27

\subsection{Dedication of Products Manufactured by UC}

The manufacturing operations at UC are divided into the processing department, where channel and tubing are made, and the press shop, where channel nuts, fittings, and pipe clamps are made. Since all the coil Indterials for these products are purchased commercial-grade, UC has assumed the responsibility for dedicating all of the coil materials that are sold as safety-related products.

The following QAPs were reviewed by the inspectors during their evaluation of the UC process:

\begin{tabular}{|c|c|c|c|}
\hline QAP NO. & TITLE & REV & DATE \\
\hline $20-01-002$ & First Piece Inspection & 3 & $7 / 6 / 90$ \\
\hline $20-01-006$ & Receiving Inspection & 5 & $7 / 31 / 90$ \\
\hline $20-01-008$ & $\begin{array}{l}\text { Traceability of Channel } \\
\text { and Tubing }\end{array}$ & 4 & $10 / 22 / 90$ \\
\hline $20-01-009$ & In-Process Inspection & 2 & $7 / 6 / 87$ \\
\hline $20-01-011$ & $\begin{array}{l}\text { Heat Treat Preparation } \\
\text { and Inspection }\end{array}$ & 2 & $7 / 6 / 87$ \\
\hline $20-01-014$ & $\begin{array}{l}\text { Pul1 Test } \\
\text { - Channel Products }\end{array}$ & 3 & $8 / 10 / 90$ \\
\hline $20-01-020$ & $\begin{array}{l}\text { Verification of Vendor } \\
\text { Integrity - Incoming } \\
\text { Materials, Products, etc. }\end{array}$ & 2 & $7 / 6 / 87$ \\
\hline $20-01-029$ & $\begin{array}{l}\text { Slip Tests of } 1-5 / 8^{\prime \prime} \\
\text { Channel Series Nuts }\end{array}$ & 3 & $8 / 21 / 90$ \\
\hline $20-01-037$ & Traceability of Fittings & 0 & $9 / 4 / 90$ \\
\hline $20-01-038$ & $\begin{array}{l}\text { lledication Program for } \\
\text { Commercia]-Grade Items }\end{array}$ & $\mathrm{O}$ & $9 / 4 / 90$ \\
\hline $20-01-041$ & $\begin{array}{l}\text { Ninety Degree Angle } \\
\text { Fittings-Bend Test }\end{array}$ & 0 & $8 / 18 / 90$ \\
\hline $20-01-042$ & $\begin{array}{l}\text { Torque Testing of } 1-5 / 8^{\prime \prime} \\
\text { Channe] Series Nuts }\end{array}$ & 0 & $8 / 20 ; 90$ \\
\hline $20-01-043$ & Channel Bend Test & 0 & $8 / 21 / 90$ \\
\hline $20-01-044$ & $\begin{array}{l}\text { Hardness Test for } \\
\text { SAE J429, grade } 2 \\
\text { Fasteners }\end{array}$ & 0 & $8 / 29 / 90$ \\
\hline $20-01-045$ & Alloy Verification Test & 0 & $9 / 4 / 90$ \\
\hline
\end{tabular}

In addition to these QAPS, Section C, "Critical Characteristics," of the UC QAM was also reviewed. 
REPORT

NO.: $999000362 / 90-01$
INSPECTION

RESULTS:

The methods UC uses to purchase coil materials and the receipt inspection of this material are the same for both the processing department and the press shop. As previously stated, UC purchases all coil material commercial-grade. A review of the UC audits of these suppliers, however, determined that UC did not adequately establish a basis for acceptance of material certifications from them, as described in more detail in Section E.8.0 of this report. In addition, the majority of their coil suppliers are distributors who do not independently test the steel that they slit and ship to UC, thus further reducing the assurance that material traceability had been maintained throughout the procurement and slitting process and whether or not the material certification correctly represents the coil. UC also did not assure the accuracy or traceability of the material certifications by performing chemical and physical tests on each coil.

The common receipt inspection procedure requires that all materials be weighed or counted and that certification documentation from the supplier must accompany the material. This documents is checked to ensure that it is in accordance with UC'S PO requirements. The procedure also requires the inspector to inspect all coil material and components in accordance with instructions, blueprints, POs, and/or engineering specifications and to record ali inspection activities performed.

a. The NRC inspecturs determined that, in the processing department, traceability is adequately maintained on the coil material from the time it enters the manufacturing process until it is shipped out as channel. The coil material is received from the vendor in the form of pieces of coil slit to the proper width for the manufacturing process bound together by heat number (milts). Upon receipt, each coif is assigned a sequential identification number, which is recorded by the Quality Assurance Department in a permanent record book. A tag is placed on each coil with the following information: part number, vendor, purchase order number, quantity received, coil number, heat number, and date. Additionally, each mult not having a tag has the coil number marked on it with a permanent black marker. When mults are roll-formed into channel or tubing, a number is indented on the inside of the channels at a spacing not to exceed 22". This number consists of the last digit of the calendar year in which the material was rolled, the identification letter of the operator who roll-formed the material, and the identification number assigned to the coil by the Quality Assurance Department. This method allows identification of the channel and tubing wher it is cut into shorter sections.

The process alsu irivolves a random visual and dimensional inspection and destructive testing of a sample piece of formed channel. This 
ORGANIZATION:

UNISTRUT CORPORATION

WAYNE, MICHIGAN

REPORT

NO.: $999000362 / 90-01$

INSPECTION

RESULTS:

PAGE 17 of 27

sample piece is taken once per eight hour shift and at every new mill set-up. The destructive testing includes hardness, bend, and flange load tests.

In further evaluation of the UC dedication process, the inspectors reviewed 4 PO packages from licensees for safety-related products other than fasteners:

UC ORDER NO. DATE LICENSEE PRODUCT

0450-1944 12/01/87 Diab To Canyon charinel nuts/brackets

0450-2028 03/10/88 Diablo Canyon channel/angle fittings

0130-1917 01/14/87 Limerick channel

0130-1944 03/04/87 Limerick channel

These packages included POs from the licensees, $C$ of $C$ from UC; and material certifications from the coil material suppliers. The NRC inspectors reviewed the tests performed on the safety-related products that were shipped to licensees to determine whether or not the products were adequately dedicated. The channel product that was ordered by the utilities listed above was produced from 16 steel coils procured from buth Rouge Steel Company and Triad Metals Incorporated. Of these $16 \mathrm{coi}$ s, the inspecturs determined that only 3 coils were traceable to sample pieces of tested channel product. All 3 sample pieces had passed the tests described above. None of the material from the 16 coils was subjected to chemical or physical tests to confirm the data in the material certificatiur:.

The inspectors consider this to be an inadequate dedication of commerclai-yrade material because (1) UC had not established a basis for accepting material certifications from its suppliers; (2) UC did not verify the chemical and physical properties of coil material by performing chemical and physical tests; and (3) LC did not perform destructive sample piece testing traceable to each coil of material used in fabrication of channel product.

b. The process in the press shop, where charriel nuts, pipe clamps, and fittings are made, begins with a receipt inspection similar to that used in the processing department. The NRC inspectors determined that since recently implementing a July 31, 1990, revision to QAP 20-01-006, "Receiving Inspection," and QAP 20-01-037, "Traceability of Fittings," UC dic maintain adequate traceability on material in the press shop. A lot number is assigned to all incoming shipments and recorded in the lot number $\log$ bouk and on a Material Control Ticket. This lot number 
REPORT

NO.: $999000362 / 90-01$

INSPECTION

RESULTS:

PAGE 18 of $\angle$;

is based on a heat number or batch number supplied by the vendor. If more than one skid, bundle, lift, or container is received, it may be given the same lot number providing the heat number or batch number is the same. A material control tag, with the lot number written on it, is placed on each skid, bundle, lift, or container. This tag remains with the material as it progresses thruugh the press shop operations until it emerges as a finished product.

1. Channel nuts are considerei $b_{j}$ UC to be more critical than the other products produced in the press shop and are heat treated during the manufacturing process. As a result, channel nuts are tested more rigorously than other press shop products. Once per shift, at a mininum, a channel nut that has been heat treated is tested to determine whether proper case hardening depth has been achieved. In addition, after heat treatilent of each lot, a sample of 5 channel nuts is selected for slip testing. This consists of performing hardiness tests on the nuts and then mounting them in a short length of channel using a special fitting, applying a load to the top of the fitting, and recording the load at which the assembly begins to slip down the channel. A torque test is also performed on a separate sample of 5 channel nuts from each lot after heat treatment. This test consists of attaching a fitting to a piece of channel by means of one nut and bolt and then torquing the bult to the reconmended torque value to ensure that neither the nut nor the bolt exhibit signs of failure.

2. Testing of the other products produced in the press shop, pipe clamps and fittings, is limited to a bend/crush test of 90 degree angle fittings. This test is performed, on a minimum of a once per heat basis, on the completed fitting. It consists of merely striking the fitting with a hammer until it is bent back upon itself and then taking another fitting and hammering it the opposite direction. If the fittings don't crack or break apart, they pass the test.

The inspectors consider the press shop process to be an indequate dedication because (1) UC had not established an adequate basis for accepting the material certificatiors from its suppliers; (2) did not verify the chemical and physical properties of coil material by performing chemical and physical tests; (3) until recently, did not maintain traceability on material in the press shop; and (4) except for channel nuts ard 90-degree angle fittings, did nut perform any testing of their products. 
REPORT

NO.: $\quad 999000362 / 90-01$

INSPECTION

RESULTS:

PAGE 19 of 27

After reviewing the operations alld procedures of both the processing department and the press shop, the NRC inspectors concluded that UC dio not have an adequate program for dedicating commercial-grade items for use in nuclear safety-related applications. This conclusion was reached because (1) UC had not established an adequate basis for accepting the material certifications from its suppliers; (2) did not verify the chemical and physical properties of coil material by performing chemical and physical tests; (3) until recently, did not mauniain traceability on material in the press shop; (4) did not perform testing traceable to eich coil of material used in the fabrication of channel products; and (5) except for channel nuts and 90-degree angle fittings, $U C$ did not perform any testing on products produced in the press shop. Therefore, UC supplied inadequately dedicated parts such as structural framing chamnel, channel nuts, screws, nuts, washers, general fittings, and mechanical accessories as safetyrelated ccrilivuricrits to the nuclear industry. As a resuit, Nonconformance (90-01-06) was identified in this area of the inspection.

\section{E.2 Dedication of Fasteners}

As stated previously in Section E.3.0 of this report, UC had never perfuried a commercial-grade dedication of fasteners supplied to the nuclear industry as safety-related. In addition, UC changed the licensees' material specifications imposed in POs and ordered fasteners from GF to a different material specification, even though UC issued $C$ of $C$ to licensees that certify compliance to the licensees' material specification. GF is only a material supplier of fasteners and performs no manufacturing activities. GF procures all of the fasteners supplied to UC from other suppliers and manufacturers. The bases of GF's procurement of fasteners was not examined during this inspection. Examples of these concerns are as follows.

a. River Bend Nuclear Station's PO No. 89-4-77172, dated August 25, 1989, ordered ASTM A3C7, grade A, safety-related fasteners. UC issued comailercial-grade PO No. P-02694, September 18, 1989, to GF ordering fasteners to material specification SAE-J429, grade 2. UC issued River Bend Nuclear Station a C of C, October 5, 1989, that certified that the material met ASTM A307, grade A.

b. Bechtel Constructors Corp. 's PO No. 20557-F1020-Q, July 17, 1990, ordered ASTM A307, grade A, safety-related fasteners for the Palisades Nuclear Plant. UC issued commercial-grade PO No. P-03779, October 4, 1990 , to GF and ordered the fasteners to material specification SAE-J429, grade 2. UC issued Palisades Nuclear Plarit a $C$ of $C$, October 10, 1990, that certifieci ihät the naateriu? met ASTM A307, grade A. 
REPORT

NO.: $999000362 / 90-01$
INSPECTION

RESULTS:

The UC, "General Engineering Catalog," No. 11, states, in part, that screws conform to SAE-J429, grade 2, and also meet and exceed ASTM A307. UC however, did not document an evaluation of these material specifications to substantiate this claim.

\subsection{Purchase Orders and UC Certificates of Conformance}

The NRC inspectors reviewed the licensees' POS to UC and the UC POs to suppliers to determine whether or not UC implemented measures to adequately assure that procurement documents include the applicable requirements, design bases, and quality program requirements. The review was intended to determine whether or not UC had an adequate basis to substantiate the $C$ of $C S$ issued to licensees that certify compliance to the ir PO requirements.

UC staff told NRC inspectors that, based on UC's review, it had determined that UC first began issuing $C$ of $C$ to the requirements of 10 CFR Part 21 and 10 CFR Part 50, Append ix $B$ in August 1988. The NRC inspectors, however, identified PO No. NMP2-FPO-15391, July 27, 1982, and PO No. NMP2-FPO-16083, September 17, 1982, from Stone \& Webster Engineering Corporation to UC for safety-related pipe clamps. Both POs were issued to supply Niagara Mohawk Power Corporation's Nine Mile Point Nuclear Station and both imposed on UC the requirements of 10 CFR Part 21 and 10 CFR Part 50, Appendix B. UC issued C of C August 1982 and November 1, 1982, respectively, certifying that, "the parts described hereon have been processed in accordance with your purchase order instructions." UC claimed that it did not understand that in issuing such a certification that it had also certified compliance with 10 CFR Part 21 and 10 CFR Part 50, Appendix B requirements imposed in the customers' $P O$. These $C$ of $C$ are listed in paragraph b., below, and represent a lack of understanding $b_{j}$ UC shat significantly impacts the bases of evaluating UC C of $C$ that are not valid because UC ordered the base material for the clamps as commercial-grade and failed to perform a dedication of the material.

The procurement process starts when licensees place PO's with UC Authorized Service Centers. The Authorized Service Centers then send the order information to UC. UC'S QAM requires that the Quality Assurance Department review and approve al1 1 icensees' POs requiring $C$ of $C$ before orders are accepted by Customer Service. This practice is intended to assure that UC is able to certify compliance with all PO requirements. Before July of 1990, when the current policy was implemented, the Authorized Service Centers frequently sent to $U C$ only the part number and a statement that a $C$ of $C$ was required. In most cases reviewed by the inspectors, the original PO requirements were not sent to UC. UC personnel interviewed during the 
REPORT

NO.: $999000362 / 90-01$

inspection stated that it was common practice for the Authorized Service Centers to filter the PO requirements, only informing UC that a $C$ of $C$ was required, and not passing on all of the quality and technical requirements imposed in the Ticenste's PO.

The inspecturs identified various examples described below where UC certified compliance to requirements that they were not aware of and did not comply with, or revised certifications without verifying prior conpliance to requirements imposed.

a. The following are examples where UC issued $C$ of $C S$ certifying compliance to the requirements of 10 CFR Part 21 and 10 CFR Part 50 , Appendix B without having received the licensee's PO or establishing an understanding of the licensee's requirements:

\begin{tabular}{|c|c|c|c|}
\hline UC ORDER NO. & DATE & LICENSEE & PRODUCT \\
\hline 3030 & $4 / 8 / 87$ & Browns Ferry & pipe clamps \\
\hline 3050 & $12 / 15 / 87$ & Browns Ferry & channel nuts/fitting \\
\hline 3050 & $7 / 18 / 88$ & Browns Ferry & $\begin{array}{l}\text { channel/fasteners/ } \\
\text { fittings }\end{array}$ \\
\hline $3030-1040$ & $7 / 22 / 88$ & Sequoyah & pipe clamps \\
\hline $0450-2231$ & $10 / 18 / 88$ & Diablo Ca & $\begin{array}{l}\text { channel/pipe clamps/ } \\
\text { fittings }\end{array}$ \\
\hline $3030-1081$ & $10 / 19 / 88$ & Browns Ferry & fasteners/pipe clamp \\
\hline $0450-2265$ & $11 / 28 / 89$ & Diablo Canyon & $\begin{array}{l}\text { channel/pipe clamps/ } \\
\text { fasteners }\end{array}$ \\
\hline $0450-2295$ & $1 / 10 / 89$ & Diablo Canyon & pipe clamps \\
\hline $0450-2550$ & $9 / 18 / 89$ & Diablo Canyon & pipe clamps/fittings \\
\hline $0450-2551$ & $9,18 / 89$ & Diablo Canyon & $\begin{array}{l}\text { pipe clamps/channel/ } \\
\text { channel nuts }\end{array}$ \\
\hline $0310-2388$ & $12 / 7 / 89$ & Hatch & pipe clamps/channel \\
\hline $0330-1893$ & $1 / 5 / 90$ & Comariche Peak & $\begin{array}{l}\text { nuts } \\
\text { channel nuts }\end{array}$ \\
\hline
\end{tabular}

b. The following are examples where UC received a copy of the licensee's original PO with the Authorized Service Center's order. The original Ticensees' POS reviewed stated that 10 CFR Part 21 and 10 CFR Part 50, Appendix $B$ were applicable to the order. UC issued $C$ of $C$ certifying compliarice with the "PO instructions." UC staff claimed they did not understand that in doing so it also certified compliance with 10 CFR Part 21 and 10 CFR Part 50, Appendix $B$ requirements. 
ORGANIZATION: UNISTRUT CORPORATION

WAYNE, MICHIGAN

REPORT

NO.: $999000362 / 90-01$

INSPECTION

RESULTS:

PAGE 22 of 27

\begin{tabular}{|c|c|c|c|}
\hline UC ORDER NO. & DATE & LICENSEE & PRODUCT \\
\hline $1070-1245$ & $8 / 82$ & Nine Mile & pipe clanps \\
\hline $1070-1325$ & $11 / 1 / 82$ & Nine Mile & pipe clamps \\
\hline $2010-1318$ & $1 / 2 / 86$ & Callaway & channel \\
\hline $0310-1478$ & $1 / 16 / 87$ & Vogtle & pipe clamps \\
\hline $0130-1917$ & $5 / 7 / 87$ & Limerick & channel \\
\hline $0130-1944$ & $6 / 15 / 87$ & Limerick & channel \\
\hline $0370-0024$ & $10 / 20 / 87$ & River Bend & fasteners \\
\hline $0450-1944$ & $12 / 1 / 87$ & Diablo Canyon & $\begin{array}{l}\text { channel nuts/ } \\
\text { fittings }\end{array}$ \\
\hline $0 \div 5 C-\therefore 027$ & $3 / 10 / 88$ & Diab 10 Canyon & $\begin{array}{l}\text { channe } 1 / p \text { ipe clamps/ } \\
; \text { ittings/fasteners }\end{array}$ \\
\hline 0450 & $3 / 1$ & Diablo Canyon & channel/fittings \\
\hline $0450-2057$ & $4 / 20 / 88$ & Diablo Canyon & fasteners \\
\hline $0450-2059$ & $4 / 21 / 88$ & Diablo Canyon & fittings/fasteners \\
\hline
\end{tabular}

c. The following are exaliples where licensees' POs specifically requested certification of compliance to the requirements of 10 CFR Part 21 or 10 CFR Part 50, Appendix B. UC issued $C$ of $C$ that certified that the "Quality control program conforms to ANSI N45.̈ and 10 CFR Part 50, Appendix B, 10 CFR Part 21 applies to this order."

\begin{tabular}{|c|c|c|c|}
\hline UC ORDER NO. & DATE & LICENSEE & PRODUCT \\
\hline $0330-1645$ & $12 / 5 / 88$ & Comanche Peak & $\begin{array}{l}\text { channe } / \text { /fittings/ } \\
\text { fasteners }\end{array}$ \\
\hline $0310-2208$ & $7 / 19 / 89$ & Sequoyah & $\begin{array}{l}\text { channel nuts/pipe } \\
\text { ciamps/fittings }\end{array}$ \\
\hline $\begin{array}{l}0310-2220 \\
0310-2284 \\
0310-2314\end{array}$ & $\begin{array}{l}7 / 28 / 89 \\
9 / 21 / 89 \\
10 / 13 / 89\end{array}$ & $\begin{array}{l}\text { Watts Bar } \\
\text { Browns Ferry } \\
\text { Sequoyah }\end{array}$ & $\begin{array}{l}\text { fittings } \\
\text { channel nuts/fitting } \\
\text { pipe clamps/channel } \\
\text { nuts }\end{array}$ \\
\hline $\begin{array}{l}0330-1865 \\
0450-2615 \\
0310-2384\end{array}$ & $\begin{array}{l}11 / 16 / 89 \\
11 / 17 / 89 \\
12 / 6 / 89\end{array}$ & $\begin{array}{l}\text { Comanche Peak } \\
\text { Diab lo Canyon } \\
\text { Browns Ferry }\end{array}$ & $\begin{array}{l}\text { beam clamps } \\
\text { fittings/channel nut } \\
\text { fasteners/channel } \\
\text { nuts/pipe clamps }\end{array}$ \\
\hline $\begin{array}{l}0330-1942 \\
0310-2574 \\
0310-2577\end{array}$ & $\begin{array}{l}3 / 15 / 90 \\
5 / 8 / 90 \\
5 / 10 / 90\end{array}$ & $\begin{array}{l}\text { Comanche Peak } \\
\text { Sequoyah } \\
\text { Browns Ferry }\end{array}$ & $\begin{array}{l}\text { pipe clamps } \\
\text { pipe clamips } \\
\text { channel nuts }\end{array}$ \\
\hline
\end{tabular}

d. The following are examples where the licensee's PO requested certification of compliance to ASME Code Section III, Subsection $N F-2600$. UC issued $C$ of $C$ certify irig con:pliänce to this requirement without having a quality program that compiies with ASME Code, Section III requirements, or an understanding of the ASME Code, 
ORGANIZATION:

UNISTRUT CORPORATION

WAYNE, MICHIGAN

REPORT

NO.: $999000362 / 90-01$

INSPECTION

RESULTS:

PAGE 23 of 27

Section III, Subsection NF-2600 technical requirements. In fact, UC cid not have a copy of the ASME Code requirements.

UC ORDER NO. DATE LICENSEE PRODUCT

3030-0942 12/4/87 Wäts Bar channel/fittings

3030-1088 11/17/88 Watts Bar fasteners

e. The inspectors identified the following examples where UC was

requested to revise previously issued $C$ of $C$ to incorporate statements certifying compliance with 10 CFR Part 21, 10 CFR Part 50, Appendix $B$, and in one case, ASME Code. UC performed these revisions without verifying that they had complied with these requirements at the time of original certification.

UC ORDER NO. ORIG.DATE REV.DATE LICENSEE PRODUCT

Stock I tems 9/18/87 4/3/89 Watts Bar pipe clamps

(P0 No. 87NBA-36447A)

Added compliance statement to the requirements of ANSI N45.2, 10 CFR

Part 50, Appendix B, 10 CFR Part 21, ASME Code, Section III, Class 2, Subsection NF-2600, and Code Case No. 1644 .

3030-0870 6/12/87 7/11/89 Watts Bar channel

Added compliance statement to the

requirements of 10 CFR fart $\hat{c} i$.

f. The NRC inspectors also reviewed UC's orders to its supplier of

fasteners. While UC believed that their supplier was providing them with safety-related fasteners, they did not impose 10 CFR Part 50 , Appendix $B$, quality requirements on these purchase orders or any other quality requirements. The following are examples of POs for fasteners that did not impose 10 CFR Part 50, Appendix $B$ requirements on the vendor and the fasteliers were supplied to the nuclear industry with UC $C$ of $C$ that certified compliance with 10 CFR Part 50, Appendix B.

PURCHASE ORDER DATE VENDOR

$\begin{array}{lll}P-02170 & 1 / 24 / 89 & G F \\ P-03418 & 4 / 20 / 90 & G F \\ P-03779 & 10 / 4 / 90 & G F \\ P-03791 & 10 / 8 / 90 & G F\end{array}$


REPORT

NO.: $999000362 / 90-01$

INSPECTION

RESULTS:

PAGE 24 of 27

From this review, the NRC inspectors coricluded that UC failed to establish measures to ensure that regulatory requirements imposed in licensees' POs are established and translated into documents that ensure adequate quality is achieved. Moreover, UC failed to assure that compliance to imposed regulatory requirements had been achieved before issuing $C$ of $C$ that certified compliance. This condition led UC to make unsubstantiated certification statements on $C$ of $C$ issued to licensees. Specifically, UC routinely failed to perform the following: (1) contrcl the receipt and review of POS froli licensees in order to establish the requirements imposed on UC; (2) establish measures necessary to translate the requirements imposed in POs from licensees into specifications or procedures; (3) ensure compliarice to the requirements imposed in POS from licensees before issuing $C$ of $C$ that certified compliance; (4) verify UC's compliance prior to revising previously issued $C$ of $C$; and (5) impose 10 CFR Part 50, Appendix $B$ or similar quality requirements in POS to suppiiers of safety-related fasteners. As a result, Nonconformance (90-01-7) was identifiec in this ared of the inspection.

\subsection{UC Audits of Suppliers}

The inspectors reviewed UC's control of purchased material with particular emphasis on how they assured themselves that purchased material, equipment, and services conformed to the procurement documents and whether UC effectively assessed the control of quality of their suppliers. UC's supplier files containing correspondence, questionnaires, checklists, and audit reports were reviewed.

A review of UC's Approved Supplier List, September 4, 1990, revealed that a11 but 2 of the 19 suppliers listed were considered to be commercial-grade suppliers. Three of these commercial-grade suppliers' files, Rouge Steel Co., Stateline Steel Corp., and Triad Metals Inc. were reviewed. UC sends out an annual vendor quality audit questionnaire to its suppliers. This questionnaire consists of a cover shet on which the supplier is asked to provide information including the standard, if any, to which their quality program complies. The questionnaire also includes 4 pages of questions about the supplier's quality progran. The questionnaire from all 3 suppliers stated that they had conmercial-grade programs that did not comply with the requirements of Appendix B to 10 CFR Part 50.

UC had performed audits of these suppliers on a triennial basis. The aucits were performed by using the questionnaire as a checklist for the UC auditor. The auditor, using the checklist, verified that the vendor had answered the questions correctly. These audit checklists/reports did not 
REPORT

NO.: $999000362 / 90-01$

INSPECTION

RESULTS:

contain objective evidence to support the conclusions of the auditor and did not provide any detail of the activities audited. The NRC inspectors determined that the audits may be considered adequate to approve a commercial-grade vendor. The audits are not adequate, however, to provide UC with a basis to accept material certifications from these vendors, as is their current practice.

The file of UC's major 10 CFR Part 50, Appendix B supplier of safetyrelated fasteners, General Fasteners Company (GF), was also reviewed. This file revealed that UC utilized the same vendor quality audit questionnaire. GF had previously indicated on the questionnaire that their quality program had been based on 10 CFR Part 50, Appendix B and until 1990 UC had audited GF on a triennial basis. Until the most recent audit, UC performed audits using the same questionnaire used for their audits of commercial-grade suppliers. The audit conducted on September 11, 1990 utilized a more extensive checklist, in keeping with 10 CFR Part 50, Appendix B quality criteria. The auditors concluded that GF had a quality program that met 10 CFR Part 50, Appendix B requirements. None of these audit checklists/ reports included objective evidence to support the conclusions of the auditors or substantiate UC's use of GF as a supplier of safety-related fasteners with a quality program that complied with 10 CFR Part 50 , Appendix B. As described in Section E.3.0 of this report, GF advised UC on October 26, 1990, that it did not have, nor had it ever had, a quality program that met the NRC requirements in 10 CFR Part 50 , Appendix $B$ and 10 CFR Part 21.

Additionally, as part of the inspection at UC, one of the NRC inspectors visited GF's facility in order to better understand the procurement relationship between UC and GF. GF stated that they had an agretuc..t with UC to certify compliance to 10 CFR Part 50 , Appendix B based on UC's reported belief that GF had an adequate quality program. Senior quality personnel at GF admitted, however, that they do not now nor have they ever had a quality program that complies with 10 CFR Part 50, Appendix B to supply nuclear safety-related fasteners.

The inspectors concluded that UC failed to establish adequate measures to assess and document the effectiveness of the quality programs of vendors supplying materials and services. Specifically, the UC audits failed to discover that the quality program of their fastener supplier did not meet 10 CFR Part 50, Appendix 8 requirements. In addition, UC did not audit their commercial-grade suppliers of steel coil material, which furnished material certifications used by UC in the commercial-grade dedication process. This is another occurrence of Nonconformance 86-01-05, identified 
REPORT

NO.: $\quad 999000362 / 90-01$

by the NRC during the previous inspection and documented in IR

No. 99900362/86-01. As a result, Noncunformanice (90-01-08) was identified in this area of the inspection.

\subsection{Licensee Audits}

Audits of UC performed by 1 icensees were reviewed by the NRC inspecturs to determine how licensees evaluated UC's quality program, what their findings were, and how UC respunded to the findings. The inspecturs noted that there was a wide range of audit conclusions among licensees. The inspectors also noted that although UC's quality program changed little from 1987 until June 1990, some licensees' audit conclusions during the same time period changed significantly.

As an example, audits performed by Tennessee Valley Authority (TVA) on Apri1 10-12, 1989, and May 21-24, and Juile 26-27, 1990, were reviewed. Both the 1989 and 1990 audit reports were comprehensive and provided detailed findings, indicating that the audits had been thorough. The 1989 audit reaffirmed TVA's previous conclusion that UC was capable of supplying 10 CFR Part 50, Appendix B quality safety-related parts and also meeting the requirements of ASME Code, Section III, even though 10 significant findings were identified during the audit. The NRC inspectors noted that UC had never been accredited by ASME. The UC staff stated that they did not know what ASME Code requirements were for reference and they did not believe that the UC QAM complied with ASME Code requirements.

UC's response to TVA's 1989 audit findings was evaluated by reviewing TVA's 1990 audit report in which TVA noted that 9 out of the 10 findings irom the 1989 audit had not been corrected. TVA reacted to UC's response by downgrading UC from a 10 CFR Part 50, Appendix B supplier to a commercialgräde supplier.

Additionally, audits by Pennsylvania Power and Light on June 5-7, 1990, American Electric Power on December 13-14, 1989, and Public Service Electric arid Gas on September 22-23, 1987, were reviewed. Based on the audit reports, all of these utilities concluded that $U C$ had an acceptable quality program, meeting the requirements of 10 CFR Part 50, Appendix B.

Audits performed by Pacific Gas \& Electric (PG\&E) on July 2, 1987, and July 26-27, 1988, were also reviewed. These audits were of interest to the inspectors because the audit conclusions differed from the other utilities previously mentioned and because they also changed from one year to the 
REPORT

NO.: $\quad 999000362 / 90-01$

INSPECTION

RESULTS:

next. The 1987 audit found that UC's quality progran adequately met only the requirements of Criteria I, II, and V through XVII of Appendix $B$ to 10 CFR Part 50. The 1988 audit found that UC's quality program only met the requirements of Criteria VII through XV, and XVII, a significant change from the previous year. However, PG\&E continued to purchase products from UC as safety-related in the period 1987 through 1989.

The audit reviewed by the inspectors performed by Florida Power \& Light (FP\&L) on May 3,1989 , resulted in audit conclusions that were opposite from the utilities that considered UC to be a 10 CFR Part 50, Appendix $B$ supplier. FP\&L's audit concluded that UC was strictly a commercial-grade supplier.

F. PERSONNEL CONTACTED:

\#Kris Weger

Vice President and General Manager

\#*Charles Nehls

Manager, Production Engineering

$\# \star$ John Springsteãd

Manager, Quality Assurance

Del Hamilton

Processing Inspector

Rich Farago

Senior Processing Inspector

Jerry Dowling

Quality Technician

John Breier

Manager, Customer Service

Richard Hines

Quality Assurance Administrator

Pat McCona logue

Purchasing Agent

$\#$ Present during the entrance meeting

* Present during the exit meeting 


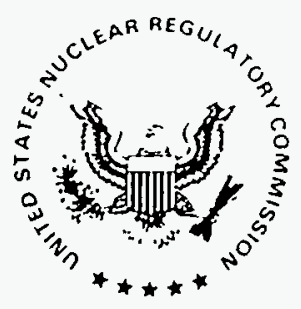

UNITED STATES

NUCLEAR REGULATORY COMMISSION

WASHINGTON, D.C. 20555-0001

May 6, 1995

Mr. Clinton W. Deisenroth, President

Whittaker Electronic Systems

Whittaker Corporation

1785 Voyager Avenue

Simi Valley, CA 93063-3349

SUBJECT: NRC INSPECTION NO. 99901164/95-01

Dear Mr. De isenroth:

This letter transmits the report of the U.S. Nuclear Regulatory Commission (NRC) inspection of Whittaker Electronic Systems at Simi Valley, California, conducted by Messrs. R.C. Wilson and R. Mendez of this office on April 3-6, 1995. The purpose of the inspection was to review activities conducted under your 10 CFR Part 50, Appendix B, quality assurance program and 10 CFR Part 21 reporting program. The inspection consisted of an examination of procedures and records, interviews with personnel, and observations by the inspectors.

The NRC inspectors found that the implementation of your quality assurance program failed to meet certain NRC requirements. Specifically, your quality assurance surveys of a supplier of hydrogen gas used to calibrate hydrogen sensors were not adequate to dedicate commercially procured standards which were subsequently used for nuclear safety-related applications. This was an example of a generic problem regarding inadequate dedication of calibration services until shortly before the NRC inspection. The specific findings and references to the pertinent requirements are identified in the tulosures to this letter.

Please provide us within 30 days from the date of this letter a written statement in accordance with the instructions specified in the enclosed Notice of Nonconformance. 
In accordance with 10 CFR Part 2.790 of the NRC's "Rules of Practice," a copy of this letter and its enclosures will be placed in the NRC's Public Document Room.

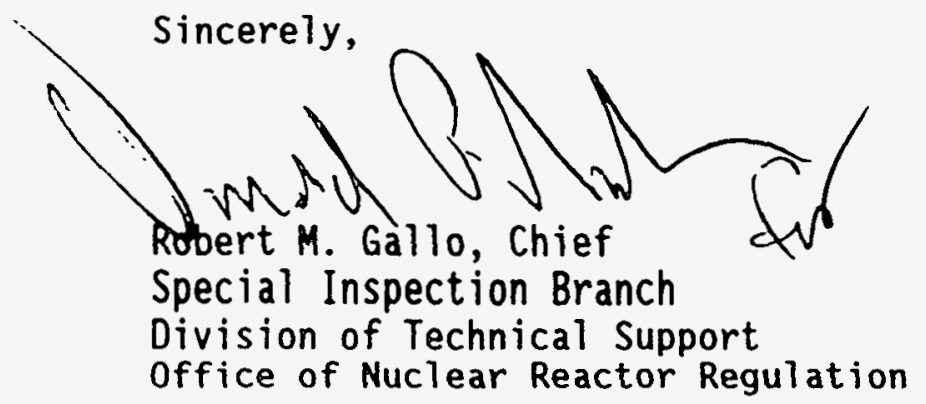

Docket No. 99901164

Enclosures: 1. Notice of Nonconformance

2. Inspection Report $99901164 / 95-01$ 
Based on the results of an inspection conducted on April 3 through 6, 1995, it appears that certain of your activities were not conducted in accordance with NRC requirements as described below.

Criterion XII of Appendix B to 10 CFR Part 50, "Control of Measuring and Test Equipment," requires, in part, that measures shall be established to assure that testing devices used in activities affecting quality are properly calibrated to maintain accuracy within specified limits.

Criterion VII of Appendix B to 10 CFR Part 50, "Control of Purchased Equipment, Material, and Services, "requires, in part, that the effectiveness of the control of quality by contractors shail be assessed.

Section 4.1.1 of the Whittaker Quality Assurance Manual Chapter QAM-07, "Control of Purchased Material, Equipment and Services, Revision M, July 29, 1994, states that Quality Assurance, Production Control, and Purchasing shail provide for source evaluation and evaluation of objective evidence of quality. Similarly, Section 7.2.1 of Revision L of the Quality Assurance Manual, dated September 1, 1989, states that sources to be used are selected based, in part, on quality assurance considerations.

Contrary to the above, at the time of the inspection, documented Whittaker quality assurance surveys of Liquid Carbonic Cylinder Gas Products were inadequate to dedicate for nuclear safety-related use the hydrogen calibration standards provided under a commercial grade purchase order. Furthermore, the standards were used in calibrating a model 113C002G4 hydrogen sensor, serial number B-2028, shipped to the Cooper nuclear station on April 9, 1993, under Nebraska Public Power District Purchase Order No. 362172. (99901264/95-01-01)

Please provide a written statement or explanation to the U.S. Nuclear Regulatory Commission, ATTN: Document Control Desk, Washington, D.C. 20555, with a copy to the Chief, Special Inspection Branch, Division of Technical Support, Office of Nuclear Reactor Regulation, within 30 days of the date of the letter transmitting this Notice of Nonconformance. This reply should be clearly marked as a "Reply to a Notice of Nonconformance" and should include for each nonconformance: (1) a description of steps that have been or will be taken to correct these items; (2) a description of steps that have been or will be taken to prevent recurrence; and (3) the dates your corrective actions and preventive measures were or will be completed.

Dated at Rockville, Maryland

this 5 th day of May, 1995 


\section{U.S. NUCLEAR REGULATORY COMMISSION \\ OFFICE OF NUCLEAR REACTOR REGULATION \\ DIVISION OF TECHNICAL SUPPORT}

REPORT NO. :

$99901164 / 95-01$

ORGANIZATION :

Whittaker Electronic Systems

Whittaker Corporation

1785 Voyager Avenue

Simi Valley, California 93063-8000

ORGANIZATIONAL

CONTACT :

Gary E. King

Director of Product Assurance

NUCLEAR INOUSTRY

ACTIVITY:

Supplies high-temperature cables and connectors for in-core instrumentation, and hydrogen and oxygen gas analyzers

INSPECTION DATES:

Apri] 3-6, 1995

LEAD INSPECTOR:

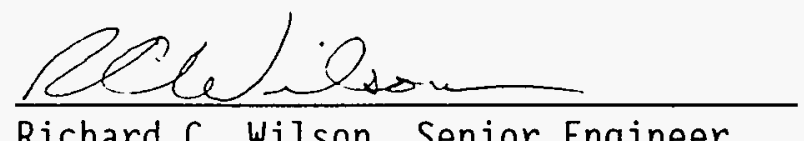

Richard C. Wilson, Senior Engineer Vendor Inspection Section (VIS) Special Inspection Branch (TSIB)

OTHER INSPECTORS:

Roger Mendez, Reactor Inspector Region III

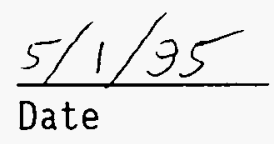

REVIEWED BY:

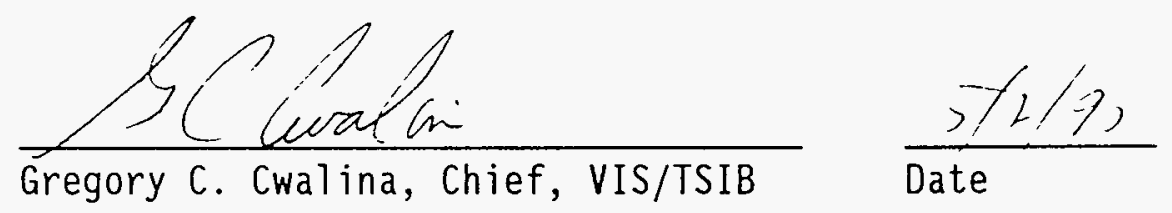

APPROVED BY:
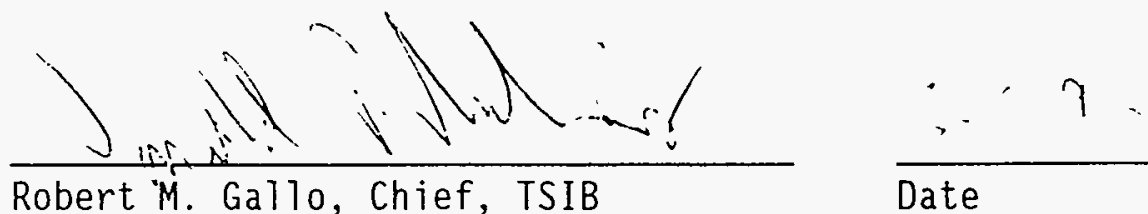
Whittaker designs and manufactures cables, connectors, and instruments, mostly for military/aerospace and nuclear applications. Nuclear products are primarily high temperature, radiation-resistant cables and connectors for applications such as in-core instrumentation and core exit thermocouples, as well as hydrogen and oxygen gas analyzers.

The NRC inspectors reviewed the implementation of selected portions of Whittaker's Appendix B quality assurance (QA) program for supplying safetygrade components, monitored corrections to discrepancies in Whittaker's manufacturing controls that were identified in a previous NRC inspection, and reviewed Whittaker's 10 CFR Part 21 program including reports that have been submitted to the NRC. The inspection bases were 10 CFR Part 50, Appendix B, and 10 CFR Part 21.

\subsection{Nonconformance $99901164 / 94-01-01$}

Contrary to Criteria XII and VII of Appendix B to 10 CFR Part 50, which were imposed on Whittaker by licensee purchase orders, Whittaker did not assure that QA surveys of a supplier of hydrogen gas calibration standards were adequate to dedicate the standards for nuclear safety-related use. Furthermore, the standards were used to calibrate a safety-related sensor (see Section 3.4 of this inspection report).

\section{STATUS OF PREVIOUS INSPECTION FINDINGS}

AT though no open findings remained from previous NRC inspections, Paragraph E.3 of NRC Inspection Report No. 99901164/89-01 identified certain discrepancies in the documentation of manufacturing controls for proprietary processes, and stated that the NRC inspector observed that Whittaker had already begun to address these discrepancies. As discussed in Section 3.3 of this inspection report, the inspectors believe that Whittaker's manufacturing controls are now appropriate.

\subsection{Entrance and Exit Meetings}

In the entrance meeting on Apri1 3, 1995, the NRC inspectors discussed the scope of the inspection, outlined the areas to be inspected, and established interfaces with Whittaker management and staff. In the exit meeting on April 6, 1995, the inspectors discussed their findings and concerns with Whittaker management and staff.

\subsection{Quality Assurance Program and Organization}

The inspectors selectively reviewed the Whittaker Electronic Resources Division QA program established by the QA Manual Revision effective July 30, 1994. The manual provided the top level requirements, with implementation covered in lower tier QA procedures (QAPS) and Quality operating procedures. Based on the review of the QAM and QAPS and discussions with the QA manager, the inspectors determined that the QA organization had sufficient authority 
and organizational freedom to identify quality problems, initiate solutions, and verify implementation of the solutions.

\subsection{Translation of Purchase Order Requirements}

The inspectors selectively reviewed files for eight purchase orders (POs) to determine if the PO requirements were correctly translated into documented specifications, procedures, drawings and testing requirements for fabricating safety-related cables, connectors, and gas analyzers and associated replacement parts. The inspectors determined that Whittaker had an excellent method for translating the PO requirements into the final product. Whittaker used a routing card system for documenting fabrication which included drawings, procedures, operational steps, operational checks, and final testing by quality control. Each step is verified by the operator's or quality control inspector's stamp.

The inspector witnessed one cable job in progress and verified that the operator was following procedures and that all related procedures and instructions were at the job site. In addition, the inspector verified that the production personnel followed each step, and that quality control documented each inspection or test in the fabrication process. The inspectors concluded that Whittaker's controls effectively ensured that customer PO requirements were correctly incorporated into finished products.

The inspector, however, noted a discrepancy during a review of Shop Order No. 6393A, cables for the San Onofre nuclear power station under ABB Combustion Engineering (CE) PO 403770-01 to Whittaker. The inspector observed that the configuration control document, which listed documents used in making the cable assemblies and which had been checked by document control personnel for the current revision status, referenced an outdated procedure. Procedure No. MPS 3.4-2, "Torch and Resistance Brazing," Revision B, was checked as being the latest applicable revision, although revision $C$ was in effect. The cable was fabricated in February 1995, and revision $C$ became effective on April 20, 1993. The inspectors reviewed the procedure and found that the revision did not affect the fabrication of the cables. All other procedures observed by the inspectors were current.

Another concern involved the environmental qualification of the cables and connectors in the same shop order. A 1984 CE report establishes environmental qualification of the cables and connectors. The qualified connector design used a Bi-wax 142 potting compound for pin anchoring, positioning, and spacing under the welded sleeve joining the connector and cable. A change order to the CE PO directed changing the potting material to Epoxilite 5403, to provide better support for the pins during connector mating. CE owns the qualification test report, and Whittaker does not certify conformance to it. Thus, responsibility for the environmental qualification of the revised cable and connector assemblies lies with CE. According to Whittaker personnel, CE documented evaluation of the change in CE-NPSD-968-P, "Qual ification Summary Report: Qual ification of Potting Compounds for Use in MI Cables, "December 1994. The NRC will review that document during a future inspection at CE.

The inspectors concluded that Whittaker exercises appropriate procedural control over manufacturing activities. 


\subsection{Accuracy and Calibration of Test Equipment}

Nebraska Public Power District PO No. 362172 dated February 2, 1993, covered testing and rebuilding one hydrogen sensor and one oxygen sensor. The PO specified applicability of an Exo-Sensor environmental qualification test report, and invoked 10 CFR Part 50, Appendix B, and 10 CFR Part 21 . Whittaker assigned Shop Order (SO) No. 12080A. The inspector's review concentrated on the hydrogen sensor, part number 1130002G4, serial number B-2028. The Manual Rework Router, which controlled work on the sensor, specified final test per Quality Operating Procedure Q0P-023, " $\mathrm{H}_{2}$ Containment Sensor Performance Characterization." QOP-023 specified calibrating the sensor with three different calibration gas supplies in the range of $1 \%$ to $6 \%$ hydrogen in nitrogen.

Whittaker obtained calibrating gas from Liquid Carbonic Cylinder Gas Products with commercial grade POs. A "Supplier Quality/Inspection System Questionnaire" from Liquid Carbonics dated October 12, 1992, was signed off by Whittaker QA on 0ctober 21, 1992. The questionnaire was a military-type checklist completed by the supplier, which does not provide the objective evidence at the Appendix $B$ level necessary to dedicate commercial grade services for nuclear safety-related applications. Whittaker took no further actions to assure the quality of the material supplied by Liquid Carbonics. As part of an internal audit, Whittaker added a notation on the questionnaire dated October 22, 1993, that an audit was required for gas certifications to support the listing of Liquid Carbonics on the Approved Suppliers List (ASL). Nonetheless, Whittaker continued to obtain hydrogen without an audit; the inspector observed three cylinders with calibration certifications dated August and October 1994. The inspector noted that the March 23, 1995, ASL still stated that an audit was required. A whiteboard in the QA area also included Liquid Carbonics in a list of suppliers to be audited, but no date was defined. The Whittaker director of product assurance committed to the NRC inspectors to perform the audit by May 1, 1995.

The inspector reviewed a recent Whittaker audit report for another supplier, EIL Instruments, Inc., dated March 27, 1995, and found that report to contain the essential elements of a survey to dedicate commercial grade calibration services.

Criterion XII of 10 CFR Part 50, Appendix B, requires proper control of testing devices affecting quality, and Criterion VII requires assessing the effectiveness of the control of quality by suppliers. Whittaker's failure to perform a commercial grade survey of Liquid Carbonics which was adequate to dedicate the helium gas calibration standard constitutes Nonconformance No. $99901164 / 95-01-01$.

The inspector also reviewed the control and calibration of Whittaker's in-house measuring and test equipment. Records showed all the instruments in the program to be calibrated within the scheduled intervals. The Whittaker Metrology Report data sheet used to document calibration of standards contained a "Test Results" section with four columns titled Function Tested, Tolerance, Received Value and Released Value. Numerical data were not entered in these columns on the sheets observed by the inspector. Whittaker personnel stated that numerical data are not recorded unless an instrument is found out of tolerance. Whittaker personnel did place checkmarks in a section indicating the results of the calibration as $0-50 \%, 50-75 \%$, or $75-100 \%$ of the 
acceptance range, to provide general trending information. However, the inspectors noted that instruments such as multimeters had a number of functions with different ranges and accuracies, and checking of one of the boxes may not apply to all of the ranges.

Whittaker personnel indicated that they interpreted their calibration procedures to require calibration of all of, the ranges of an instrument, using the manufacturer's manual and the accuracy criteria stated in the manual, al though the procedures did not specifically so state. The director of product assurance agreed, by May 1, 1995, to ensure that the documentation of in-house calibrations clearly defines the specific ranges tested and the acceptance criteria for each calibration. One possibility is to change the procedures to specify that all ranges will be tested against the accuracy specifications of a designated revision of the manufacturer's manual.

\subsection{CFR Part 21 Program}

The NRC inspector reviewed Whittaker's procedure for reporting activities in accordance with 10 CFR Part 21, QA Procedure (QAP) 15-02, "Substantial Safety Hazard Reporting," Revision A, dated September 8, 1994. The inspector discussed strong and weak points of the procedure with the Whittaker director of product assurance and the $Q A$ engineer who wrote the procedure.

QAP 15-02 focused on evaluating deviations and failures to comply with the technical requirements of procurement documents, and only briefly addressed the identification and reporting of such concerns. QAP 15-02 did not specifically encourage or require reporting by the employees most likely to identify potential deviations or failures to comply, except that the section on discovery procedure (5.2.1) states that "Discovery occurs when a material or equipment deviation or discrepancy is documented, e.g., on a Defect Report, MRT [Material Removal Ticket], etc.; or a failure to comply is documented." The inspector pointed out that this statement does not cover all possible sources of potential deviations, and suggested revising the procedure to emphasize such reporting.

The inspector also noted that whittaker would rarely have the plant-specific information necessary to perform the required evaluation of deviations, and suggested instead that the procedure concentrate on the five-day notification of customers addressed in 10 CFR 21.21(b), so that customers can perform the evaluation. The suggested changes would result in a shorter procedure that would better address the Part 21-related activities that Whittaker normally performs.

Review of selected specific issues, as detailed below, indicated that Whittaker's Part 21 reporting program was functioning properly. The inspector noted that copies of QAP 15-02 and 10 CFR Part 21 were posted in several locations, and a copy of section 206 of the Energy Reorganization Act of 1974 was posted on one bulletin board. The inspectors concluded that Whittaker's activities with respect to 10 CFR Part 21 appeared to be acceptable.

\subsection{Review of Specific Part 21 Reports}

- Hydrogen analyzer sensor low sensitivity - Interim Report dated February 3, 1994, and Final Report dated June 9, 1994 
The concern, originally identified at the Prairie Island nuclear power station, was determined by Whittaker to involve a manufacturing lot also affecting the H.B. Robinson and San Onofre stations. The manufacturing lot was produced by a newly-certified technician and a trainee, using a procedure which required repetitively adding electrolyte, evacuating, and venting a sensor until bubbles no longer came out of solution. Evaluation of returned sensors showed low electrolyte levels, indicating incomplete initial fill. The manufacturing procedure was revised to add a specification for a minimum electrolyte volume. The inspector considered Whittaker's analysis, notifications, and corrective actions to be acceptable.

- Hydrogen analyzer flow switch wire insulation - Written notification dated March 8, 1991 and Licensee Event Report No. 91-003 dated March 4, 1991, from the Fermi 2 nuclear power plant.

The concern involved the use of Teflon wire insulation, which could suffer radiation degradation and cause a short circuit, instead of the qualified Tefzel insulation for a reed switch in a hydrogen analyzer flow switch. The concern arose from the acquisition of Exo-Sensor, the original manufacturer, by whittaker. The reed switch specified on Exo-Sensor's drawing was normally supplied commercial grade by Chem-Tec with Teflon wire insulation; the ExoSensor drawing contained a note specifying Tefzel, which was available from the switch supplier as an option. Exo-Sensor's practice, but not Whittaker's, was to include drawing notes in purchase orders. Thus, Whittaker's first procurement of these switches failed to specify Tefzel. The drawing was changed to assign a unique part number to the switch using Tefzel. The inspector considered Whittaker's analysis, notifications, and corrective actions to be acceptable.

- Excessive play in control rod step counters - Licensee Event Report (LER) No. 93-005, Revision 1, dated February 22, 1993, from the Sequoyah unit 2 nuclear plant.

Although this concern was not reported as a formal Part 21 notification, the inspector pursued it as having reportability potential. The LER stated that the malfunctioning step counters were manufactured by Whittaker and obtained from Scientific Sales, Inc. The LER failed to state that the counters were supplied by Whittaker as commercial grade items. Thus Whittaker had no Part 21 responsibilities for the counters.

\subsection{Commercial Grade Item Dedication}

One of the eight 1 icensee PO files reviewed by the NRC inspectors included dedication of a commercial grade power supply for nuclear safety-related use. The dedication was accomplished by functional testing in accordance with a five-page test procedure. The NRC inspector considered the dedication to be adequate. The inspector noted that Whittaker's current dedication form appeared to focus on the essential elements of a dedication: equipment description, safety function, failure modes, critical characteristics, and the verification requirement for each characteristic.

The inspector also reviewed files for two licensee inspections of Whittaker, a surveillance by an individual utility in January 1994, and an audit by an industry group in September 1994. Both inspections identified findings for inconsistencies in Whittaker's implementation of its dedication program, 
particularly with respect to completeness of the critical characteristics list. These licensee activities appear to be adequately addressing concerns with implementation of the dedication program.

4 PERSONNEL CONTACTED

\section{Whittaker:}

\begin{tabular}{|c|c|c|}
\hline & & C.W. Deisenroth, President \\
\hline & & G.E. King, Director of Product Assurance \\
\hline & & F.P. Rudek, Program Manager \\
\hline & & L.L. Nickoley, Quality Engineering Manager \\
\hline & * & G.D. Griffis, Quality Assurance Engineer \\
\hline & * & R. Stuart, Quality Assurance Engineer \\
\hline & * & J. Williams, Quality Administrator \\
\hline & * & $\begin{array}{l}\text { K. Johnston, Quality Control Manager } \\
\text { F. Accario, Calibration Laboratory Manager } \\
\text { R. Mauldin. Chief Enqineer }\end{array}$ \\
\hline & & $\begin{array}{l}\text { R. Mauldin, Chief Engineer } \\
\text { J. Fuller, Project Engineer }\end{array}$ \\
\hline & & B. Battin, Technician \\
\hline & & M. Erixon, Director of Offsite Operations \\
\hline & & $\begin{array}{l}\text { D. Briggs, Business Area Manager } \\
\text { R. McKinnay, Production Control Manager }\end{array}$ \\
\hline & * & C.J. Hutchison, Contract Administrator \\
\hline & & ] T \\
\hline
\end{tabular}

+ Attended the entrance meeting on April 3, 1995

* Attended the exit meeting on April 6, 1995 
Selected Generic Correspondence on the Adequacy of

Vendor Audits and the Quality of Vendor Products

Identifier

Information Notice $95-22$

Information Notice $95-26$

\section{Title}

Hardened or Contaminated Lubricants Cause Metal Clad Circuit Breaker Failures

Defect in Safety Related Pump Parts Due to Inadequate Heat Treatments 
CORRESPONDENCE RELATED TO VENDOR ISSUES 
Mr. Randy P. Smith, President

Automatic Switch Company

50-56 Hanover Road

Florham Park, NJ 07932

SUBJECT: ASCO RESPONSE TO A NOTICE OF NONCONFORMANCE CONTAINED IN NRC INSPECTION REPORT 99900369/95-01

This letter addresses the Automatic Switch Company (ASCO), May 19, 1995, response letter to the U.S. Nuclear Regulatory Comission (NRC) regarding the Hotice of Nonconformance (NON) issued to ASCO on May 15, 1995, with NRC Inspection Report 99900369/95-01.

The NRC review of your May 19, 1995, NON response letter found that the ASCO statements were generally responsive to our concerns. However, as discussed with Messrs. S. Casadevall and G. Plechy of your staff on May 31, 1995, some additional clarifications to your response were required to ensure that your corrective action responded to the NON. As a result of our conversation, it is our understanding that ASCO will ensure that its new HV-270000 SOV series, which has replaced ASCO's NP8323 SOV series for certain main steam isolation valve (MSIV) applications, will not be manufactured using any greases or lubricants internal to the SOV.

Your proposed corrective action to Nonconformance 95-01-01, as a result of our discussion, was found to be acceptable and further communication regarding tris issue is not required. We will review the implementation of your corrective action during a future NRC inspection to determine the adequacy of your corrective action and ensure that full compliance has been achieved and will be maintained.

In accordance with 10 CFR 2.790 of the NRC's "Rules of Practice," a copy of this letter will be placed in the NRC Public Document Room.

Sincerely,

(Original signed by)

Robert M. Gallo, Chief

Special Inspection Branch

Division of Technical Support

office of Nuclear Reactor Regulation

Docket No. 99900369

cc: See next page. 
cc:

Mr. F. R. B. Matthews, Vice President

Product Development and Technology

Valve Department

Automatic Switch Company

50-56 Hanover Road

Florham Park, NJ 07932

Mr. David B. Tompsen, Quality Assurance Director Automatic Switch Company

50-56 Hanover Road

Florham Park, NJ 07932

Mr. William C. Kirchhoff, NED Superintendent

LaSalle Site Support Engineering

LaSalle County Nuclear Station

RR\#1 Post Office Box 220

2601 North 21st Road

Marseilles, IL 61341 


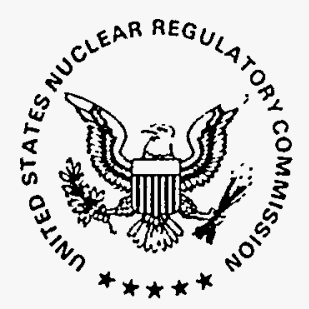

UNITED STATES

NUCLEAR REGULATORY COMMISSION

WASHINGTON, D.C. 20555-0001

April 24, 1995

Mr. Scott Akers, Jr., Chief Executive Officer

Cardinal Industrial Products,

Limited Partnership

3873 West Oquendo

Las Vegas, Nevada 89118

SUBJECT: EVALUATION AND CONCLUSION REGARDING THE REPLY TO THE NOTICE OF

NONCONFORMANCE (NRC INSPECTION REPORT NO. 999001076/94-01)

Dear Mr. Akers:

I am responding to your January 30, 1995, reply to the Notice of Nonconformance (NON) that was issued by the U.S. Nuclear Regulatory Commission (NRC) on December 30, 1994, following an NRC inspection of Cardinal Industrial Product's (Cardinal's) facility in Las Vegas, Nevada. The Notice of Nonconformance identified Cardinal activities which failed to comply with the requirements of Appendix $B$ of Part 50 to Title 10 of the Code of Federal Regulations (10 CFR Part 50).

In your response to Nonconformance 99901076/94-01-03, you state that you have been unable to establish a relationship or applicability of the NRC-cited requirements to Cardinal's documented Quality Systems Manual (QSM)

requirements. You further state that Cardinal's QSM does, in fact, require that procured material and/or product comply with the invoked procurement document requirements. Additionally, you state that criterion VII of 10 CFR Part 50, Appendix B does not address the use of sampling plans for verification of compliance to the applicable procurement document requirements, and that you consider that Cardinal's sampling plan, which was reviewed during the inspection, provides reasonable assurance that the product complies with the applicable procurement requirements.

NRC staff comments concerning the relationship between NRC requirements and Cardinal's sampling practices are summarized in the following paragraphs. These comments are applicable to procurements where the purchase documents invoke 10 CFR Part 50, Appendix $B$, as the basis for product acceptance. Where specific acceptance criteria or sampling plans are specified by the customer, it is expected that the customer (licensee) will assure the compliance with Appendix B for the intended application.

- $\quad 10$ CFR Part 50, Appendix B, Criterion II requires, in part, that a quality assurance program be established to provide control over activities affecting the quality of structures, systems, and components. Conformance with this Criterion would generally require Cardinal to impose the applicable provisions of 10 CFR Part 50, Appendix B, on their suppliers and subsuppliers and assure compliance with these provisions. 
- $\quad 10$ CFR Part 50, Appendix B, Criterion VII states, in part, that measures shall be established to assure that purchased material, equipment, and services, whether purchased directly or through contractors and subcontractors, conform to the procurement documents. The American Society for Testing and Materials (ASTM) fastener specifications referenced in most customer purchase orders involving Cardinal are considered part of the procurement documents.

For certain applications, the NRC staff has accepted commercial grade item (CGI) dedication as an alternative method to the programmatic quality assurance measures prescribed in Criteria II and VII of 10 CFR Part 50, Appendix $B$, for assuring that items purchased from commercial sources will meet the applicable purchase specification requirements. For organizations such as Cardinal that choose to supply material in this manner, it would be acceptable to follow NRC CGI dedication guidance. Such guidance has been published in NRC Generic Letters 89-02 and 91-05. With respect to sampling plans, NRC Inspection Manual Procedure 38703 inspection guidance states that such plans should be controlled and have an adequate technical bas is and also discusses the application of different sampling plans based on lot/batch homogeneity. These documents are provided to you as enclosures to this letter.

Cardinal's destructive testing sample plan, which is based on the Shipping Lot Method sampling plan described in ASTM Specification A-325, "Specification for High Strength Bolts for Structural Steel Joints," does not provide reasonable assurance that material procured from commercial manufacturers or distributors (heat/lot traceability not established) will conform to the specified requirements. The lack of assurance can be demonstrated by a probability calculation assuming a lot of 280 fasteners with $50 \%$ of the fasteners (140) being nonconforming with respect to chemical composition. Since, according to Cardinal's sampling plan, only 2 fasteners are tested for chemistry, the probability of the two fasteners being acceptable is

$(140 / 280) \times(139 / 279)=25 \%$. This implies that there is a $75 \%$ chance that the lot will be rejected. Thus, the confidence level is only $75 \%$ that a lot of fasteners with $50 \%$ of them being nonconforming, will be rejected.

The above example assumes testing a random population of fasteners. The NRC staff recognizes that additional assurance of adequate fastener performance could be achieved by combining Cardinal's sampling approach with other factors such as test results of other parameters which may be indicative of heat/lot traceability and homogeneity and the historical performance of fasteners obtained from a particular supplier. When such factors are considered, the rationale for their use and the basis for their contribution to the overall confidence level can be explained in the sampling plan. Neither at the time of the NRC inspection nor in its submittal has Cardinal provided documentation how, if at all, such factors were considered in the technical basis for its sampling plan.

Additionally, the A-325 Shipping Lot Method sampling plan, as used by Cardinal, does not appear to be an appropriate application to assure product 
compliance to other fastener specifications when sampling a wide range of fastener products obtained from several commercial manufacturers and distributors. Other fastener specifications such as ASTM A-193, "Specification for Alloy-Steel and Stainless Steel Bolting Material for High Temperature Service," require more rigorous sampling as a part of the manufacturing process. Section 11.1 .3 of that specification requires one tension test for studs, bolts, and screws for each diameter of every heat of material from a given lot of fasteners. Thus, a distributor such as Cardinal selling fasteners obtained from an unqualified source would not be able to assure conformance to ASTM A-193 by relying on the Shipping Lot Method of sampling as described in ASTM A-325.

For safety related items, the NRC staff would generally accept a confidence level of $90-95 \%$ that no more than $5-10 \%$ of items sampled are nonconforming. The most common sampling standard used by NRC 1 icensees that is accepted by the NRC staff is MIL-STD-1050. This standard contains various samoling plans and provides sampling procedures ana tables for inspection by att ibutes.

In your response to Nonconformance 99901076/94-01-03 you also state that all of your customers have accepted your existing sampling programs. As discussed in Inspection Report 99901076/94-01, the inspectors reviewed the report of the last audit by the Nuclear Utilities Procurement Issues Committee (NUPIC) which was performed in Apri1, 1994. That NUPIC audit report did not address sampling methods used by Cardinal during its commercial grade dedication process. Therefore, licensees using the NUPIC audit as the basis for qualifying and procuring safety related items from Cardinal would be unaware of the use of Cardinal's destructive testing sample plan in its commercial grade item dedication process.

The NRC staff has reviewed your response to Nonconformance 99901076/94-01-04 and finds that it adequately addresses our concerns. We will review your corrective actions and actions to prevent recurrence during a future inspection.

You are requested to address the NRC staff comments above concerning your January 30, 1995, response to Nonconformance 99901076/94-01-03 and provide additional response within 30 days of your receipt of this letter.

In accordance with Section 2.790 of 10 CFR, a copy of this letter will be placed in the NRC's Public Document Room. 
If you should have any questions concerning the inspection or the additional information requested by this letter, we will be glad to discuss them with you.

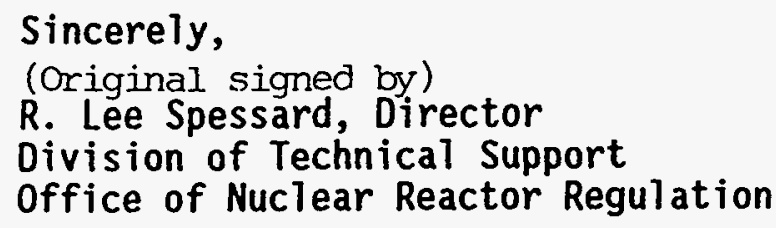

Docket No.: 99901076

Enclosures:

1. NRC Generic Letters $89-02$ and 91-05

2. NRC Inspection Manual Procedure 38703 


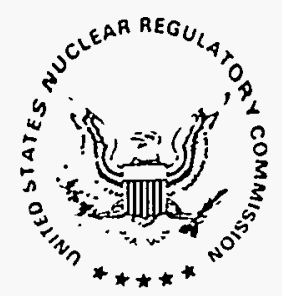

\author{
UNITED STATES \\ NUCLEAR REGULATORY COMMISSION \\ WASHINGTON, D. C. 20555 \\ i. $\operatorname{arch} 21,1989$
}

TO: $\quad$ ALL HOLDERS OF OPERATING LICENSES AND CONSTRUCTION PERMITS FOR NUCLEAR POWER REACTORS

SUBJECT: ACTIONS TO IMPROVE THE DETECTION OF COUNTERFEIT AND FRAUDULENTLY MARKETED PRODUCTS (GENERIC LETTER 89-02)

Recent instances of counterfeit and fraudulently marketed vendor products have heightened the NRC's concerns for licensees' capability to assure the quality of procured products and to reduce the likelihood of the use of count ifeit or fraudulent products in nuclear power plants. During recent NRC inspections of licensees and vendors, the NRC has observed a wide variety of practices and programs for procurement, receipt inspection, testing and dedication of equipment and material for safety-related applications. The purpose of this generic letter is to share with all licensees some of the elements of programs that appear to be effective in providing the capability to detect counterfeit or fraudulently marketed products and in assuring the quality of vendor products. The staff is aware of and encourages the industry working group efforts to develop guidance in these areas.

Three characteristics of effective procurement and dedication programs have been identified during these NRC inspections. These characteristics are (1) the involvement of engineering staff in the procurement and product acceptance process, (2) effective source inspection, receipt inspection, and testing programs, and (3) thorough, engineering based, programs for review, testing, and dedication of commercial-grade products for suitability for use in safety-related applications. NRC has found that programs that embodied the above three elements were generally effective in providing enhanced capability to detect counterfeit or fraudulently marketed products and in assuring the quality of procured products, both in safety-related and other plant systems.

Licensees may want to consider the applicability of these characteristics to their programs to reduce the likelihood of the introduction of counterfeit or fraudulent products into their plants and to assure the quality of procured vendor products.

ic should be noted that the NRC staff conditionally endorses the guidelines contained in EPRI NP-5652, "Guideline for the Utilization of Commercial-Grade Items in Nuclear Safety-Related Applications (NCIG-07), " that was issued by EPRI in June 1988 for evaluating commercial-grade products for suitability for use in safety-related applications.

Background:

Numerous instances have been identified by the NRC during the past 2 years in which the nuclear industry received, accepted, and installed items of hardware 
that were not of the quality purported by the manufacturer or suppiier due to apparent misrepresentation. Significant deficiencies have also been identified in the programs for dedicating commercial-grade products for use in safetyrelated applications.

The use in nuclear facilities of products which are counterfeit or fraudulently marketed increases the likelihood that some plant equipment may not perform as expected. (See the enclosed list of NRC Information Notices and Bulletins regarding this matter.)

Discussion:

Procurement quality assurance (QA) controls for products to be used in safetyrelated applications are established in Appendix $B$ to 10 CFR Part 50, and in Regulatory Guides $1.28,1.33$, and 1.123. It is recognized that Appendix $B$ provides criteria for QA programs and does not specificâlly address fraudulent activities; however, an effectively implemented 1 icensee QA program would increase the likeiihood of detecting fraudulentiy marketed vendor products. Although a properly implemented QA program may more readily detec $i$ substandard products than will the commercial-grade component upgrade process, a licensee's commercial-grade dedication process, as described in paragraph C., will greatly enhance the effectiveness of current upgrade practices. The actions described in paragraphs $A$. and $B$. have also proved useful in detecting substandard, counterfeit or fraudulently marketed products intended for use in systems needed for the safe operation of the facility.

A. Engineering Involvement in the Procurement Process

Appropriate engineering involvement is warranted during the procurement arid product dcceptance processes, including testing, for products used in nuclear power plants. Inadequate engineering involvement has been a common weakness in 1 icensees' procurement programs, particularly when commercial-grade procurements were involved. Involvement of a iicensee's engineering staff in an effective procurement process would normaliy include (1) development of specifications to be used for the procurement of products to be used in the plant, (2) determination of the critical characteristics of the selected products that are to be verified during product acceptance, (3) determination of specific testing requiremitits applicable to the selected products, and (4) evaluation of test results. The extent of necessary engineering involvement is dependent on the nature and use of the products involved.

E. Product A.cceptance Programs

Experience indicates that reliance on part number verification and certification documeritation is insufficient to ensure the quality of procured products. Licensees with effective product acceptance programs have included receipt/source inspection and appropriate testing criteria, effective vendor audits, special tests and inspections and post-installation tests in their programs. These licensees have applied the inspection 
and testing criteria to products procured for use in safety-related systems and for all commercial-grade products being evaluated for suitability for use in safety-related systems. The inspection and testing criteria also have required identification and verification of the products' critical characteristics. In selecting the critical characteristics to be verified, consideration may be given to the safety significance, complexity, and application of the various products. For suppliers with acceptable QA programs, as confirmed by licensee audits, samplinq plans are of ten utilized to perform the required inspections and tests. In addition to these receipt/source inspections and tests, effective licensee programs normally verify the traceability to the original manufacturers of procured materials, equipment, and components in those cases where original manufacturer's certifications are elements of the safety-related procurement or commercial-grade dedication program. Effective audits have included consideration of audit approach, depth of audit, and audit team compociticn and have included appropriate engineering/technical representatives. Comprehensive multi-licensee audit teams have also been found to be effecti,e.

\section{Dedication Programs}

It is each licensee's responsibility to provide reasonable assurance that nonconforming products are not introduced into their plants. Dedication programs that ensure the adequacy of critical parameters of products used in safety-related applications can also contribute to the identification of counterfeit or fraudulently marketed vendor products.

The NRC staff believes that licensees who use methods similar to those described in EPRI IsP-5652 "Guideline for the Utilization of CommercialGrade Items in Nuclear Safety-Related Applications (NCIG-07), " to verify the critical characteristics of commercial-grade items intended for safetyrelated appiiations have the basis for effective dedication programs.

Properly implemented, the EPRI guidelines, as modified below, establish methods which satisfy existing requirements of Appendix $B$ to 10 CFR Part 50 as they apply to the dedication process of commercial-grade items.

1. Acceptance Method 2, "Commercial-Grade Survey of Supplier," should not be employed as the basis for accepting items from suppliers with undocumented commercial quality control programs or with programs that do not effectively implement their own necessary controls. Likewise, Method 2 should not be employed as the basis for accepting items from distributors unless the survey includes the part manufacturer(s) and the survey confirms adequate controls by both the distributor arid the part manufacturer(s).

2. Acceptance Method 4, "Acceptable Supplier/Item Performance Record," should not be employed alone unless: 
a. The established historical record is based on industrywide perforiance data that is directly applicable to the item's critical characteristics and the intended safetyrelated application; and

b. The manufacturer's measures for the control of design, process, and material changes have been adequately iniplemented as verified by audit (multi-licensee team audits are acceptable).

The NRC staff beiieves that if licensees' procurement prograns effectively implement the elements discussed in paragraphs, A., B., and C., they will reduce the likelihood of the introduction of counterfeit or fraudulent products into their plants.

Although no response to this letter is required, if you have any questions reyarding this matter, please contact the technical contact listed below.

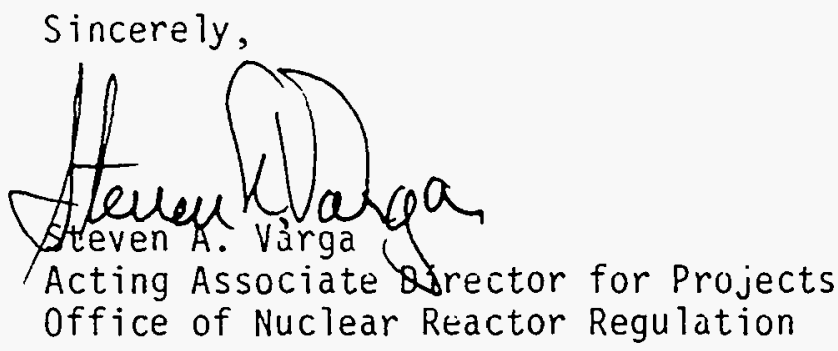

Enclosures:

1. List of Bulletins and Information Notices

2. List of Recently Issued Gerieric Letters

CONTACT:

E. Hilliam Brach, NRR

(301) 492-0961 
BULLETINS AND INFORMATION NOTICES CONCERNING NONCONFORMING MATERIALS AND EQUIPMENT AND INSTANCES OF INADEQUATE DEDICATION OF EQUIPMENT FOR SAFETY-RELATED APPLICATIONS

Bulletin No. $87-02 *$
Title

Fastener Testing to Determine Conformance with Applicable Material Specifications

Date

$11 / 06 / 87$

$04 / 22 / 8 \varepsilon$

$06 / 10 / 88$

$87-02$, Supplement $1^{\star}$
$87-02$, Supplement $2^{\star}$

$05 / 06 / 88$

$88-05^{*}$

Nonconforming Materials Supplied by Piping

Supplies, Inc., at Folsum, New Jersey, and

Hest Jersey Manufacturing Company at

Williamstown, New Jersoy

88-05, Supp Tement 1 *

$06 / 15 / 88$

88-05, Supplement $2 *$

$08 / 03 / 88$

$88-10 *$

Nonconforming Molded-Case Circuit Breakers

$11 / 22 / 88$

Information Notice No.

$87-66$

Inappropriate Application of Commercial-Grade

$12 / 31 / 87$ Components

88-19*

Questionable Certificarion of Class IE Components

$04 / 26 / 88$

88-35

Inadequate Licensee Performed Vendor Audits

$06 / 03 / 88$

$88-46^{*}$

Licensee Report of Defective Refurbished

$07 / 08 / 88$ Circuit Breakers

88-46, Supplement 1 *

$07 / 21 / 88$

88-46, Supplement $2 *$

$12 / 30 / 88$

$88-48 *$

Licensee Report of Defective Refurbished Valves

$07 / 12 / 88$

88-48, Supp lement 1*

$08 / 24 / 88$

$88-97$

Potentially: Substandard Valve Replacement Parts

$12 / 16 / 88$

*These items reflect instances in which suppliers and manufacturers of safetyrelated material may have intentionally eluded $Q A$ requirements to misrepresent the quality of their products. In the instances mark blem was brought to NRC's attention by either a licensee or a nuclear supplier. 
LIST OF RECENTLY ISSUED GENERIC LETTERS

\begin{tabular}{|c|c|c|c|}
\hline $\begin{array}{l}\text { Generic } \\
\text { Letter No. }\end{array}$ & Subject & $\begin{array}{l}\text { Date of } \\
\text { Issuance }\end{array}$ & Is sued To \\
\hline $89-01$ & $\begin{array}{l}\text { IMPLEMENTATION OF } \\
\text { PROGRAMMATIC CONTROLS } \\
\text { FOR RADIOLOGICAL EFFLUENT } \\
\text { TECHNICAL SPECIFICATIONS } \\
\text { IN THE ADMINISTRATIVE } \\
\text { CONTROLS SECTION OF THE } \\
\text { TECHNICAL SPECIFICATIONS } \\
\text { AND THE RELOCATION OF } \\
\text { PROCEDURAL DETAILS OF } \\
\text { RETS TO THE OFFSITE DOSE } \\
\text { CAL CULATION MANUAL OR TO } \\
\text { THE PROCESS CONTROL PROGRAM. }\end{array}$ & $1 / 31 / 89$ & $\begin{array}{l}\text { ALL LICENSEES HOLDING } \\
\text { OPERATING LICENSES } \\
\text { AND CONSTRUCTION } \\
\text { PERMITS FOR NUCLEAR } \\
\text { POWER REACTOR FACILITIES. }\end{array}$ \\
\hline $88-20$ & $\begin{array}{l}\text { INDIVIDUAL PLANT } \\
\text { EXAMINATION FOR SEVERE } \\
\text { ACCIDENT VULNERABILITIES - } \\
10 \text { CFR } 50.54(\mathrm{f})\end{array}$ & $11 / 23 / 88$ & $\begin{array}{l}\text { ALL LICFI; ;EES HOLDING } \\
\text { OPERATIP. LICENSES } \\
\text { AND CONSTRUCTION } \\
\text { PERMITS FOR NUCLEAR } \\
\text { POWER REACTOR FACILITIES }\end{array}$ \\
\hline $88-19$ & $\begin{array}{l}\text { USE OF DEADLY FORCE BY } \\
\text { LICENSEE GUARDS TO PREVENT } \\
\text { THEFT OF SPECIAL NUCLEAR } \\
\text { MATERIAL }\end{array}$ & $10 / 28 / 88$ & $\begin{array}{l}\text { ALL FUEL CYCLE FACILITY } \\
\text { LICENSEES WHO POSSESS, } \\
\text { USE, IMPORT, EXPORT, } \\
\text { OR TRANSPORT FORMULA } \\
\text { QUANTITIES OF STRATEGIC } \\
\text { SPECIAL NUCLEAR MATERIAL }\end{array}$ \\
\hline $88-18$ & $\begin{array}{l}\text { PLANT RECORD STORAGE ON } \\
\text { OPTICAL DISKS }\end{array}$ & $10 / 20 / 88$ & $\begin{array}{l}\text { ALL LICENSEES OF } \\
\text { OPERATING REACTORS } \\
\text { AND HOLDERS OF } \\
\text { CONSTRUCTION PERMITS }\end{array}$ \\
\hline $88-17$ & $\begin{array}{l}\text { LOSS OF DECAY HEAT REMOVAL } \\
10 \text { CFR } 50.54(\mathrm{f})\end{array}$ & $10 / 17 / 88$ & $\begin{array}{l}\text { ALL HOLDERS OF } \\
\text { OPERATING LICENSES } \\
\text { OR CONSTRUCTION } \\
\text { PERMITS FOR } \\
\text { PRESSURIZED WATER } \\
\text { REACTORS }\end{array}$ \\
\hline $88-16$ & $\begin{array}{l}\text { REMOVAL OF CYCLE-SPECIFIC } \\
\text { PARAMETER LIMITS FROM } \\
\text { TECHNICAL SPECIFICATIONS }\end{array}$ & $10 / 04 / 88$ & $\begin{array}{l}\text { ALL POWER REACTOR } \\
\text { LICENSEES AND } \\
\text { APPLICANTS }\end{array}$ \\
\hline $88-15$ & $\begin{array}{l}\text { ELECTRIC POWER SYSTEMS - } \\
\text { INADEQUATE CONTROL OVER } \\
\text { DESIGN PROCESSES }\end{array}$ & $09 / 12 / 88$ & $\begin{array}{l}\text { ALL POWER REACTOR } \\
\text { LICENSEES AND } \\
\text { APPLICANTS }\end{array}$ \\
\hline
\end{tabular}




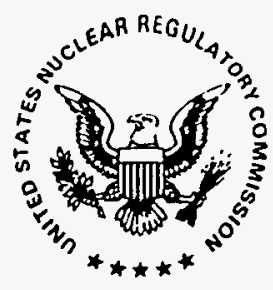

UNITED STATES

NUCLEAR REGULATORY COMMISSION

WASHINGTON, D. C. 20555

Apri1 9, 1991

TO: ALL HOLDERS OF OPERATING LICENSES AND CONSTRUCTION PERMITS FOR
NUCLEAR POWER REACTORS

SUBJECT: LICENSEE COMMERCIAL-GRADE PROCUREMENT AND DEDICATION PROGRAMS (GENERIC LETTER 91-05)

This generic letter notifies the industry of the staff's pause in conducting certain procurement inspection and enforcement activities and identifies a number of failures in licensees' conmercial-grade dedication programs identified during recent team inspections performed by the U.S. Nuclear Regulatory Commission (NRC). The pause, which began in March of 1990, will end in late summer of 1991. The purpoje of the pause is to allow licensees sufficient $t^{-n} n_{2}$ to fully understand and implement guidance developed by industry to improve procurement and commercial-grade dedication programs. This generic letter expresses staff positions regarding certain aspects of licensee commercial-grade procurement and dedication programs which would provide acceptable methods to meet regulatory requirements.

During the period from 1986 to 1989, the NRC concucted 13 team inspections of the licensees' procurement and commercial-grade dedication progranis. During these inspections, the NRC staff identified a common, programmatic deficiency in the licensees' control of the procurement and dedication process of commercial-grade items for safety-related applications. In a number of cases, the staff found that licensees had failed to adequately maintain programs as required by 10 CFR Part 50, Appendix $B$, to assure the suitability of commercially procured and dedicated equipment for its intended safety-related applications. In addition, the staff identified equipment of indeterminate quality installed in the licensees' facilities.

Because of a decrease in the number of qualified nuclear-grade vendors, the NRC staff is aware that there has been a change in the industry's procurement practices. Ten years ago, 1icensees procured major assemblies from approved vendors who maintained quality assurance programs pursuant to Appendix $B$ of Part 50 of Title 10 of the Code of Federal Regulations (10 CFR). Currently, due to the reduction in the number of qualified nuclear-grade vendurs, licensees are increasing the numbers of commercial-grade replacement parts that they procure and dedicate for use in safety-related applications. This is a substantial change from the environment in which 10 CFR Part 50, Appendix $B$ was promulgated. This has necessitated an increased emphasis by licensees and the NRC staff to mainta in procurement and dedication programs that adhere to the requirements of 10 CFR Part 50, Appendix $B$, and thus assure the quality of items purchased and installed in safety-related applications. Therefore, dedication processes for commercial-grade parts have increased in importance and NRC inspections have determired that a number of licensees have not satisfactorily performed this procurement and dedication process. 
The industry has been made fully aware of the NRC's concerns in this program area. In the past, escalated enforcement cases have provided notice to the affected licensees and to the industry of NRC's findings, concerns, and expectations in the implementation of procurement and dedication programs.

Further, the NRC staff continues to participate in numerous industry meetings and conferences at which the NRC's positions in this area have been presented. The Nuclear Utility Management and Resources Council (NUMARC) Board of Directors recently approved a comprehensive procurement initiative as described in NUMARC 90-13, "Nuclear Procurement Program Improvements," which commits licensees to assess the ir procurement programs and take specific action to enhance or upgrade the program if they are determined to be inadequate. The initiative on the dedication of commercial-grade items, which is part of NUMARC 90-13, was to be implemented by January 1, 1990. The staff is monitoring implementation of 1 icensee program improvements by conducting assessments of the ir procurement and commercial-grade dedication programs and maintaining close interaction with the nuclear industry through participation in conferences, panels, and meetings.

The staff will continue to perform reactive inspections relating to plant specific operational events or to defective equipment and, as required, will continue to initiate resultant enforcement actions. In addition, the staff will continue to perform inspections of vendors. The staff expects to resume procurement and dedication inspection activities in the late summer of 1991. These resumed inspections will be conducted using 10 CFR Part 50, Appendix B (not the NUMARC initiatives) as the applicable regulatory requirement. Licensee programs must assure the suitability of commercially procured and dedicated equipment for its intended safety-related application.

The staff position is that the staff will not initiate enforcement action in cases of past programmatic violations that have been adequately corrected. In addition, the staff does not expect licensees to review all past procurements. However, if during current procurement activities, licensees identify shortcomings in the form, fit, or function of specific vendor products, or if failure experience or current information on supplier adequacy indicates that a component may not be suitable for service, corrective actions are required for all such installed and stored items in accordance with Criterion XVI of 10 CFR Part 50, Appendix B. Also in accordance with Criterion XVI, licensees must determine programmatic causes when actual deficiencies in several products from different vendors are identified during current procurement activities and these deficiencies lead to the replacement of installed items as part of the corrective action. In such cases, a further sampling of previously procured commercial-grade items may be warranted.

In NRC Generic Letter (GL) 89-02, "Actions to Improve the Detection of Counterfeit and Fraudulently Marketed Products," the staff described its perspective on good practices in procurement and dedication and provided the NRC's conditional 
endorsement of an industry ständard (EPRI NP-5652) on methods of commercialgrade procurement and dedication. A number of recent inspection findings, as discussed in Enclosure 1, indicate that licensees have failed to include certain key activities, as appropriate, in the implementation of the dedication process. The NRC staff's positions on the successful implementation of Ticensees' progranis for commercial-grade dedication with respect to critical characteristics and like-for-like replacements are as follows. (These are also inc'uded in Enclosure 1.)

The term "critical characteristics" is not contained in Appendix B ario has no special regulatory significance beyond its use and definition in various industry guides and standards. The NRC first used the term critica 7 characteristics in GL 89-02 as constituting those characteristics which need to be identifiec and verifiec ciliring product acceptal.ce as part of the procurement process. The NRC has not taken the position that àll design requirements nust be considered to be critical characteristics as defined and used in EPRI MP-565\%. Rather, as stated in Appendix B, Criterion IIl, licensees must assure the suitability of all parts, materials, and services for their intended safety-related applications (i.e., there rieeds to be assurance that the itemi will perform its intended saiety functiun, when required). The licensee is responsible for identifying the important design, material, and performance characteristics for each part, material, and service intended for safetyreldied applications, establishing acceptance criteria, and providing reasonable assurance of the curformance of items to these criteria.

A like-for-like replacement is defined as the replacement of an item with an item that is identical. For example, the replacement item would be identicäl if it was purchased at the same time from the same vendor as the item it is replacing, or if the user can verify that there have been no changes in the design, materials, or lianufacturing process since procuremcnt of the item beins replaced. If differences from the original iten are identified in che replacement item, then the item is not identical, but similar to the item being repiaced, and an evaluation is necessary to deternine if any changes in design, material, or the manufacturing process could impact the functional characteristics and ultimately the cumponent's ability to perform its required safety function. If the licensee can demonstrate that the replacement iteni is identical, then the licensee need not identify the safety function or review and verify the design requirements and critical characteristics. Engineering involvement is necessary in the above activities. Reliance on part number verification and certification documentation is irisufficient to ensure the quality of commercially procured products.

The other matters discussed in Enclosure 1 do not ccristitute NRC staff positions, but provide information on inspection findings and clarify the characterization of effective procurenent and dedication programs previously described in GL 89-02.

\section{BACKFIT DISCUSSION:}

Based cr past inspection findings and the resulting enforcement actions, the INC staff has determined that licensee commercial-grade procurement and 
deaication programs needeci to be improved to comply with the existing NRC requirements as described in 10 CFR Part 50, Appendix B, Criterior III (Design Coritrol), IV iProcurement Document Control), VII (Control of Purchased Materiai, Equipment and Services), and XVIII (Audits). Specifically, licensees have failed to adequately maintain programs to assure the suitability of conmercially prucured ard dedicated equipment for its intended safety-related application. Since the generic letter presents staff pcsitions regarding impiementation of existing regulatory requirements, as contained in Appelidix $B$ to 10 CFR Part 50, the staff has concluded, that this is a conpliance backfit arid has prepared the gerieric letter in accordance with 10 CFR 50.109 (a)(4)(i). In light of the inadequacies identified in the procurement and dedication prograns of a large number of licerisees, the issuance of this generic letter is necessary to express the staff's pusition on the key element that licensees must inclucit as part of the dedication process, specificaliy that commercialgrade procurement and dedication programs must assure the suitability of tquipment for its intended safety-related application. This generic letter is also intended to clarify the elements of effective procurement and commercial-grade dedication programs that were previously provided to licensees in GL 89-02. Since licensets' procurement and decication programs may contain programmatic deficiencies, the staff has ilicluded in the generic leiter the necessary licel,see corrective action to address shortcomings identified in specific vendor products or components that directly lead to the component not being suitahle for safety-related service.

Although no response to this letter is required, if you have any questions regarding this matter, please contact the persons listed below.

Sincerely,

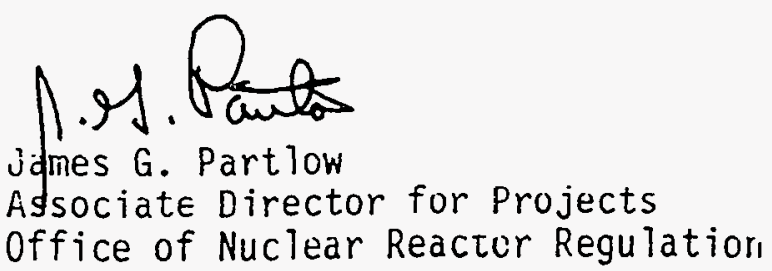

Enclosures:

1. Characteristics of Effective Commercial-Grade

Procurement and Dedication Prugrams

2. List of Recently Issued Generic Letters

Technical Contacts: Richard P. HcIntyre, NRR

(301) $49 \hat{\imath}-3215$

Uldis Potapovs, NRR

(301) 492 -0959 


\section{CHARACTERISTICS OF EFFECTIVE COMMERCIAL-GRADE}

PROCUREMENT AND DEDICATION PROGRAMS

\section{Background}

Appendix B to 10 CFR Part 50 contains the NRC's regulations for procurement quality assurance (QA) and quality control (QC) for products to be used in safety-related applications. In addition, the NRC has provided further guidance in Regulatory Guides $1.28,1.33$, and 1.123 . These requirements and guides, if properly implemented, provide a measure of assurance for the suitability of equipment, including commercial-grade items for use in safety-related systems. Criterion III of Appendix B requires licensees to select and review for suitability of application materials, parts, equipment, and processes that are essential to the safety-related functions of the structures, systems, and components. Criterion IV requires that procurement documents specify the applicable requirements necessary to ensure functional performance. Criterion VII requires licensees to assure that the following are sufficient to identify whether specification requirements for the purchased material and equipment have been met: source evaluation and selection, objective evidence of quality, inspection of the source, and examination of products upon delivery. The process used to satisfy these requirements when upgrading commercial-grade items for safety-related applications is commonly called "dedication." The process of ensuring compliance with 10 CFR Part 50, Appendix $B$, must include a 11 those activities necessary to establish and confirm the quality and suitability of commercially procured and dedicated equipment for its intended safety-related application. Some of the dedication activities may occur early in the procurement cycle, before the item is accepted from the manufacturer. Generic Letter (GL) 89-02, "Actions to Improve the Detection of Counterfeit and Fraudulently Marketed Products, "discussed commercial-grade dedication in terms of engineering involvement in the procurement process, product acceptunce, and the dedication process as identified in the EPRI NP-5652 guidelines. This enclosure further discusses the characteristics of effective procurement and dedication programs previously discussed in GL 89-02 and provides examples of specific failures by licensees to effectively implement these characteristics for dedicating and ensuring the suitability of commercial-grade products for safety-related applications. Appropriate implementation of these characteristics would have avoided many of the failures to meet 10 CFR Part 50, Appendix $B$ requirements in licensee procurement and commercial-grade dedication programs which were identified during past NRC inspections.

\section{Inspection Observations and Findings}

From 1986 to 1989, headquarters and regional personnel conducted 13 team inspections of licensees' procurement and dedication programs. These inspections have identified a common, broad programmatic deficiency in licensees' control over the process of procurement and dedication of commercial-grade 
items. In a nuriber of cases, licerısees have not maintäined programs to ensure the suitability of equipment for use ir safety-related applications as required by 10 CFR Part 50, Appendix B, Criterion III. These 13 inspections resulted in findings with significant safety implications. The staff identified eight findings that were consiciered to be Severity Level III violations and three findings that were Severity Level IV violations. At one plant, the staff did not assign a severity level to iridividual violations. Instead, the staff considered the entire group to be a Severity Level III problem and used enfurcement discretion, as provided under the enforcenent pulicy, based on the licensee's corrective actions (see 10 CFR Part 2, fippendix C, Section V.G.2). Only one of the plants that were inspected did not receive violations in this prograrn area.

In GL 89-02, the $\mathrm{ARC}$ has conditionally endorsed the dedication methods described in EPRI NP-5652 guidelines. The staff believes that licensees who implenelit these dedication methods, in accordance with the NRC's endorsement, can establish a basis for satisfying the existing requirements of Appendix $B$ to 10 CFR Part 50 as these requirements appily to the dedication process for commercial-grade items. An effective curimercial-grade dedication progran must include prn:isions to demonstrate that a dedicated item is sliitable for safety-related applications. For a licensee to acequattily establish suitability, certain key activities must be performed, as appropriate, as part of the dedication process. This generic letter is intended to clarify the aedication approaches described in GL 89-02.

During each of the 13 inspections, the staff ideritified a comion element in each of the inspection findings. This element was the failure of the licensee to assure that a commercially procured and dedicated item was suitable for the iritended safety-related application. A dedicated commercial-grade item must be equivalerit in its ability to perform its intended safety function to the same iten procured under a 10 CFR Part 50, Appendix B QA program. The following is a list of the 13 licensees inspected and the inspection report numbers. A sumiary of the general inspection findings and NRC cbservations on these findings follows the list of licensee inspections.

\section{LICENSEE and PLANT}

1. Tennessee Valley Authority (Sequoyah)

2. Southern Cálifornia Edison (San Onofre)

3. Alabama Power (Farley)

4. Louisiana Power and Light (Waterford)
INSPECTION REPORT NO.

$50-327 / 86-61$

$50-328 / 86-61$

$50-206 / 87-02$

$50-361 / 87-03$

$50-362 / 87-04$

$50-348 / 87-11$

$50-364 / 87-11$

$50-38 c / 87-19$ 
5. Sacramento Municipal Utility District (Rancho Seco)

$50-312 / 88-02$

6. Maine Yankee Atomic Power (Maine Yankee)

$50-309 / 88-200$

7. Northern States Power (Prairie Island)

$50-282 / 88-201$

$50-306 / 88-201$

8. Portland General Electric (Trojan)

$50-344 / 88-39$

$50-344 / 88-46$

9. Connecticut Yankee Atomic Power (Haddam Neck)

$50-213 / 89-200$

10. Washington Public Power Supply System (WNP-2)

$50-397 / 89-21$

$50-397 / 89-28$

11. Florida Power (Crystal River)

$50-302 / 89-200$

12. Gulf 'tates Utilities (River Bend)

$50-458 / 89-200$

13. Commonwealth Edison (Zion)

$50-295 / 89-200$

$50-304 / 89-200$

1. Inspection Findings

a. Failure to identify the methods and acceptance criteria for verifying the critical characteristics, such as during receipt inspection, dedication process, or post-installation testing.

b. Failure to establish verifiable, documented traceability of complex commercial-grade items to their original equipment manufacturers in those cases where the dedication program cannot verify the critical characteristics.

c. Failure to recognize that some commercial-grade items cannot be fully dedicated once received on site. Certain items are manufactured using special processes, such as welding and heat treating. Dedication testing of these items as finished products would destroy them. For these items, licensees may need to conduct vendor surveillances or to witness certain activities during the manufacturing process.

\section{Discussion}

The NRC staff has met on several occasions with NUMARC and licensee representatives to discuss "critical characteristics" as used in the context of commercial-grade procurement and dedication. The term "critical characteristics" is not contained in Appendix B and has no special regulatory significance beyond its use and definition in various industry 
guides and standards. The NRC first used the term critical characteristics in GL 89-02 as constituting those characteristics which need to be identified and verified during product acceptance as part of the procurement process. The NRC has not taken the position that all design requirements must be considered to be critical characteristics as defined and used in EPRI NP-5652. Rather, as stated in Apperidix B, Criterion III, 1 icensees must assure the suitability of all parts, materials, and services for their intended safety-related applications (i.e., there needs to be assurance that the item will perform its intended safety function when required). The licerisee is responsible for identifying the important design, material, and performance characteristics for each part, material, and service intended for safety-related applications, establishing acceptance criteria, and providing reasonable assurance of the conformance of items to these criteria. There is no mininum or maximum number of cricical characteristics that need to be verified. Further, the critical characteristics for an item may vary from application to application cepending on the design and perfurmance requirenents unique to each applicatiull.

A licensee maly take different approaches for the verification of the critical characteristics, depending on the complexity of the item. In niany cases, the iicensee can verify the critical characteristics of each item during receipt inspection testing. However, for a complex item with internal parts which receive sfecial processing during manufacturing, the licensee may need to conduct a suurce verification of the manufacturer during production to verify the critical characteristics identified as necessary for the item to perform its safety function. When these methods cannot verify the critical characteristics related to special processes and tests, certification by the original equipment manufact:rer may be an acceptable alternative provided documented, verified iraceability to the original equipment manufacturer has been established and the purchaser has verified by audit or survey that the original equiprnent manufacturer has iliplemented adequate quality controls for the : tivity being certified.

For items with critical characteristics that can be verified 2 . the most severe or limiting plant application, the licensee might prefer to identify and verify the item's critical characteristics to qualify that item for a il possible plant applications. For complex items that would be purchased for specific plant applications, it may be appropriate to address the acceptance criteria for each item individually. Engineering involvement is important in either method because the technical evaluation will identify the critical characteristics, acceptance criteria, and the methods to be used for verification.

2. Irspection Findings

a. Failure to demonstrate that a like-for-like replacement iten is identical in form, fit, and function to the item it is replacing. part number verification is not sufficient because of the probability of undocumented changes in the design, material, or fabrication of commercial-grade items using the same part number. 
5. Failure to evaluate changes in the design, material, or manufacturing process for the effect of these changes on safety function perforliance (particularly under aesign basis event ccliaitions) of replacement items that are similar as opposed to ideritical to the items being replicicd.

c. Failure to enslire that iteris will function under all design requiremerits. On some occasions, licunsees only ensured thai the commercialgrade item would function uricier normal operation coriditions.

d. Failure to verify the validity of certificates of cunformance received from vendors not on the licensee's list of approved vendors/ suppliers. An unverified certificate of conformarice from a commercialgrade veridor is not sufficier:t.

\section{Discussion}

A like-for-like replacement is defined as the replacenent of an iten with an item that is identicai. For example, the replacement item would be identiral if it was purchased at the same time from the same vendor as the item $t$ is replacing, or if the user call verify that there have been nc changes in the design, materials, or manufacturing process since procurement of the item being replaced. 11 differences from the original iter. are identified in the replacement item, then the item is lict identical, but similar to the item being replaced, and evaluation is necessary to determine if any changes in design, material, or the nanufacturing process could impact the furictional characteristics and ultinately the coliponent's ability to perform its required safecy function If the licensee can denicnstrate that the replacement item is ideritical, then the licensee need not identify the safety function or review and verify the design requirements and critical characteristics.

Engineering involvement is recessary in the above activities. The extent of this invol:ement is dependelit or the nature, complexit. and use of the items to be dedicated. Participation of engireering persolinel is appropriate in the procurement process, alid product acceptance, to develop purchase specificaticns, determine specific testing requirements applicable to the products, and evaluate the test results. When engineering perscrinel specify design requirements for inclusion on the purchase documents for replacement components, they need not reconstruct and reveriiy design adequacy for procurement purposes, but need only ensure that the existing design requirements (which may reference the original design basis) are properly translated into the purchase order.

Reliance on part rimber verification and certification documeritation is insufficient to ensure the qua lity of commercially procured products. Effective product acceptance progräns have as telients, receipt anc surce inspection, appropriate testiris criteria, effective vendor audits and surveillances (including witness/hold pcirits as apuropriate), special tests and inspections, and post-installation tests. Procedures and adequate quálificaticrs and tráining for implementing personnel are à isu necessary factors in successful implenentation. 
LIST OF RECENTLY ISSUED GENERIC LETTERS cRIC IOSURE 6

\begin{tabular}{|c|c|c|c|}
\hline $\begin{array}{l}\text { Generic } \\
\text { Letter No. } \\
\frac{91-04}{}\end{array}$ & $\begin{array}{l}\text { Subject } \\
\text { CHANGES IN TECHNICAL SFECIF } \\
\text { VEILLANCE INTERVALS TO ACCO } \\
\text { MONTH FUEL CYCLE (GENERIC L }\end{array}$ & $\begin{array}{l}\text { Date of } \\
\text { I ssuance } \\
\text { ATION SUR- } \\
\text { ODATE A 24- } \\
\text { TER 91-04) }\end{array}$ & $\begin{array}{l}\text { Is sued To } \\
\text { ALL ROLDERS OF OL } \\
\text { OR CONSTRUCTION PER- } \\
\text { MITS FOR NUCLEAR } \\
\text { POWER REACTORS }\end{array}$ \\
\hline $91-03$ & $\begin{array}{l}\text { REPORTING OF SAFEGUARDS } \\
\text { EVENTS }\end{array}$ & $03 / 06 / 91$ & $\begin{array}{l}\text { ALL HOLDERS OF OLS } \\
\text { OR CPS FOR NUCLEAR } \\
\text { POWER REACTORS AND } \\
\text { ALL OTHER LICENSED } \\
\text { ACTIVITIES INVOLVING } \\
\text { A FORMULA QUANTITY } \\
\text { OF SPECIAL NUCLEAR } \\
\text { MATERIAL (SNM) }\end{array}$ \\
\hline $91-02$ & $\begin{array}{l}\text { REPORTING MISHAPS INVOLVING } \\
\text { LLW FORMS PREPARED FOR } \\
\text { DISPOSAL }\end{array}$ & $12 / 28 / 90$ & $\begin{array}{l}\text { ALL OPERATORS OF } \\
\text { LOW-LEVEL RADIO- } \\
\text { ACTIVE WASTE (LLW) } \\
\text { OISPOSAL SITES, } \\
\text { WASTE PROCESSORS, } \\
\& \text { ALL HOLDERS OF } \\
\text { LICENSES FOR NUCLEAR } \\
\text { FUELS, NUCLEAR } \\
\text { MATERIALS \& NUCLEAR } \\
\text { POWER REACTORS }\end{array}$ \\
\hline
\end{tabular}

91-01 REMOVAL OF THE SCHEDULE FOR 01/04/91 THE WITHDRAWAL OF REACTOR VESSEL MATERIAL SPECIMENS FROM TECHNICAL SPECIFICATIONS
$90-09$
ALTERNATIVE REQUIREMENTS FOR SNUBBER VISUAL INSPECTION INTERVALS AND CORRECTIVE ACTIONS
$12 / 11 / 90$

ALL LIGHT-WATER REACTOR LICENSEES AND APPLICANTS
89-10 CONSIDERATION OF THE RESULTS $10 / 25 / 90$ SUPP. 3 OF NRC-SPONSORED TESTS OF MOTOR-OPERATED VALVES

ALL LICENSEES OF
OPERATING NUCLEAR
POWER PLANTS AND
HOLDERS OF CONSTRUC-
TION PERMITS FOR
NUCLEAR POWER PLANTS

90-08 SIMULATION FACILITY 08/10/90 EXEMPTIONS

ALL HOLDERS OF OPERATING LICENSES OR CONSTRUCTION PERMITS FOR NUCLEAR POWER REACTORS

90-07 OPERATOR LICENSING NATIONAL 08/10/90 EXAMINATION SCHEDULE

ALL POWER REACTOR LICENSEES AND APPLICANTS FOR AN OPERATING LICENSE

$\begin{array}{lll}89-10 & \text { AVAILABILITY OF PROGRAM } & 08 / 03 / 90 \\ \text { SUPP. } 2 & \text { DESCRIPTIONS }\end{array}$

ALL LICENSEES OF OPERATING NPPS AND HOLDERS OF CPS FOR NPPS 


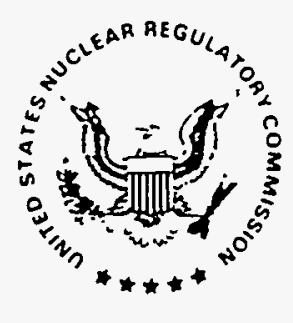

INSPECTION PROCEDURE 38703

COMMERCIAL GRADE DEDICATION

PROGRAM APPLICABILITY: 2515

SALP FUNCTIONAL AREA: ENGINEERING (SOETS-0)

38703-01 INSPECTION OBJECTIVES

01.01 To determine whether the failure of a safety-related system, itructure, component (SSC), or part to perform its intended safety function was the result of a deficient commercial grade item (CGI) dedication process.

01.02 To verify that the licensee's process for dedicating CGIs, as implemented, meets the applicable portions of Appendix B to 10 CFR Part 50 and provides reasonable assurance that CGIs will perform their intended safety function.

\section{3-02 INSPECTION REQUIREMENTS}

\subsection{Reactive Inspection Requirements}

a. Initial Evaluation. After reviewing the licensee's evaluation of the failed item, determine if the failed item was procured as a CGI and dedicated for safety-related applications. If the failed item was dedicated, review the complete procurement and dedication records to determine if the commercial grade dedication process was sufficientiy thorough.

b. Further Assessments. If it is determined that the dedicated item failed as the result of certain critical characteristics not being identified and/or properly accepted, the inspector should perform the following assessments:

1. Determine if other CGIs from the same accepted lot or batch as the failed dedicated CGI have been similarly dedicated and installed in other safety-related applications. If yes, determine if the ifcensee has evaluated the operability of the systems or components where these CGIs are installed. The inspector also should review licensee-provided data, if available, for some CGIs (non-dedicated) that failed in applications that were not safety-related. Explore the possibility that the same CGIs also may have been used (following dedication) in a safety-related application and may have the potential to affect the safe operation of a SSC. 
2. If possible select and evaluate, as in step 1 above, at least three other dedicated CGIs having similar applications and critical characteristics as the CGI(s) that resulted in the identified failures.

3. If, after performing step 2 above, it is determined that there were weaknesses in the commercial grade dedication process, the inspector should perform a more comprehensive inspection of the licensee's dedication process in accordance with the inspection requirements in Section 02.02 below.

\subsection{Programatic Inspection Requirements}

a. Review of Program and Procedures. Using the inspection guidance contained in Section 03.02 and Appendix $A$ to this procedure, review the licensee's program and procedures for the procurement and dedication of CGIs in order to understand the basic operation of the licensee's program.

b. Selection of Dedication Packages. Select approximately 20 dedication packages for evaluation from a list of commercially dedicated items provided by the licensee. Request that the licensee provide (or make available for review) a complete package of the pertinent procurement and dedication records for each item.

c. Evaluation of Dedication Packages. Using the inspection guidance contained in Section 03.01 of this procedure, perform a detailed evaluation of the dedication packages selected in item $b$ above.

d. Evaluation of Training Effectiveness. If the inspector's evaluation of commercial grade dedication activities indicates there are weaknesses in the way these activities are being performed, the inspector should investigate further to determine if weaknesses within the licensee's training program may have contributed to the cause. The inspector should determine if the licensee is implementing an effective training program.

\section{3-03 INSPECTION GUIDANCE}

\section{GENERAL GUIDANCE}

Background. Licensees are required to ensure the quality of items purchased and installed in safety-related applications. In the past, licensees procured major assemblies from approved vendors who maintained quality assurance (QA) programs pursuant to Appendix B to 10 CFR Part 50. Because of the decrease in the number of qualified nuclear-grade vendors, licensees are increasing the numbers of commercial grade replacement parts that they procure and dedicate for use in safety-related applications.

Since commercial grade dedications have increased in number, the Auclear Regulatory Comission (NRC) has developed this inspection procedure to provide guidance to assist the inspector in assessing the effectiveness of the implementation of the licensee's commercial grade procurement practices and provide for early identification of any adverse trends or emerging problems.

The Vendor Inspection Branch, of the NRC's Office of Nuclear Reactor Regulation, is available to assist vith specific questioris that arise during the performance of this procedure. 
Scheduling the Inspection. This inspection procedure should be considered for implementation when there is reason to believe that the failure of a SSC or part to perform its intended safety function was the result of weaknesses in CGI dedication. This inspection procedure may be implemented independently or it may be used as a supplement to other major team inspections. Such inspections may include maintenance, modification, or system-specific inspections where review of failed SSCS or parts is appropriate, or an augmented inspection team investigating failures.

The NRC should contact the appropriate NRC and licensee personnel to schedule the inspection. When practical, inform the licensee of the objectives of the inspection 4-6 weeks before the inspection is to begin and advise them of information that will be needed, such as a list of items that the licensee purchased as commercial grade after July 1990 and subsequently dedicated for use in safety-related applications. Before the beginning of the onsite inspection, the inspector should request and review the licensee's program and procedures to become familiar with the licensee's procurement and dedication process. Also explore with the licensee the possibility of obtaining a list of recent component failures. Request this list only if the licensee states this type of information would be easily retrievable. The list of component failures can be used by the inspector during the selection of dedication packages for review described in Section 02.02 of this inspection procedure.

This inspection procedure is consistent with the Nuclear Management and Resources Council (NUMARC) initiative for improving the utilization of CGIs in nuclear safety-related applications that was implemented in July 1990. The methods used to commercially dedicate items procured by licensees before that date will not necessarily meet the guidance contained in this inspection procedure. If the inspector encounters a significant failure of a commercially dedicated item, which was dedicated before July 1990 , the inspector may review the dedication of that item with the understanding that the licensee was not expected to meet the current guidelines.

\section{SPECIFIC GUIDANCE}

\subsection{Reactive Inspection}

a. Initial Evaluation. A fallure resulting from general weaknesses in the commercial grade dedication program may occur when the important design, material, and performance characteristics that are necessary to provide reasonabie assurance that the dedicated CGI will perform its intended safety function are not addressed during dedication. For example, failures of safety-related bolting have occurred when the dedication process did not verify that the material composition and/or mechanical properties met the specified requirements and nonconforming material was supplied.

Review and discuss with licensee personnel the failure/root-cause analysis then required or applicable for the failed CGI. The inspector should attempt to determine if the failure was due to a design deficiency, failure unrelated to the item's safety function, or normal wear, and eliminate these from further review. The inspector should focus on the inspection of failures that appear to be due to reaknesses in the commercial grade dedication process. If none of the failures are due to weaknesses in the commercial grade dedication process, then the inspector should not continue using this inspection procedure. If the insfector decides to change the focus of the insuection to examine other issues related to the failures, such as the adequacy of corrective 
actions, other procedures should be used, such as NRC Inspection Procedure 92720, "Corrective Action." Once the fallure mode and cause of failure have been postulated or determined, review the dedication package as described in Section 03.01a(1) to determine if appropriate critical characteristics had been identified by the licensee. Appendix $A$ to this inspection procedure should not be interpreted as inspection requirements but only as a discussion of dedication issues including guidance on selection and verification of critical characteristics. Appendix $A$, if properly implemented, represents an acceptable means of complying with regulatory requirements. Individual licensee's may develop alternate methods of achieving Appendix B compliance. Appendix B provides definitions of terms used for commercial grade dedication activities, and Appendix $C$ provides the typical contents of a dedication package.

The goal of the review of the dedication packages is to provide reasonable assurance that the CGIs dedicated for safety-related applications will perform their intended safety functions. Inspection effort should be directed towards the identification of weaknesses in the dedication process that could potentially render SSCs or parts inoperable. When reviewing licensee's operability determinations for dedication of CGIs, the inspector should refer to the "Technical Guidance" section of NRC Inspection Manual, Part 9900, for further guidance.

a(1) Review of Dedication Packages. After becoming familiar with the 1icensee's procurement and dedication program and procedures, perform a detailed review of the dedication package as described below.

- Determine if the safety function of the item for its intended use has been identified by reviewing the documents associated with the technical evaluation including, as applicable:

- classification of the item

- consideration of credible failure modes

- item equivalency/substitution evaluations

- Determine if the important design, material, and performance characteristics relevant to the safety function have been identified. Determine whether the licensee verified the characteristics necessary to provide reasonable assurance that the item will perform its intended safety function. If appropriate, take into account post-installation testing and periodic surveillance testing and inspection. Review the basis for engineering judgment when it is used as the basis for selection or verification of critical characteristics.

- Determine whether the item is an equivalent replacement or a new item replacement of an obsolete item.

- Determine if the item is or may be used in a different safetyrelated application than previously evaluated in which different design, material, and performance characteristics may be applicable. This is especially applicable for generic dedications of bulk items and stock material. Determine if the dedication ensures those design, material, and performance characteristics relevant to the safety function. 
- Determine why the item is being replaced. Have there been repeated failures? Is the degraded performance a result of adverse environment? Did it fail because it was a refurbished or fraudulent item? General information on similar activities subject to Appendix $B$ to 10 CFR Part 50 is provided in American National Standards Institute (ANSI) ANSI N45.2-1977, "Quality Assurance Program Requirements for Nuclear Power Plants," Section 17, "Corrective Action."

- Determine how the identity of the item is controlled from the time it is receipt inspected until the time it is installed. General information on similar activities subject to Appendix $B$ to 10 CFR Part 50 is provided in ANSI N45.2-1977, Section 9, "Control of Parts and Components."

- Determine if information Tearned during the dedication process is fed back to the appropriate persons to evaluate existing stock items, or installed items, and for future use in surveys and source verifications. This information could include positive and adverse findings obtained during surveys and source verifications. General information on similar activities subject to Appendix B to 10 CFR Part 50 is provided in ANSI N45.2.13-1976, "Quality Assurance Requirements for Control of Procurement of Items and $\dot{s}$ rvices for Nuclear Power Plants," Section 9, "Corrective Action."

Refer to the discussion of significant dedication issues in Appendix A for guidance during the review of dedication packages. Also refer to the specific guidance for each of the four dedication methods provided below.

Focus should be on those activities that are likely to affect the performance of the items being dedicated. It is not necessary to review the licensee's programatic compliance to the 18 criteria of Appendix $B$ to 10 CFR Part 50 as they may not apply to the activities reviewed. Appendix $B$ to 10 CFR 50 does not apply to comercial grade activities which occur prior to dedication for use in a safety-related system. It al so should be recognized that this appendix provides for the application of QA to safety-related systems and components consistent with their importance to safety (graded quality approach).

Although guidance concerning the application of graded quality assurance is discussed in the first paragraph of Appendix A to this inspection procedure, it is expected that the inspector will need to exercise considerable judgment in determining the adequacy of controls applied to a specific activity.

The following are the four acceptance methods that can be used to accept CGIs. These methods provide, either individually or in combination, a means to reasonably ensure that a CGI that is received meets the requirements of the item specified. The results of employing each method should be documented.

\section{Method 1 - Special Tests and Inspections}

General information on similar activities subject to Appendix $B$ to 10 CFR Part 50 is provided in ANSI N45.2.13-1976, Section 10, "Acceptance of Item or Service." Use the following approach to review packages that were dedicated using this method: 
- To the extent practicable, attempt to witness receipt inspections and tests of in-process dedication of CGIs that are similar to that of the failed item to verify the identified critical characteristics.

- Review receiving records and associated tests and inspections.

- Review post-installation test records.

- Verify that the tests and inspections specified for acceptance adequately verify the identified critical characteristics.

- Verify that sampling plans are controlled and have adequate technical basis, considering lot traceabllity and homogeneity, complexity of the item, and adequacy of supplier controls.

- Verify that CGI receiving inspection activities are adequately conirolled under a quality program regardless of whether they are being performed in conjunction with other plant receipt inspection activities.

- Verify that receipt inspection activities establish and maintain traceability of CGIs by capturing and appropriately relating traceability documents through identification and monitoring of CGIs.

- Verify that measuring and test equipment was properly calibrated, that approved vendors were used to perform tests, and that personnel were qualified to perform the tests.

\section{Method 2 - Commercial Grade Survey}

Use the following guidance to review packages that were dedicated using this method:

- Determine if the guidance of Generic Letter 89-02, or an appropriate alternate, is included in the appropriate procedures. Specifically, confirm that (1) the documented commercial quality program was effectively implemented and (2) the surveys were conducted at the location necessary to verify that adequate controls were exercised on distributors as well as manufacturers.

- Through interview, determine if the persons who perform vendor surveys are knowledgeable in the following:

- the use of performance-based surveys

- screening third-party surveys

- processing and evaluating adverse findings resulting from the review of third-party surveys to ascertain if those findings affect CGIs already installed or stored in the warehouse awaiting future installation

General information on similar activities subject to Appendix $B$ to 10 CFR Part 50 is provided in ANSI N45.2.12-1977, "Requirements for Auditing of Quality Assurance Programs for Nuclear Power Plants," and ANSI N45.2.231978, "Qualification of Quality Assurance Program Audit Personnel for Nuclear Power Plants." 
- Verify that the supplier's commercial quality controls are imposed in the procurement documents.

- Determine if the critical characteristics that are to be verified by the survey team are accurately and completely incorporated in the survey plans.

- Determine if the validity of supplier documentation, relied on in the dedication of the item, is verified during the survey.

- Determine if surveys of commercial grade suppliers are performance based as opposed to programmatic. Specifically, verify that the critical characteristics for the CGIs being surveyed are controlled by the supplier's quality activities.

- Determine if survey teams inciude technical and quality personnel, as appropriate, that are knowledgeable in the operation of the item(s) and the associated critical characteristics to be verified, including any special processes such as welding and heat treatment that are specific to the critical characteristics.

- Determine if surveys are conducted at appropriate times relative to the procurement. Are surveys required to be updated on a regular basis to support dedication?

- Determine if the control of subvendors is adequately addressed by the surveys so that the supplier has an adequate basis to accept test results and certifications from the subvendor.

- Determine if pertinent information about a supplier or its products is used to plan, conduct, and report results of surveys and source verifications. Such information could have been available from source verifications, receiving inspections, the dedication process, supplier/product performance history, or outside sources such as NRC information notices and bulletins, nuclear plant reliability data system reports, or Nuclear Utility Procurement Issues Comittee (NUPIC) commercial grade survey reports.

\section{Method 3 - Source Verification}

General information on similar activities subject to Appendix B to 10 CFR Part 50 is provided in ANSI N45.2.13-1976, Section 10.3.2, "Acceptance by Source Verification." Use the following approach to review packages that were dedicated using this method:

- Determine if source verifications involve witnessing the supplier performing quality activities on the actual items being procured and adequately verify the item's critical characteristics.

- Determine if personnel who participated in the source verification surveys were qualified for their specific assignment.

- Determine if appropriate hold points are imposed in the purchase orders. This would include a hold point to verify design, material, and performance characteristics relevant to the safety function that cannot be verified after the item has been completely manufactured. 
- Determine if the results of the source verifications were adequately documented.

Method 4 - Acceptable Supplier/Item Performance Record

Use the following guidance to review packages that were dedicated using this method:

- Determine if the guidance of Generic Letter 89-02, or an appropriate alternate, has been incorporated. Specifically, (1) the established historical record is based on industry-wide performance data that is directly applicable to the item's critical characteristics and the intended safety-related application and (2) the manufacturer's measures for the control of design, process, and material changes have been adequately implemented as verified by survey (multilicensee team surveys are acceptable).

- Determine if information pertinent to the CGI's quality of performance, obtained from outside sources (e.g., operational event reports, NRC, vendor equipment and technical information program, and Institute of Nuclear Power Operations) and from commercial grade surveys, source verifications, receipt inspectior-, previous dedication or qualification and operational history, is factored into the dedication process.

- Determine if the item or manufacturer is included in the licensee's performance trending program.

\section{b. Further Assessments}

1. No inspection guidance.

2. From the list of dedicated items provided by the licensee, the inspector should select for review approximately three other dedication packages having similar applications and critical characteristics as the CGI(s) that resulted in the identified failures. After the selections have been made, the inspector should request that the licensee compile a complete package of all the procurement and dedication records for each item. Typical contents of a dedication package are described in Appendix $C$ of this inspection procedure. The inspector should review the dedication packages as described in Section 03.01a(1) of this inspection procedure.

3. No inspection guidance.

\subsection{Programatic Inspection}

a. Review of Program and Procedures. The review of the program and procedures should be performed to familiarize the inspector with the licensee's CGI dedication process. For cases in which problems are identified with the licensee's CGI dedication process, the inspector may decide to perform a more extensive review of the program and procedures to determine if these problems are the result of inadequate procedures.

The inspector's review should include procedures that control: procurement activities; material control; the dedication of CGIs, including receipt inspection and acceptance testing; surveys of 
commercial grade suppliers; classification of components; training of personne 1; trending of supplier performance; and equipment failures. Attempt to identify any apparent weak areas to concentrate on during the evaluation of the program implementation.

After arriving onsite, the inspector should request that the licensee explain its commercial grade dedication process and conduct a walkthrough of areas associated with it. Areas in the walkthrough could include the engineering, receipt inspection, component testing, and warehouse. The inspector should become familiar with key licensee personnel involved in the commercial grade dedication process. These key personnel should include the responsible engineer(s) who developed the dedication package(s) and systems engineers, procurement engineers, receipt inspectors, quality assurance engineers and inspectors, and warehouse personnel. The inspector should discuss the commercial grade dedication process with these key personne? to gain a better understanding of the process, including:

- How processing of CGI procurement documents is controlled under the quality program and how they receive review and approval. General information on similar activities subject to Appendix B to 10 CFR Part 50 is provided in ANSI N45.2.13-1976, Section 3, "Procurement Document Preparation, Review, and Change Control."

- How technical personnel participate in the preparation, review, and approval process of procurement documents.

- How consistency and coordination is maintained between corporate level, engineering/support level, and site level programs and implementing procedures.

b. Selection of Dedication Packages. As discussed in the general guidance section above, the NUMARC initiative for the utilization of CGIs in nuclear safety-related applications was not implemented until July 1990. Therefore, the methods used to perform commercial grade dedication of items procured or dedicated by licensees before that date will not necessarity meet the guidance contained in this inspection procedure.

The selection process should be performance oriented (e.g., weighted toward the review of dedication packages for equipment, components, or parts that have experienced failures). To accomplish this, the inspector should request from the licensee approximately 20 packages for review using the two-step approach described below. The licensee should be given sufficient lead time to prepare the 20 packages and make them available for the first day of onsite inspection.

Step 1: Review the licensee's records available at the plant site to identify recent failures (approximately the last 2 years) of equipment, components, or parts. Review these failures to determine if any were CGIs dedicated for use in safety-related applications. If available, select approximately 75 percent of the total sample from CGI failures.

Step 2: From the list of dedication packages supplied by the licensee, under the "Inspection Guidance" section of this procedure, select the remainder of packages for review. The total sample size including packages from steps 1 and 2 should be approximately 20 packages. However, the inspector can select a larger or smaller sample depending on the complexity of the packages and the time available. The inspector 
should select these packages on the basis of the following considerations:

- The inspector should select packages for items whose failure would have the most effect on the ability of the plant to safely operate, safely shutdown from an adverse condition, or maintain a safe shutdown condition. If time permits, review the plant-specific probabilistic risk assessment, individual plant examination, and risk-based inspection guides that provide information on the risk significance of safety-related plant equipment.

- The inspector should take a performance oriented approach to the selection process by including in the sample packages those items that have been problems, in the past. Revidw available sources of information to identify any known failures of CGIs that were used in safety-related applications. These sources of information could include:

- componeni failure lisis or lists of items requiring frequent maintenance or replacement as provided by the licensee

- misrepresented or fraudulent items reported in NRC information notices

- licensee trending of equipment and supplier performance

- previous history of component failures or malfunctions as reported in licensee event reports or plant nonconformance reports

- The inspector should include both simple and complex packages in the sample as well as packages that include a variety of dedication methods (e.g., Methods 1 through 4) described in Section 03.01a(1) above.

- In addition to selecting packages based on the above considerations (safety significance, complexity, and failures), the inspector should attempt to select samples from each of the following areas: electrical, instrumentation and control, mechanical equipment, and materials.

c. Evaluatizr. if Dedication Packages. Perform a detailed review of the dedication packages as described above in Section 03.01a(1).

d. Evaluation of Training Effectiveness. Experience gained during the procurement assessments and pilot inspections suggested that training of personnel involved in CGI dedication activities was a very important factor in the development of a good CGI dedication program. The CGI dedication process generally requires more highly qualified/trained personnel than specified in Appendix B to 10 CFR Part 50 procurement. Personnel involved in this process need to be familiar with current industry and NRC guidance and have a strong interface with the licensee's design/engineering organizations. The training expectations, however, should not exceed what is required by the existing licensee's QA program.

As applicable to their job function, select and review the training records for individuals involved in the following areas:

- Determining the safety classification of an item. Training in this area is appropriate when the job function includes reclassification 
of items or establishing safety classification of piece parts of safety-related components.

- Specifying design, material, and performance characteristics relevant to the safety function and establishing the acceptance criteria for these characteristics.

- Specifying or performing commercial grade surveys, source verifications, and tests and inspections, including enhanced postreceipt verification testing or inspection.

- The preparation and review of procurement documents.

Through observation, interviews, and a review of records of work performed by the individuals:

- Determine if the individuals selected have adequate knowiedge to perform the specific tasks assigned to them. Attend a training course, if available, or review the lesson plans for selected training courses.

- Determine if training inadequacies contributed to any of the deficiencies that may be identified during the inspection.

- Determine if the personnel are familiar with the program requirements and procedures and if they have been properly trained in the dedication process.

It should be noted that alternatives to a formal training program may be adequate to ensure satisfactory program implementation (e.g., on the job training). Additional information in this area is provided in NRC Inspection Procedure 41500, "Training and Qual ification Effectiveness."

\section{3-04 INSPECTION RESOURCE ESTIMATE}

The estimated number of onsite inspection hours required to complete all inspection requirements is 144 hours when both the reactive and programmatic options are implemented. This estimate is for broad resource planning and is not intended as a quota or standard for judging inspector or regional performance. The on-site hours can be expected to vary significantly depending on the specific circumstance and scope of each inspection.

\section{3-05 REFERENCES}

The following documents are listed for the inspector's information only and are not considered regulatory requirements unless the licensee has formally committed to implementing any of these documents for application to safety-related activities. The inspector may wish to review these documents to become familiar with commercial grade dedication issues.

ANSI N45.2-1977, "Quality Assurance Program Requirements for Nuclear Power Plants," as endorsed by NRC Regulatory Guide 1.28, Revision 2.

ANSI N45.2.13-1976, "Quality Assurance Requirements for Control of Procurement of Items and Services for Nuclear Power Plants," as endorsed by NRC Regulatory Guide 1.123, Revision 1.

Issue Date: 11/08/93 - $11-$

38703 
Electric Power Research Institute (EPRI) NP-5652, "Guidelines for the Utilization of Commercial-grade Items in Nuclear Safety Related Applications (NCIG-07), " as conditionally endorsed in NRC Generic Letter 89-02.

Generic Letter 89-02, "Actions to Improve the Detection of Counterfeit and Fraudulently Marketed Products" (microfiche 48960-001).

Generic Letter 91-05, "Licensee Commercial Grade Procurement and Dedication Programs" (microfiche 57468-264).

NRC Inspection Procedure 41500, "Training and Qualification Effectiveness."

SECY-90-304, "NUMARC Initiatives on Procurement" (microfiche 55277-049).

SECY-91-291, "Status of NRC's Procurement Assessments and Resumption of Programatic Inspection Activity" (microfiche 59490-079).

Appendices:

A. Dedication Issues

B. Definitions

C. Contents of Dedication Packages 
APPENDIX A

DEDICATION ISSUES

\section{BASIS FOR THE SELECTION AND VERIFICATION OF CRITICAL CHARACTERISTICS}

\section{Consideration of Item's Safety Function}

Critical characteristics should be based on the item's safety function. The licensee is responsible for (a) identifying the important design, material, and performance characteristics that have a direct effect on the item's ability to accomplish its intended safety function and (b) selecting from these characteristics a set of critical (or acceptance) characteristics that, once verified, will provide reasonable assurance that the item will perform its intended safety function. Criterion II of Appendix $B$ to 10 CFR Part 50 provides for the application of quality assurance over activities affecting the quality of structures, systems, and components to an extent consistent with their importance to safety. This graded quality approach can be used in the selection and verification of critical characteristics for commercial grade items (CGIs). When an existing equipment specification is avaiiable that contains adequate technical requirements for the item being purchased, that specification can be used to select the critical characteristics for this item.

2. Graded Qual ity Assurance

The application of graded quality assurance to the CGI dedication process should include consideration of the item's importance to safety and other factors specific to the item being procured. Certain items and services may require extensive controis throughout all stages of development while others may require only a limited quality assurance involvement in selected phases of development. The following factors should be considered in determining the extent of quality assurance to be applied: (a) The importance of malfunction or failure of the item to plant safety, (b) the complexity or uniqueness of the item, (c) the need for special controls and surveillance over process and equipment, (d) the degree to which functional compliance can be demonstrated by inspection and test, and (e) the quality history and degree of standardization of the item. Additional guidance on the use of graded quality assurance can be found in the nonmandatory appendix to ANSI N45.2.13-1976.

3. Consideration of Failure Modes

An evaluation of credible failure modes of an item in its operating environment and the effects of these failure modes on the item's safety function may be used in the safety classification of an item and as a basis for the selection of critical characteristics.

4. Reasonable Assurance

The dedication process represents an acceptable method of achieving compliance with Appendix B to 10 CFR Part 50 with the purchaser assuming many of the responsibilities for ensuring quality and functionality of an item that had previously been the responsibility of the vendor. In this context, reasonable assurance consists of the purchaser controlling or 
verifying the activities affecting the item's quality to an extent consistent with the item's importance to safety or ensuring that these activities are adequately controlled by the supplier. For more complex items, dialogue with the original equipment manufacturer may be necessary to identify the design and functional parameters of specific piece parts. Once the dedication process is completed, the quality assurance and/or other measures applied to those aspects of the item that directly affect its safety function should result in the same level of performance as for a like item manufactured or purchased under a quality assurance program of Appendix B to 10 CFR Part 50.

\section{Engineering Judgment}

Engineering judgment can be used in selecting chose important design, material, and performance characteristics that are identified as the item's critical characteristics. The bases for engineering judgment for this application should be documented.

\section{TRACEABILITY}

\section{Material/Items Purchased From Distributors}

Traceability can be defined as the ability to verify the history, location, or application of an item by means of recorded identification. Where the item's acceptance is based entirely or partially on a certification by the manufacturer, the traceability must extend to the manufacturer. The purchaser should ensure by survey or by other means that the manufacturer has established adequate traceability controls and that these controls are effectively implemented. For situations in which intermediaries (distributors) are included in the supply chain, the activities of these organizations may need to be surveyed to ensure that traceability and proper storage conditions are maintained. A survey of the distributor may not be necessary if the distributor acts only as a broker and does not warehouse or repackage the items or in cases where traceability can be established by other means such as verification of the manufacturer's markings or shipping records.

\section{SAMPLING}

1. Established Heat Traceability (Materials)

When heat traceability of metallic material has been established and each piece of the material is identified with the material heat number, chemical analysis and destructive testing required for the acceptance of this material may be performed on one piece of the material. The same rationale may be used for the acceptance of containers of nonmetallic materials such as lubricants providing that traceability has been established and each container is identified with a unique mix or batch number.

\section{Established Lot/Batch Control (Items)}

When lot/batch (defined as units of product of a single type, grade, class, size, and composition, manufactured under essentially the same conditions and at essentially the same time) control is established through a commercial grade survey, the party performing dedication of such items can use sampling prescribed by standard statistical methods

38703, Appendix A A-2

Issue Dare: 11/08/93 
that are based on homogeneous product lots. Such sample plans should be identified and should provide for the verification of the critical characteristics with confidence level consistent with the item's importance to safety. Other means of demonstrating adequate lot/batch control may include satisfactory performance history and the results of receipt inspection/testing. When such methods are used as a basis for developing product sampling strategy, they should be supported by documented objective evidence.

\section{Material and Items With No Lot/Batch Control}

When lot/batch control cannot be established, sampling plans need to be considered on individual, item-specific basis and ensure that they are capable of providing a high level of assurance of the item's suitability for service. There may be situations where each item needs to be tested.

\section{COMMERCIAL GRADE SURVEYS}

1. Yerification of Vendor's Control of Specific Characteristics

A commercial grade survey should be specific to the scope of the CGI(s) being purchased. The vendor's controls of specific critical characteristics to be verified during the survey should be identified in the survey plan. The verification should be accomplished by reviewing the vendor's program/procedures controlling these characteristics and observing the actual implementation of these controls in the manufacture of items identical or similar to the items being purchased.

2. Identification of Applicable Program/Procedures

The vendor must have a documented program and/or procedures to control the critical characteristics of the item or items being procured that are to be verified during the survey. When many items are being purchased, a survey of a representative group of similar items may be sufficient to demonstrate that adequate controls exist. If the vendor's controls are determined to be satisfactory, purchase orders for these items should invoke these controls as contract requirements by referencing the applicable program/procedure(s) and revision. If multiple working level procedures are applicable to the vendor's activities, which affect the item's critical characteristics and these procedures, in turn, are controlled by a higher level document, it may be appropriate to reference that document in the purchase order. It is important to ensure that the specific controls reviewed and accepted during the survey be applied during the manufacturing process. Upon completion of the work, the vendor should certify compliance with the purchase order requirements.

3. Documentation of Survey Results

Commercial grade survey documentation should include the identification of the item or items for which the vendor is being surveyed, identification of the critical characteristics of these items that the vendor is expected to control, identification of the controls to be applied (program/procedure and revision), and a description of the verification activities performed and results obtained. Critical characteristics that are not adequately controlled should be addressed by contractually requiring the vendor to institute additional controls or by utilizing other verification and acceptance methods.

Issue Date: 11/08/93 A-3

38703, Appendix A 


\section{Survey Frequency}

Commercial grade surveys should be conducted at sufficient frequency to ensure that the process controls applicable to the critical characteristics of the item procured continue to be effectively implemented. Factors to be considered in determining the frequency of commercial grade surveys include the complexity of the item, frequency of procurement, receipt inspection, item performance history, and knowledge of changes in the vendor's controls. The survey frequency should not exceed the audit frequency established for 10 CFR Part 50, Appendix B, suppliers.

\section{ACCEPTANCE OF CERTIFIED MATERIAL TEST REPORTS (CMTRS) AND CERTIFICATES OF COHPLIANCE (COCS)}

\section{Validity Verified Through Vendor/Supplier Audit or Testing}

When the verification of critical characteristics is based on vendor CMTRs or CoCs, the validity of these documents should be ensured. This can be accomplished through a commercial grade survey or, for simple items, periodic testing of the product on receipt. Such verifications should be conducted at intervals commensurate with the vendor's past performance. If the item's supply chain includes a distributor, a survey of the distributor's act i. wes may be necessary (see "Traceability").

\section{USE OF INDUSTRY GUIDANCE}

The Electric Power Research Institute (EPRI) NP-5652, "Guideline for the Utilization of Commercial Grade Items in Nuclear Safety Related Applications (NCIG-07)," defines critical characteristics as "identifiable and measurable attributes/variables of a CGI, which once selected to be verified, provide reasonable assurance that the item received is the item specified." "NRC's conditional endorsement of EPRI NP-5652 by Generic Letter 89-02 was based on interpreting that in the EPRI definition of critical characteristics the "item specified" encompassed those attributes that are essential for the performance of the item's safety function. This interpretation is consistent with the definition of "critical characteristics for acceptance" found in EPRI NP-6406, "Guidelines for the Technical Evaluation of Replacement Items in Nuclear Power Plants," which notes that critical characteristics for acceptance are a subset of "critical characteristics for design." The EPRI NP-6406 definition of "critical characteristics for design" includes those attributes that ensure the performance of the item's design function.

Published NRC guidance does not differentiate between design and acceptance critical characteristics and the CGI dedication guidance provided in Generic Letters 89-02 and 91-05 does not suggest that all design requirements of an item need to be verified during the dedication process. Rather, the licensee is expected to identify the item's design, material, and performance characteristics that have a direct effect on the item's ability to accomplish its intended safety function and select from these characteristics a set of critical (or acceptance) characteristics that, once verified, will provide reasonable assurance that the item will perform that function. Consistency in the definition of critical characteristics can be improved by equating the NRC's definition of critical characteristics to the EPRI definition of "critical characteristics for acceptance." 


\section{DEFINITIONS}

The following terms are listed to provide the inspectors with working definitions of important terms used during the procurement and dedication of commercial grade items (CGIs). These terms are defined only in the context of the CGI dedication process and are solely to aid the inspector in the inspection process.

Basic Component - A plant structure, system, component, or part thereof necessary to ensure one of the following:

- the integrity of the reactor coolant pressure boundary

- capability to shut down the reactor and maintain it in a safe shutdown condition

- the capability to prevent or mitigate the consequences of accidents that could result in offsite radiation exposures comparable to those referred to in 10 CFR Part 100.11

Certificate of Compliance - A written statement attesting that the macerials are in accordance with specified requirements.

Certified Material Test Report - A document attesting that the material is in accordance with specified requirements, including the actual results of all required chemical analyses, tests, and examinations.

Commercial Grade Item - An item satisfying all the following criteria:

- not subject to design or specification requirements that are unique to nuclear facilities

- used in applications other than nuclear facilities

- ordered from the manufacturer/supplier on the basis of specifications set forth in the manufacturer's published product description (e.g., catalog)

Commercial Grade Survey - Activities conducted by the purchaser or its agent to verify that a supplier of CGIs controls, through quality activities, the critical characteristics of specifically designated CGIs, as a method to accept those items for safety-related use.

Critical Characteristics - Those important design, material, and performance characteristics that, once verified, will provide reasonable assurance that the item will perform its intended safety function.

Dedication - The process by which a CGI is designated for use as a basic component. This process includes the identification and verification of critical characteristics. (Also refer to definition in 10 CFR Part $21.3(4)(c-1)$ )

Engineering Judament - A process of logical reasoning that leads from stated premises to a conclusion. This process should be supported by sufficient documentation to permit verification by a qualified individual. 
Source Verification - Activities witnessed at the suppliers' facilities by the purchaser or its agent for specific items to verify that a supplier of CGIs controls the critical characteristics of that item as a method to accept the item for safety-related use.

Iraceability - Is the ability to verify the history, location, or application of an item by means of recorded identification.

END 


\section{CONTENTS OF DEDICATION PACKAGES}

The dedication packages compiled by the licensee may contain the following items, as applicable, depending on the item chosen and the dedication methods used.

- Purchase requisitions and purchase orders.

- Other pertinent vendor/licensee correspondence.

- Design specifications - original and updated to verify certain important parameters, such as original design pressure of a system or degraded pickup voltage of a solenoid or relay.

- Catalog specifications.

- Procurement basis evaluation - like-for-like, equivalency, plant design change packages, drawing and specification updates.

- 10 CFR Part 50.59 safety evaluation, if required.

- Material receiving reports, packing lists/invoices, and other shipping documents.

- Receipt inspection reports and any related test reports.

- Other documents to trace the item from the time it was dedicated to the time it was installed, tested, and accepted.

- Certificates of conformance/compliance/quality.

- Vendor test and inspection reports.

- Third-party or subvendor test and inspection reports.

- Shelf life information.

- Vendor dedication/partial dedication information.

- Design/materiai/process change history information.

- Completed commercial grade dedication document including:

- safety classification

- identification of safety functions/application requirements

- identification of critical characteristics

- identification of verification methods and acceptance criteria for the critical characteristics

- evaluation of credible failure modes (if applicable)

- Any deviation from design, material, and performance characteristics relevant Issue Date: 11/08/93 
to the safety function (nonconformance dispositions).

- Documents showing objective evidence:

- special test and inspection procedures and results

- commercial grade survey reports - item, design, material, and specific performance characteristic (relevant to safety function)

- source inspection reports

- Completed post-installation test procedure and results.

- Completed stock or material issue forms and installation work orders or reports.

- Historical performance information.

END 


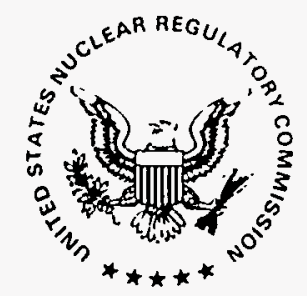

\author{
UNITED STATES \\ NUCLEAR REGULATORY COMMISSION \\ WASHINGTON, D.C. 20555-0001 \\ June 29, 1995
}

Mr. Scott Akers, Jr., Chief Executive Officer

Cardinal Industrial Products,

Limited Partnership

3873 West Oquendo

Las Vegas, NV 89118

$\begin{array}{ll}\text { SUBJECT: } & \text { CARDINAL'S MAY 30, } 1995 \text { REPLY TO NOTICE OF NONCONFORMANCE } \\ & 99901076 / 94-01-03 \text { (NRC INSPECTION REPORT NO. 999001076/94-01) }\end{array}$

Dear Mr. Akers:

Thank you for Mr. Hathcock's letter of May 30, 1995, in response to our letter of April 24, 1995, which documented our evaluation and conclusions regarding your January 30, 1995 response to Notice of Nonconformance 99901076/94-01. Accordingly, as agreed in a June 26 telephone conversation between Messrs. Potapovs, of this office and Hathcock, of your staff, we would like to have a telephone conference with you on July 6,1995 , to further discuss the concerns identified in this letter.

We agree that NRC Generic Letters 89-02 and 91-05 do not apply to manufacturers and suppliers. Additionally, the guidance contained in these letters does not constitute regulatory requirements for NRC 1icensees. Copies of these documents were provided to you for information only.

Our April 24, 1995, letter to you outlined the relationship between NRC requirements and the activities of manufacturers and suppliers that provide safety related items for use in licensed facilities. In summary, when an NRC 1 icensee invokes the quality assurance program set out in 10 CFR 50 , Appendix B, in its purchase order to a supplier, the supplier is expected to certify conformance with this program. To the extent that the supplier's program is inadequate to demonstrate conformance, a notice of nonconformance may be warranted for the supplier and a notice of violation may be warranted for the licensee. The responsibility of the supplier would include assuring that the applicable provisions of 10 CFR 50, Appendix B, are passed on to lower tier vendors whose activities affect the product's conformance with the applicable specification.

A material supplier does not need to use any sampling plans in order to provide material in conformance with the provisions of 10 CFR 50, Appendix $B$. Methods of supplying material in this manner include purchasing the source material from qual ified manufacturers or supplying such material in accordance with the quality program of the ASME Code which has been endorsed by the NRC as complying with the NRC quality assurance provisions.

As stated in our April 24 letter, for certain applications, the NRC staff has accepted commercial grade item (CGI) dedication as an alternative method to the programmatic quality assurance measures prescribed in Criteria II and VII 
of 10 CFR Part 50, Appendix B, for assuring that the items purchased from commercial sources will meet the applicable purchase specification. This method of achieving conformance with NRC quality assurance provisions relies on the identification and verification of the CGI's critical characteristics which are those characteristics that are necessary for the item to perform its safety function.

The use of CGI dedication is most practical when the dedicating entity knows the end use of the item, since the end user controls the item's application and can, therefore, identify those characteristics of the item which are essential for the performance of the item's safety function. The end user of the item may also be able to adjust the Acceptable Quality Level (AQL) of a sampling plan based on the safety significance of the item's application when sampling is used to verify the item's critical characteristics. When a material manufacturer or supplier elects to use CGI dedication to provide safety-related material, he generally does not know the end application of the material and, therefore, is not able to identify a specific set of characteristics required for the material to perform its safety function. In order to certify such material as conforming with 10 CFR 50, Appendix $B$, the supplier has the option of assuming that all material requirements specified in the procurement documents are critical and must be verified. Alternatively, the supplier can request the purchaser of the item to identify specific product acceptance requirements in the procurement documents and certify conformance only to those requirements.

The NRC has not published or endorsed any material sampling plans for generic use. The references to MIL-STD-105D in our April 24, 1995, Tetter were for the purpose of recognizing a sampling standard that has been used by NRC licensees and accepted by the NRC for specific applications. However, the generic letters and NRC Inspection Manual Procedure 38703 which were enclosures to our April 24, 1995, letter, can be used by vendors for guidance in developing CGI dedication and sampling strategies if they elect to supply safety related items using the dedication process and to certify such items as conforming with 10 CFR 50, Appendix B. This guidance provides a rationale for developing sampling strategies based on material traceability considerations and lot/batch control.

In our April 24, 1995, letter, we also detailed our concerns regarding Cardinal's destructive testing sampling plan. Your letter of May 30, 1995, stated that the use of certain factors, such as "trending process and additional testing (i.e., chemical, mechanical, dimensional, etc.)" in selecting a sampling plan, were discussed with the inspectors but not considered in the NRC inspection report. As stated in Inspection Report 99901076/94-01, and reiterated in our Apri1 24, 1995, letter, the NRC inspectors were not provided any documented bases for the sampling plan during that inspection.

We have considered the suggestion in your May 30, 1995, letter, that the NRC should provide licensees and suppliers with a clear definition of "reasonable assurance" and "acceptable sampling plans." Based on the results of recent 
NRC vendor inspections, including the inspection of Cardinal, the NRC staff has initiated a study of industry practices and existing guidance in this area. This study, when completed, may result in NRC's endorsement of specific sampling approaches.

In accordance with Section 2.790 of 10 CFR, a copy of this letter will be placed in the NRC's Public Document Room.

No response to this letter is required.

Sincerely,

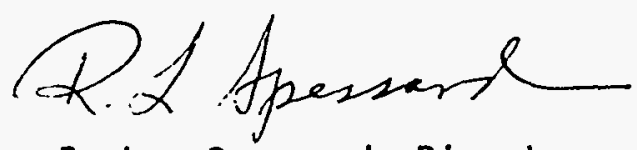

R. Lee Spessard, Director Division of Technical Support Office of Nuclear Reactor Regulation

Docket No.: 99901076 
(See instructions on the reverse)

NUREG-0040

Vol. 19, No. 2

3. DATE REPORT PUBLISHED

Licensee Contractor and Vendor Inspection

Status Report

Quarterly Report

Apri] - June 1995

\begin{tabular}{c|c}
\hline MONTH & YEAR \\
August & 1995
\end{tabular}

4. FIN OR GRANT NUMBER

Quarterly

7. PERIOD COVERED (Inclusive Dates/ April 1995 -

June 1995

8. PERFORMING ORGANIZATION - NAME AND ADDRESS (If NRC, provide Division, Office or Region, U.S. Nuclear Regulatory Commission, and mailing address; if contractor, provide name and mailling address)

Division of Inspection and Support Programs

Office of Nuclear Reactor Regulation

U.S. Nuclear Regulatory Commission

Washington, DC 20555-0001

9. SPONSORING ORGANIZATION - NAME AND ADDRESS IIf NRC, type "Same as above"; if contractor, provide NRC Division, Office or Region, U.S. Nuclear Regulatory Commission. and malling address.)

Same as above.

10. SUPPLEMENTARY NOTES

11. ABSTRACT 1200 words or less)

This periodical covers the results of inspections performed by the NRC's Special Inspection Branch, Vendor Inspection Section, that have been distributed to the inspection organizations during the period from April through June 1995.

\begin{tabular}{l} 
13. AVAILABILITY STATEMENT \\
Unl imited \\
\hline 14. SECURITY CLASSIFICATION \\
IThis Pagel \\
Unclass ified \\
\hline IThis Repori) \\
Unclass ified \\
\hline 15. NUMBER OF PAGES \\
\hline 16. PRICE
\end{tabular}


$\theta$ 